\title{
253 $\mathrm{M4}$
}

\$B 659396 WTAROL

LAABORATORY GUUDDE

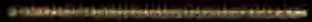

\section{CHARLES W:MeLICK}




\section{GIFT OF \\ H. E. VAN NORMAN}
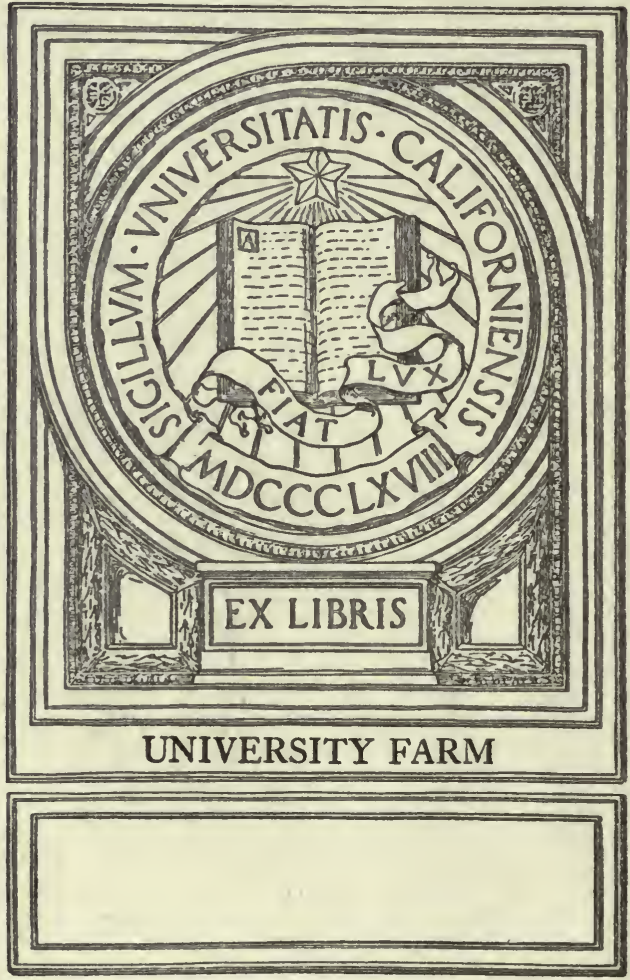
H. E. VAN NORMAN

ETATE COLLECE, PA. 
Digitized by the Internet Archive in 2007 with funding from Microsoft Corporation 


\section{A I R Y}

\section{LABORATORY GUIDE}

BY

CHARLES W. MELICK, B.S.A., M.S.

Professor of Dairy Husbandry. Maryland Agricultural Experiment Station

FIFTY-TWO ILLUSTRATIONS

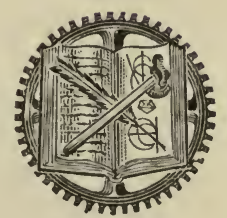

NEW YORK

D. VAN NOSTRAND COMPANY

23 Murray and 27 Warren Streets

1907

UNIVERSITY OF CALIFORNIA 


\section{Copyright, 1907 \\ By D. Van Nostrand Company}

The Plimpton Press Norwood Mass. U.S.A. 


\section{CONTENTS}

EXERCISE

PAGE

I Cleaning and Arranging Laboratory ApParatus Prepartory for USE . . . . 1

II Cream Separators . . . . . . . . 2

III Separation of Cream . . . . . . . . . . 6

IV The Use of the Babcock Tester . . . . 9

V The Use of the Lactometer . . . . . 18

VI Testing the Acidity of Milk . . . . 20

ViI Pasteurization . . . . . . . . . . 24

VIII Starter Making . . . . . . . . 28

IX Curd Test . . . . . . . . . . . . 32

X Cream Ripening . . . . . . . . 33

XI Cream Grading . . . . . . . . . 36

XII Churning . . . . . . . . . . . . 38

XiII Determination of the water Content of Butter . . . . . . . . . . . 49

XiV Determination of Casein, Ash, and Salt of Butter . . . . . . . . . . 57

XV Cheese Making . . . . . . . . 61

XVI Gouda Cheese . . . . . . . . . 72

XVII Cottage Cheese . . . . . . . . 72

XVIII ICE Cream . . . . . . . . . . 75

XIX Dairy Bacteriology . . . . . . . 79

XX Milk Paint . . . . . . . . . . . 89

XXI Tests for Preservatives . . . . . . 90

XXII Test for Oleomargarine . . . . . . 91

XXIII Repairing Creamery Machinery . . . . 92

XXIV Modification of Milk for Infants and InVALIDS . . . . . . . . . . 95

XXV Standardization of Milk . . . . . 97

XXVi Condensing Milk, Milk Paste, Dried Milk,

Milk Sugar . . . . . . . 100-102

XXVII Junket, Papanized Cheese Paste . . 102, 103 
XXVIII Atimidcaseose, Milk Shake, Buttermilk Highball, Buttermilk Pop, Koumiss, But termilk, Moose, Dried Milk Cocktail 104-107 XXIX Preparations made from MilK . . . 107 XXX Solid Milk, Soap, Preparation for Ivy Poison, A Method of Modifying Milk for Invalids, Preserving Casein . . 108, 109 XXXI Disinfectants . . . . . . . . 109 XXXII Mechanical Refrigeration . . . . . 110 XXXIII Creamery Bookkeeping . . . . . . 117 XXXIV Writing to Patrons . . . . . . 121 XXXV Creamery Conveniences . . . . . . 122 


\section{DAIRY LABORATORY GUIDE}

\section{INTRODUCTION}

This laboratory manual is published for the benefit of the dairy short courses where the classes are largely made up of farm-boys whose education ranges from the Eighth Grade to High School graduates. Consequently it begins with the most elementary work and touches only the practical side, with which every dairy or creamery operator should be familiar.

Dairy classes are usually large, and where the instructor cannot give personal attention some students will not grasp the fundamental principles underlying the work. By following the outline of the manual the student may work out for himself these principles and their application. There is also a growing demand for systematic laboratory work in the short courses where a large amount of work is crowded haphazard into a small space of time. The purpose of this manual, therefore, is to aid the beginner in obtaining the greatest amount of benefit from the limited time spent in the dairy short courses.

Exercises in the operation of boilers and engines are not included in this manual because that work should be taken up in the mechanic arts department. 



\section{EXERCISE I}

Arranging Laboratory Apparatus Preparatory FOR USE

Mix potassium bichromate $\mathrm{K}_{2} \mathrm{Cr}_{2} \mathrm{O}_{7}$ and sulphuric acid $\mathrm{H}_{2} \mathrm{SO}_{4}$ in equal parts in eight to twelve of water for a cleaning mixture. Clean all glassware with this mixture by allowing the articles to stand

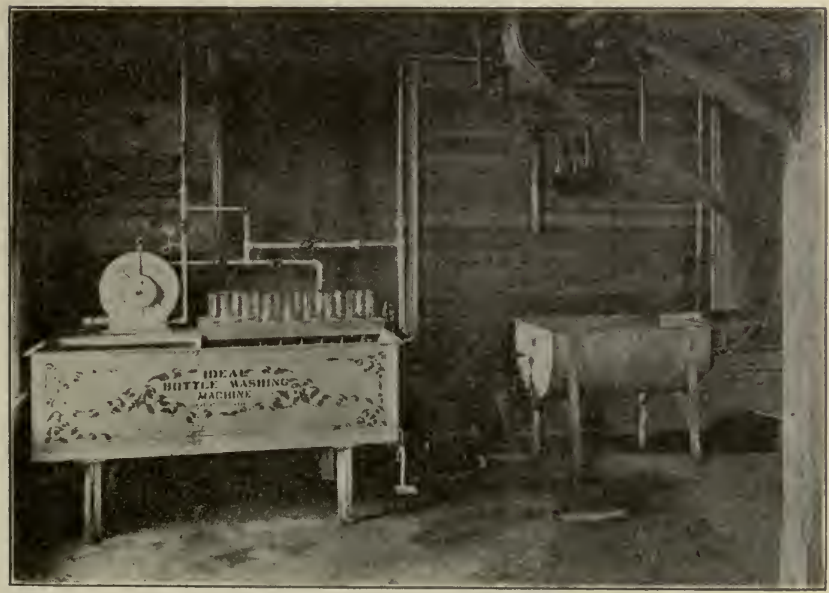

FIG. 1. - Bottle washing machine and sanitary wash tank, showing trap connections. This prevents water from splashing on the floor and soiling elothes or disfiguring machinery. The horizontal pipe should be six inches lower for convenience in stepping over it.

submerged in it for at least twenty minutes. Remove them from the cleaning mixture, wash with a solution of warm water and good washing powder, 
rinse thoroughly with hot water and allow them to drain. Wipe every part of the remaining laboratory apparatus with clean waste, also the shelves

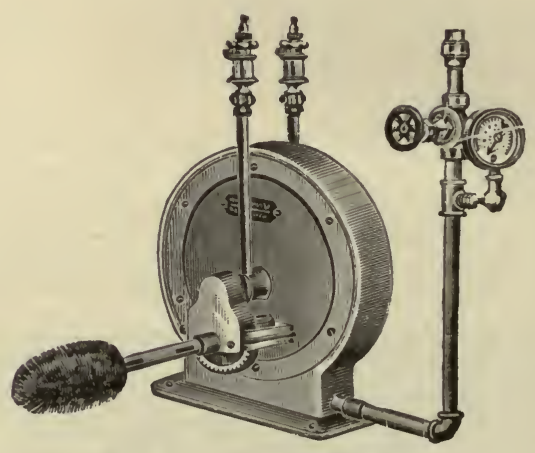

FIG. 2. - Bottle Washer

and drawers to be used, removing every particle of dust. Arrange apparatus in a neat, convenient, and orderly manner for future use.

\section{EXERCISE II}

\section{Cream Separators}

Carefully examine all parts of each separator, beginning with the frame. See that it is perfectly level. Why? Note foundation of the separator and see that it is solid and that the separator is firmly fastened to it. Take out upper and lower bearings and wipe carefully with clcan waste, oil with clear separator oil and replace. Determine method of raising and lowering the bowl for proper adjustment. 
Examine parts of bowl and put them together. Place bowl in the machine and adjust cream screw. Turn screw in to skim thick cream, and out to skim

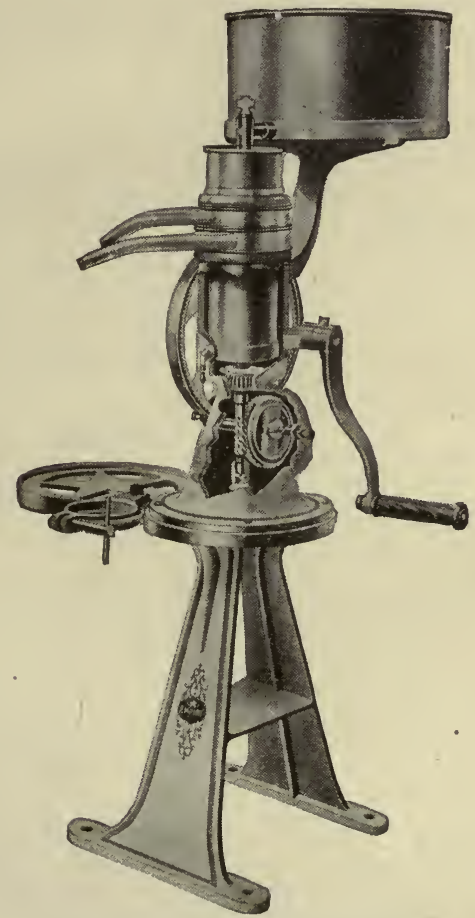

Fig. 3. - Empire Cream Separator showing Bearings

thin cream. Why? Put on cream and milk covers and note purpose of float. Adjust oil cups and fill with proper separator oil. Find speed of bowl by counting number of revolutions of bowl to one of the crank. If the crank makes fifty (50) revolutions 
per minute and the bowl makes one hundred and fifty (150) revolutions to one of the crank the speed of the bowl is $50 \times 150=7500$ revolutions per

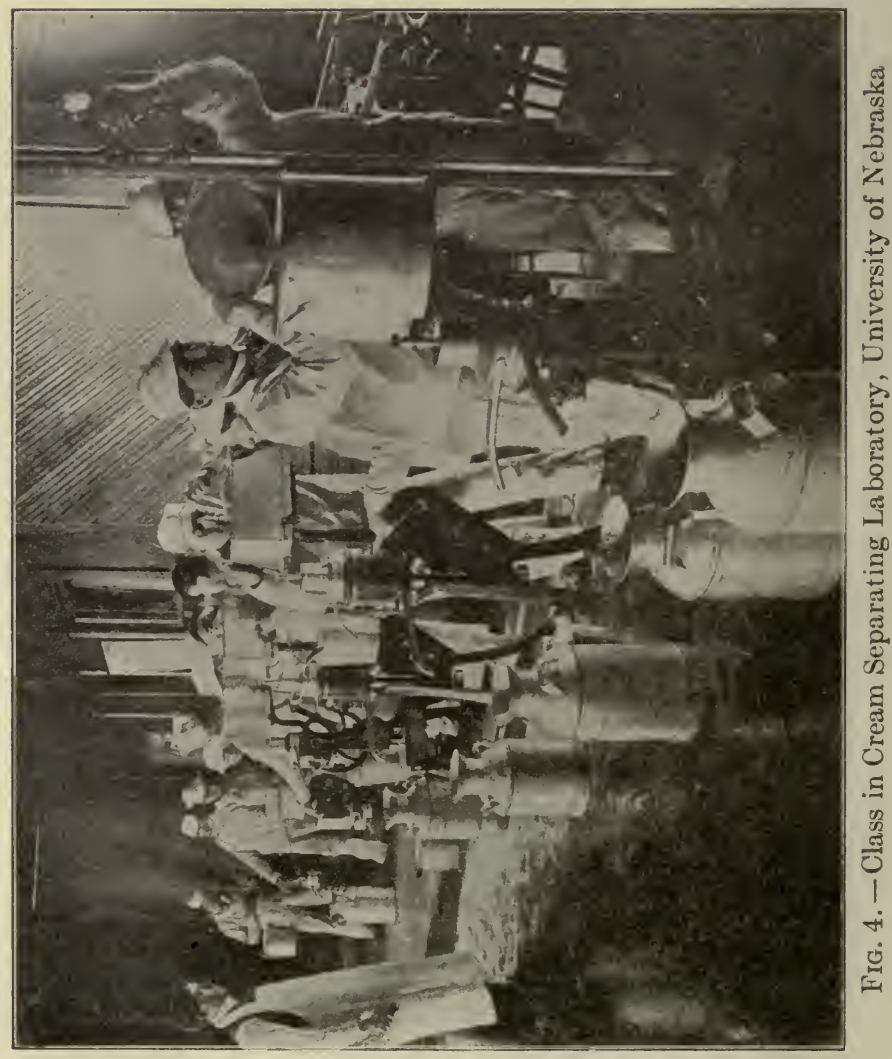

minute. Wash with warm water, using good washing powder, rinse with hot water and sterilize by use of steam or boiling water all parts of the separator and put them away, arranging each so that no two 


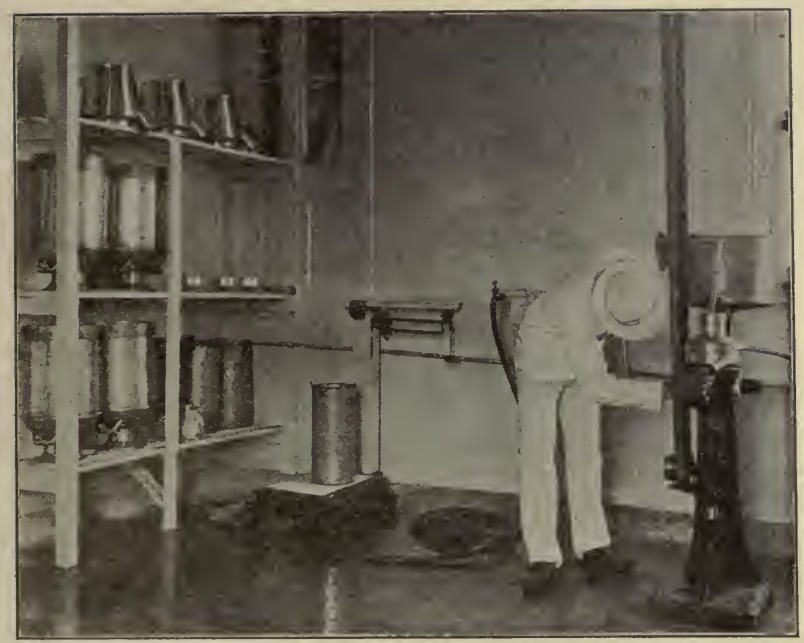

FIG. 5. - Dairy-room, Maryland Agricultural Experiment Station, Dairy Building; showing correct method of draining pails and cans; properly rounded cement corners of room; and student regulating the flow of oil into the upper bearing of cream separator.

parts touch; they will thus areate and dry without rusting. Repeat, using each separator, and note difference in construction.

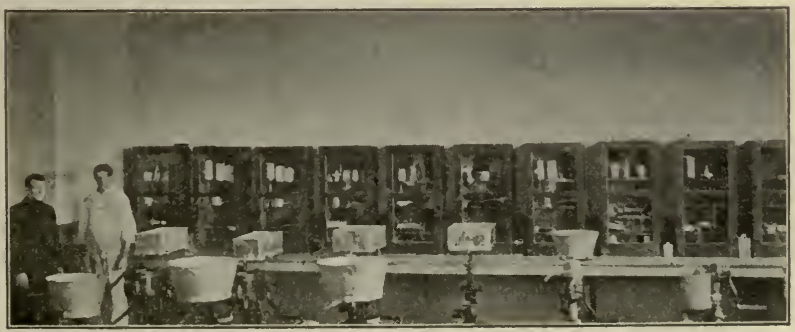

Fig. 6. - Showing Cases for separator parts. These are conveniently arranged on the wall of the separator room. The dust is excluded hy means of glass doors. Kansas Agricultural College Creamery Building. 


\section{EXERCISE III}

Take a given number of pouncls of milk, separate, and fill out the following blank:

\section{SEPARATING REPORT}

Date................... $190 \ldots$

Name of separator used.

Size of separator used

Rated eapaeity .................. Per hour.

Actual capacity .................. Per hour.

Quantity of milk separated................. Pounds. Average temperature of milk entering heater.

Average temperature of milk entering separator.

Average temperature of cream leaving separator.

Average temperature of cream leaving cooler.

Average temperature of skim-milk leaving separator.

Average temperature of skim-milk leaving pasteurizer

Speed of separator bowl: Listed........ ; Aetual.

Average test skim-milk

Average test eream .

\section{SEPARATOR TEST}

Sample Taken from Entire Run

\begin{tabular}{|c|c|c|c|c|c|c|c|}
\hline & \multicolumn{6}{|c|}{ Samples } & Average \\
\hline Time sample taken & 1 & 2 & 3 & 4 & 5 & 6 & \\
\hline Temperature whole milk. & & & & & & & \\
\hline Temperature skim-milk & & & & & & & \\
\hline Temperature eream ... & & & & & & & \\
\hline Capacity per hour . & & & & & & & \\
\hline Speed of bowl ... & & & & & & & \\
\hline Remarks:..... & & & & & & & \\
\hline
\end{tabular}

(Signed)

O. K.

Instructor. 
In starting the separator fill the bowl full of lukewarm water or skim-milk. Why? Start separator slowly and increase to proper speed in about three to five minutes. Why?

All cream and skim-milk should be cooled immediately after separating.

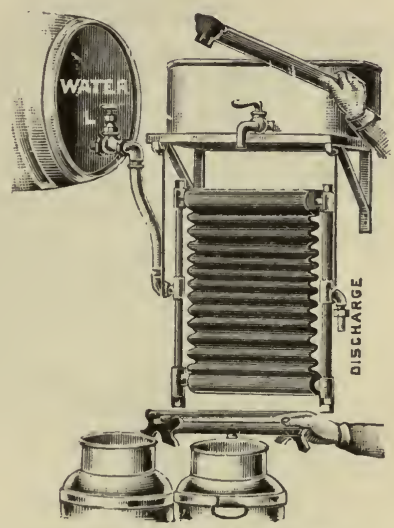

Fig. 7. - Star Milk Cooler

1. Separate 10 gallons of about 4 per cent milk at $90^{\circ} \mathrm{F}$. and another can of the same per cent milk at $70^{\circ} \mathrm{F}$. Note difference in test of cream and skimmilk.

2. Repeat experiment, using in one instance no flush water and in the next the usual amount; just enough to rinse out of the bowl the milk that remains after separating.

3. Repeat experiment with separator running in perfect condition, and again with the bowl unsteady and vibrating. 
4. Repeat experiment one, using a high speed of bowl in one instance and in the other a low speed.

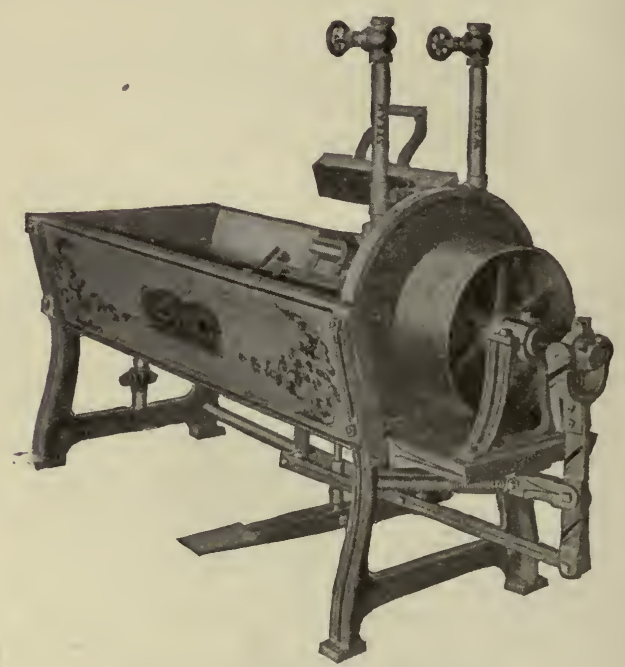

Fig. 8. - Milk Can Washer

5. Similarly separate a can of milk, allowing the milk to flow slowly through the separator bowl at

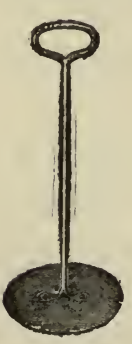
about one-half capacity. Then separate can of milk running at full capacity.

6. Separate a can of milk testing less than .2 per cent acid and another can at the same temperature but testing 35 per cent to .4 per cent acid. In every experiment make careful tests of cream and milk to ascertain causes of varia-

Fig. 9. Milk Stirrer and Aerator cream. 
Repeat operation, using each separator in dairy room and note difference in skimming, simplicity, and ease of running. Cool cream immediately after separating.

\section{EXERCISE IV}

\section{The Use of The Babcock Tester}

Examine the tester and bottles carefully. Note that the principle of centrifugal force in tester is same as that of the separator. Mix thoroughly a

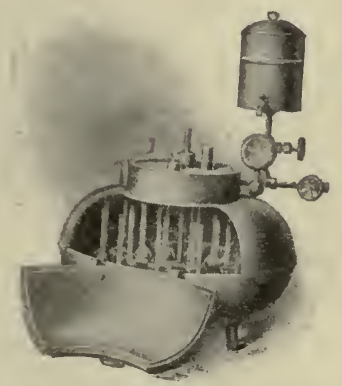

Fig. 10. - Babcock Tester

sample of whole milk of about $60^{\circ} \mathrm{F}$. by pouring from one vessel to another several times, so as to obtain an aliquot part of the mixture. Draw a sample of this milk into a 17.6 c.c. pipette by placing the mouth over the upper end and sucking the air out of the tube. When the milk rises above the 17.6 c.c. mark remove the lips from the tube and place the index finger over the end of the same. 
Allow the milk to drop from the opposite end of the pipette by loosening the finger slightly until the edge of the meniscus (rim of the crescent surface) touches

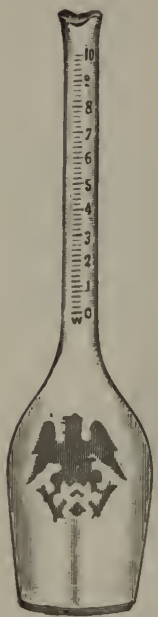

Fig. 11. - Whole Milk Test Bottle

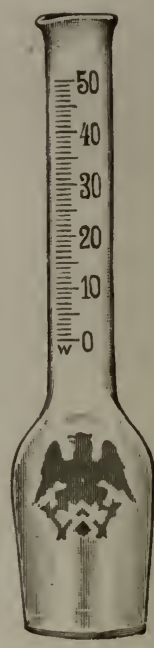

FIG. 12. - Cream Test Bottle

the 17.6 c.c. mark. Then place the contents of the tube into a whole milk test bottle, adding 17.5 c.c. of commercial sulphuric acid from a graduated bottle

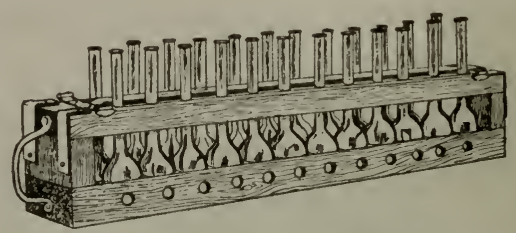

Fig. 13. - Rack for Babcock Test Bottles

Note. - For cleaning discolored test bottles add $1 \mathrm{lb}$. good washing powder to a gallon warm water. Fill bottles one-third full and add 1 c.c. sulphuric acid to each. 
or cylinder, being careful to pour the acid at an angle of about 45 degrees down the neck of the bottle so that it will not cause a violent reaction until ready to be shaken. Revolve milk and acid with a gentle
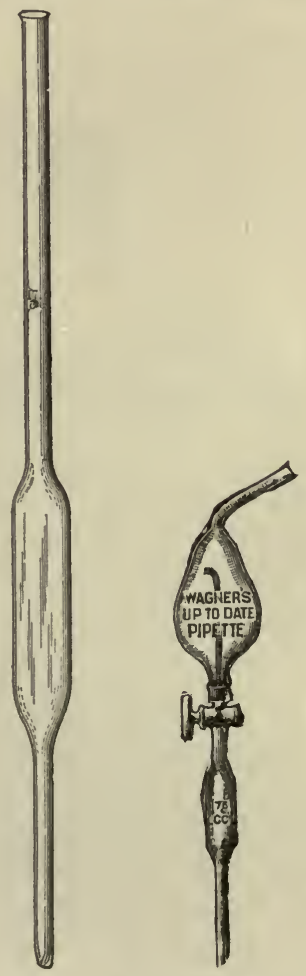

FIg. 14. - Pipettes

rotary motion until the curd of the milk is entirely dissolved. Place bottles in tester, being careful to put the same number on opposite sides of the tester 
to balance the machine. Oil tester and see that it runs steadily. Revolve at listed speed for three minutes. Then fill to the lower part of the neck with hot water $150^{\circ}$ to $200^{\circ} \mathrm{F}$. Whirl again for two minutes and fill to the upper part of the graduated neck. Then whirl for one minute to a minute and

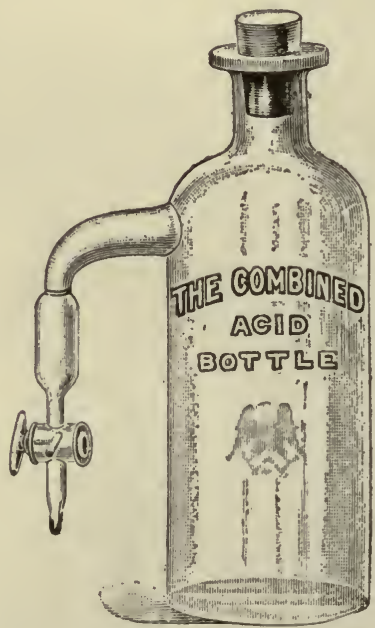

Fig. 15. - Combined Acid Bottle and Pipette

a half, and read result at once before fat column begins to cool and shrink. Read the per cent of fat at about $120^{\circ} \mathrm{F}$. If warmer it will be too high; if colder too low. Butter fat solidifies at $80^{\circ} \mathrm{F}$.

The speed of the tester required to produce the necessary centrifugal force depends upon the diameter of the wheel containing the cups. The less the diameter the greater the number of revolutions. 


\begin{tabular}{c|c}
\hline Diameter of Wheel in Inches & Revolutions of Wheel Per Minute \\
\hline 10 & 1074 \\
12 & 980 \\
14 & 909 \\
16 & 840 \\
18 & 800 \\
20 & 759 \\
22 & 724 \\
24 & 693 \\
\hline
\end{tabular}

In reading the per cent of fat place the lower point of the dividers at the lower surface of the fat column, and the upper point at the upper edge of the meniscus.

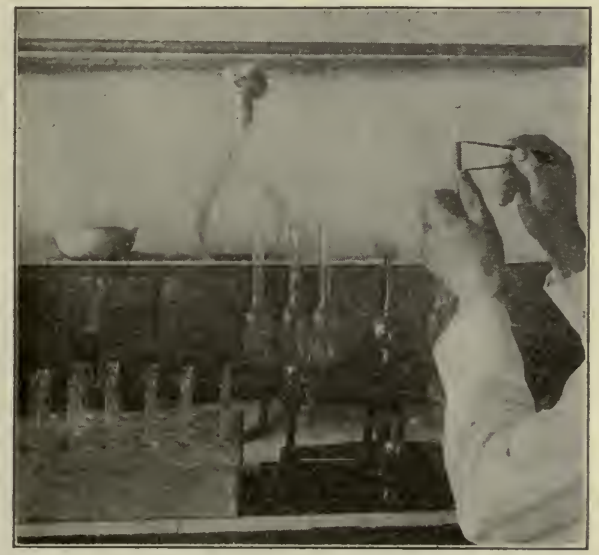

FIG. 16. - Correct method of holding dividers in reading of the per cent of butter fat. Resting the lower point of the dividers on the tip of the thumb facilitates steadiness. Balance seales for weighing cream. Tin box for washing test bottles.

Now placing the lower point of the dividers at the zero mark, and reading the result at the upper point. 


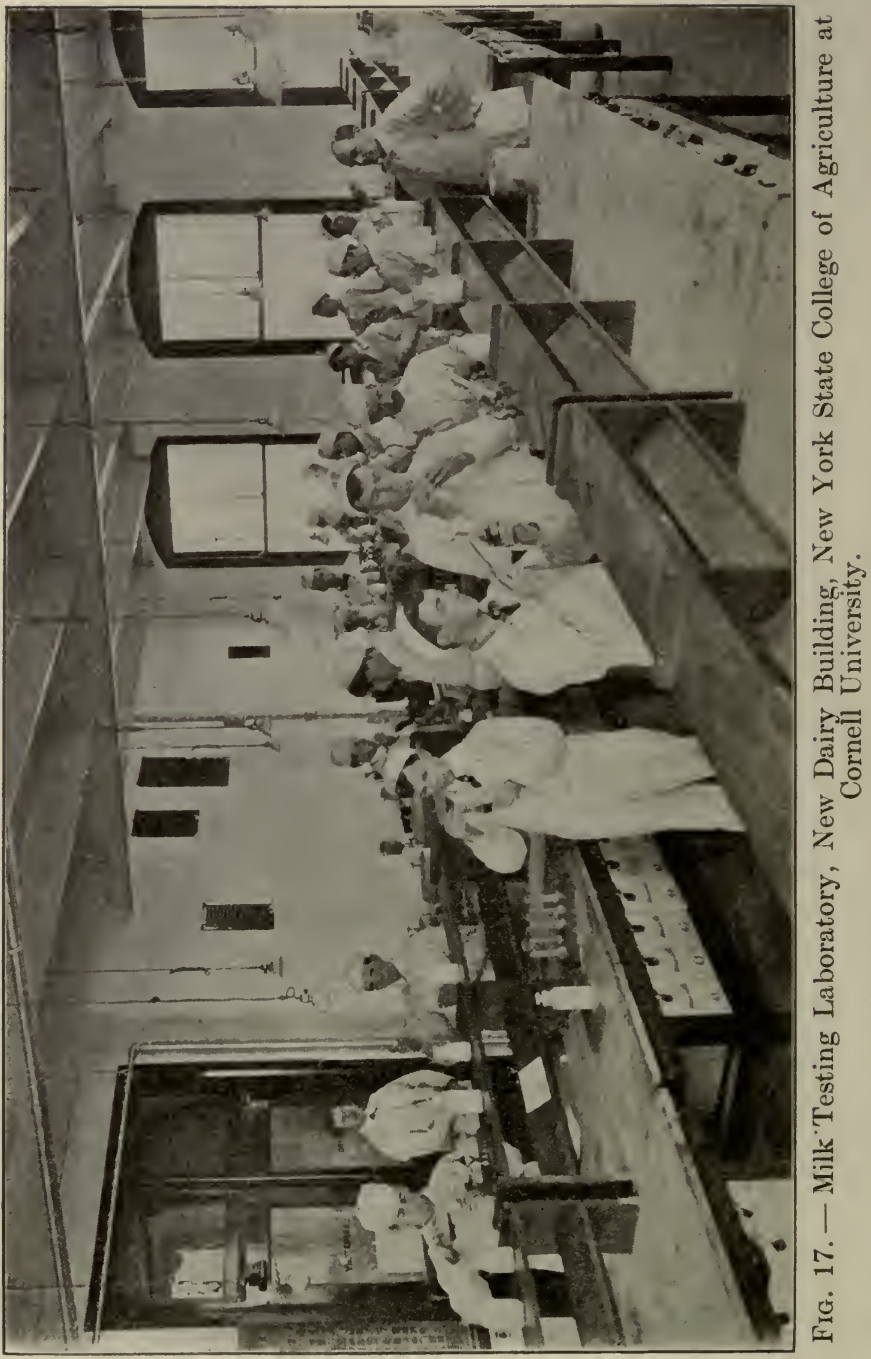


This measurement gives a correct reading for whole milk. For cream, take reading from the center of the meniscus, on account of the larger amount of fat in neck of cream bottle, and consequently in the meniscus.

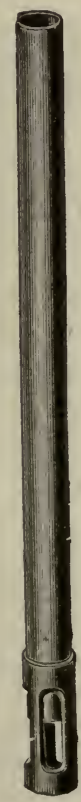

Fig. 18.-Scovell Milk Sampling Tube

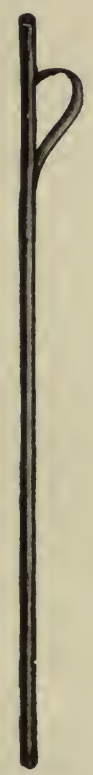

Fig. 19.-McKay

Milk Sampler

In testing skim-milk an increased proportion of sulphuric acid must be used on account of the lesser amount of fat present and the increased proportions of solids which must be dissolved by the acid. The 
reverse is true of cream. Repeat tests, using cream, but instead of measuring with pipette, weigh on cream scales prepared for the purpose, using 18 grams on account of the difference in specific gravity (comparative weight) between milk and cream. A still more accurate test for heavy cream is obtained by using 9 grams of cream with about the same quantity of water and multiplying the result by two (2). The richer the cream the more fat it contains and consequently the lighter it is, and vice versa.

The variation between measurements and weights of a given amount of cream is as follows:

Cream testing 15 per cent equals 8 pounds and 7 ounces per gallon.

Cream testing 20 per cent equals 8 pounds and $6 \frac{1}{2}$ ounces per gallon.

Cream testing 25 per cent equals 8 pounds and 6 ounces per gallon.

Cream testing 30 per cent equals 8 pounds and $5 \frac{1}{2}$ ounces per gallon.

Cream testing 35 per cent equals 8 pounds and 3 ounces per gallon.

Cream testing 40 per cent equals 8 pounds and 1 ounce per gallon.

Cream testing 45 per cent equals 7 pounds and 15 ounces per gallon.

Cream testing 50 per cent equals 7 pounds and $14 \frac{1}{2}$ ounces per gallon.

Repeat; using in first experiment less acid; second experiment, cold milk; and third experiment, cold water. Note results. Similarly test butter and 
finely pulverized cheese, using 9 grams in each test, and multiplying the result by 2 . Obtain accurate sample by inserting trier in various places in the cheese or butter to be tested.

Also test samples of ice cream using a mixture of equal parts of Conc. hydrochloric acid and glacial acetic acid.

Hydrochloric acid alone chars the milk sugar on heating almost as bad as sulphuric acid, and, therefore, is useless. Acetic acid alone will not dissolve the milk solids, but the mixture works perfectly.

When milk has become sour the casein may be redissolved by adding powdered potash, baking soda, or liquid ammonia. Care should be taken not to use too much alkali as it reacts with the acid and sometimes throws a part of the sample out of the bottle. Dissolve the potash or soda in water before using. A volume equal to about 5 per cent of the volume of the milk will be sufficient to dissolve the casein. This solution increases the volume of milk and thus necessarily decreases the per cent of fat. Measure the volume of milk to be tested, and measure the solvent before adding. Calculate the decrease in the per cent of fat in the following manner:

If 9 cubic centimeters of alkaline solution has been added to 180 cubic centimeters milk to dissolve the casein, which is 5 per cent of the milk used (180:9 : $: 100: \mathrm{x}=5$ ), the mixture gives a test of 3.9 per cent of butter fat. The test must be increased 0.195 per cent $(3.9 \times .05=0.195)$. Hence, the per cent of fat in the original milk is $4.095(3.9+0.195=4.095)$. 


\section{Testing Strength of Acid}

Test strength of acid by finding its specific gravity, which should be 1.82 to 1.83 . This can be done by weighing an exact measured volume of acid and comparing its weight with the same volume of distilled water. Then divide the weight of the acid by the weight of the same volume of water and the quotient will be the specific gravity of the acid. If the fat column is very light and contains white specks the acid is too weak, not enough used, or milk was too cold. If very dark or if it contains black specks the acid is too strong, too much was used, or milk or acid was too hot. The fat column should be of a light straw color.

\section{EXERCISE V}

\section{USE OF THE LACTOMETER}

The lactometer is used to determine the specific gravity of a liquid; that is, its weight compared with the weight of an equal volume of distilled water. Where a given volume of distilled water weighs one pound, an equal volume of whole milk weighs 1.029 to 1.033, depending upon the per cent and kind of solids present. The higher the per cent of fat in milk the less the specific gravity and vice versa. The specific gravity of milk serum is 1.036 . That of fat is .93 . The Quevenne lactometer is generally used. Examine the lactometer carefully and note enclosed thermometer and graduations. Place in graduated beaker of milk 
having a temperature of $50^{\circ} \mathrm{F}$. Heat milk to $60^{\circ} \mathrm{F}$., noting changes in lactometer reading. Take sample of milk for fat test and set it aside. Now add a
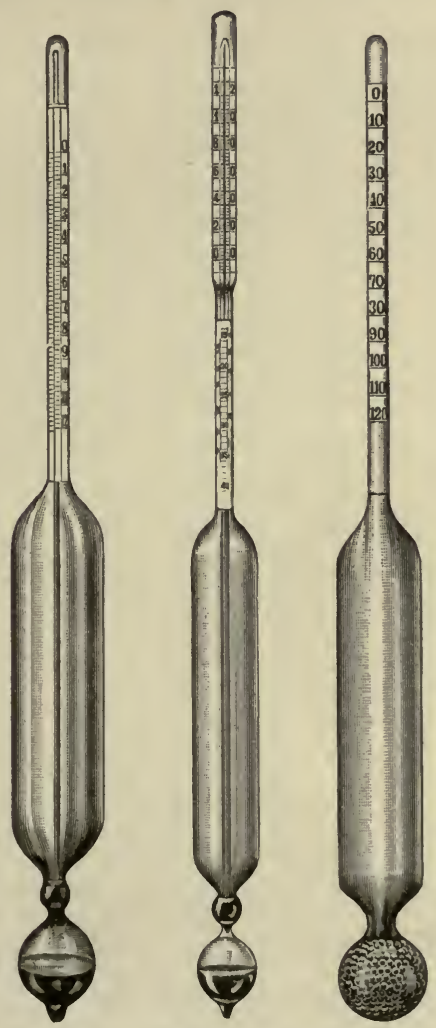

FIG. 20.-Quevenne Lactometers

definite proportion of water to the milk in the beaker and take readings at the same temperatures as before. What is the difference? Why? Calculate formula 
for obtaining correct readings at varying temperatures. Find solids not fat, and per cent of water as follows: $\frac{1}{5}$ of fat found in the milk plus $\frac{1}{4}$ of lactometer reading equals solids not fat. Total solids are obtained by adding the solids not fat to the fat. For example: Where lactometer reading is 32 and fat is 3.5 per cent $\left(\frac{32}{4}+\frac{3.5}{5}\right)=(8.0+.7)=8.7 ; 8.7+$ $3.5=12.3=$ total solids. For finding per cent of water in milk: solids not fat of normal milk minus solids not fat in watered milk, multiplied by 100 and divided by solids not fat of normal milk, equals per cent of adulteration. For example:

S. N. F. Normal Milk - S. N. F. Adulterated Milk S. N. F. Normal Milk

$\times 100=$ per cent adulteration.

\section{EXERCISE VI}

\section{Testing Acidity of Milk}

The acidity of normal milk is caused by the breaking down of milk sugar by bacteria and converting it into lactic acid. The change is supposed to occur in the following manner:

$\begin{array}{ccc}\text { Milk-sugar. } & \text { Water. } & \text { Lactic acid. } \\ \mathrm{C}_{12} \mathrm{H}_{22} \mathrm{O}_{11} & +\mathrm{H}_{2} \mathrm{O} & =4 \mathrm{C}_{3} \mathrm{H}_{6} \mathrm{O}_{3}\end{array}$

There are several tests. for the acidity of milk. Those most commonly used are as follows:

Mann's Acid Test.

Farrington's Alkaline Test. 
Van Norman's Alkaline Test.

Marshall's Acid Test.

\section{Mann's Acid Test}

Fill a 50 c.c. burette to zero mark with tenth normal solution of sodium hydroxide $\mathrm{NaOH}$. Measure 50 c.c. of milk or cream to be tested into a beaker. In the case of cream dilute with water, the amount depending upon the thickness of the cream. Add a few drops, two to five, of indicator; phenolphthalein is generally used. Add the alkali solution to the cream very slowly, and stir constantly until a permanent pinkish color remains in the milk. The per cent of acid is found by multiplying the number of c.c. of alkali solution used by .009, dividing by the number of c.c. of milk or cream used and multiplying the result by 100 . The explanation of this formula is that the alkali of the sodium

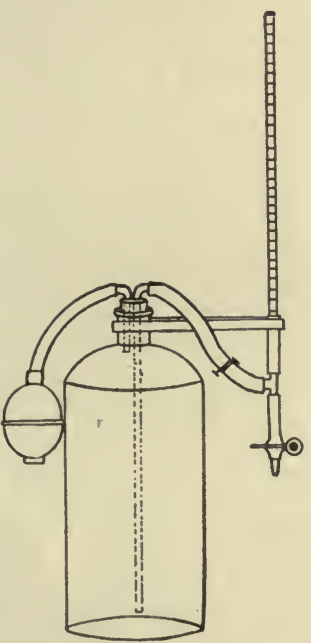
hydroxide neutralizes the acid Fig. 21.-Acid Bottle of the milk. 1 c.c. of tenth norwith Burette mal solution contains .004 of a gram of sodium hydroxide which neutralizes .009 of a gram of lactic acid. This is obtained from the fact that a normal solution of lactic acid contains 90 grams of acid in each liter, or 1000 c.c. Example: 


\section{$\frac{\text { c.c. alkali } 34 \times .009}{50 \text { c.c. Cream }} \times 100=.612 \%$ acid.}

Obtain by means of a pipette a sample of milk from the top and one from the bottom of a beaker of milk that has been allowed to stand for several minutes. Test and note difference. Why?

\section{Farrington's Alkaline Test}

Dissolve five of Farrington's tablets in enough water to make solution 97 c.c. Mix well and measure out 17.6 c.c. of the milk or cream to be tested, and add the alkali solution as in previous tests until the characteristic pink color remains. The number of c.c. of alkali solution required to produce this result indicates the number of hundredths per cent acid, since 1 c.c. of alkali neutralizes .01 per cent of acid when 17.6 c.c. of milk are used. Therefore the number of c.c. neutralizer used divided by 100 equals per cent of acid. For instance: If 50 c.c. solution be used the acidity of the milk in question is .5 per cent. The Farrington tablets contain alkali equal to 3.8 c.c. of tenth normal solution and also the color indicator.

\section{Van Norman's Alkaline Test}

Pour into a 1000 c.c. graduated flask 20 c.c. of normal caustic soda $(\mathrm{NaOH})$ solution, fill to the 1000 c.c. mark with distilled water, making 50th normal alkali solution. Put 17.6 c.c. of milk or cream to be tested into a beaker and add four to 
five drops of phenolphthalein. ${ }^{1}$ Allow the alkali solution to drop slowly into the milk or cream being tested; meanwhile continually stir until a pinkish color is noticeable which does not disappear immediaetly by continued stirring. The number of c.c. of alkali solution required to bring about this result will indicate the number of hundredths per cent of acid, since 1 c.c. of alkali will neutralize .01 per cent of acid when 17.6 c.c. of milk or cream is used, as in Farrington's Test. Thus if 50 c.c. neutralizer be used the milk has an acidity of .5 per cent.

\section{Marshall's Acid Test}

Carefully mix milk or cream to obtain an accurate sample as in above cases, and fill a 9 c.c. pipette with one-tenth normal solution alkali as prepared at the factory. Add from two to four drops of indicator. Allow alkali solution to drop into the milk, constantly

${ }^{1}$ Phenolphthalein is one of the dyes made by a combination of certain coal tar derivatives (phenols) with phthalic acid; in the presence of free alkali a chemical combination is formed having a red color. When a few drops of phenolphthalein solution are added to milk containing free lactic acid no color is appreciable in the milk; as the alkali is added the lactic acid (which has a greater affinity for the alkali than has the phenolphthalein) is neutralized; and as soon as it is all neutralized the slightest further addition of alkali ehanges the indicator to a pink color. Shaking, or stirring, during the test is necessary because the effect of the alkali in producing the red or pink color in the indicator may be seen locally, where the alkali falls into the milk, before the acid in the milk is all neutralized. As soon as all the acid in the sample is neutralized the pink color remains. 
stirring as in the previous tests until a permanent pink color remains in the milk. The number of c.c. used divided by 10 indicates the per cent of acid in

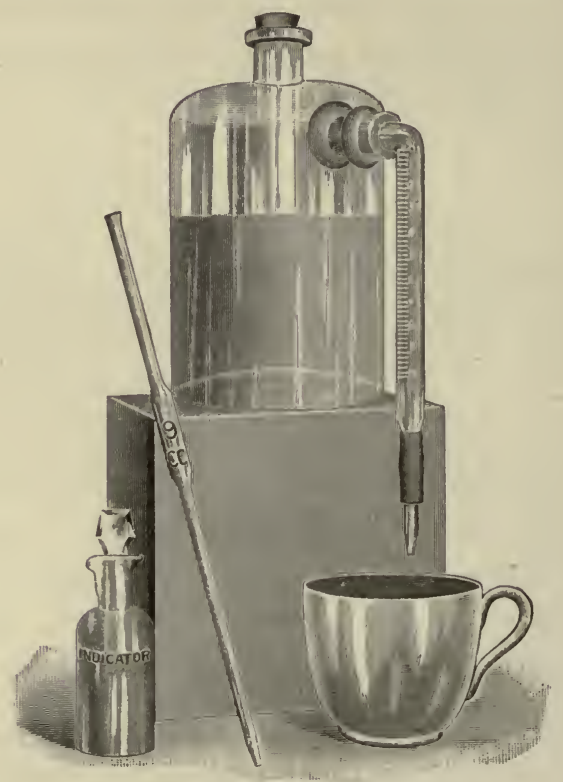

FIG. 22. - Apparatus for Marshall's Acid Test

the milk or cream being tested. Thus, if two (2) c.c. of neutralizer has been used the milk contains .2 per cent of acid.

\section{EXERCISE VII}

\section{Pasteurization}

Fill jacketed space of pasteurizer with water and turn on steam until the desired temperature is 
reached; from $150^{\circ}$ to $190^{\circ} \mathrm{F}$., depending on condition of milk. Start motion of pasteurizer by throwing belt on tight pulley, and when the desired speed is reached open milk inlet. Notice temperature of milk at the outlet from pasteurizer and regulate by the connecting steam valve. Draw pasteurized milk off into sterile cans, placing a clean white cloth or parchment paper above spout and opening of can to prevent contamination from the surrounding atmosphere. Among the pasteurizers in common use are the Jensen, Reid, Miller-Tyson, Miller, and Farrington.

\section{The Miller-Tyson Pasteurizer}

The machine is dependent upon centrifugal force for its action. The film decreases in thickness and . increases in speed as it nears the periphery of the treating plate. It requires fifteen seconds to com-

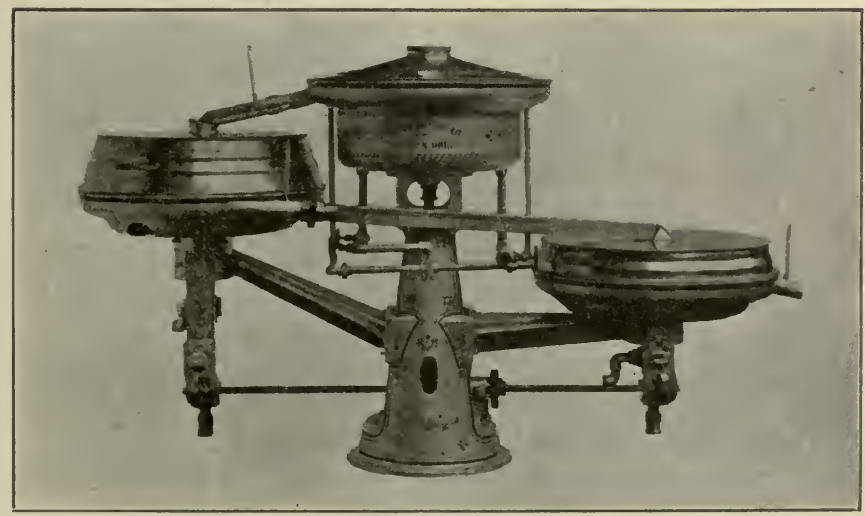

FIG. 23 
plete the process of pasteurization, heating to 180 degrees, and cooling to desired temperature.

After pasteurization there is no milk left in machine and it does not have to be taken apart for cleansing, but by lifting covers all contact surfaces are in direct view and can be touched with a brush.

It is said to be equally adapted for the pastcurization of sweet milk and thick, sour cream.

The essential point in the construction of a Regenerator is the employment of a non-conducting, revolving cylinder which permits the uniting in a single apparatus, the heating on a water-heated surface with an effective interchange of heat. The Regenerator consists of a bank of pipes, perfectly smooth inside, connected by means of vertical end plates, and communicating one with the other by means of sanitary detachable manifolds. The milk coming from the Pasteurizer passes through this bank of pipes, entering the same at the bottom, and being discharged at the top so that the hottest milk fills the lowest pipe, and as it becomes colder, the coldest milk leaves at the top to be discharged to the cooler. The cold milk runs over this bank of pipes on the outside, striking a pipe first nearly its own temperature and gradually becoming hotter as it passes down over the apparatus, finally getting almost as warm as the milk leaving the Pasteurizer. A great saving is therefore effected in the use of steam on the one hand, and in the use of cooling with cold water or ice on the other. In other words the heat which has once been imparted to the 


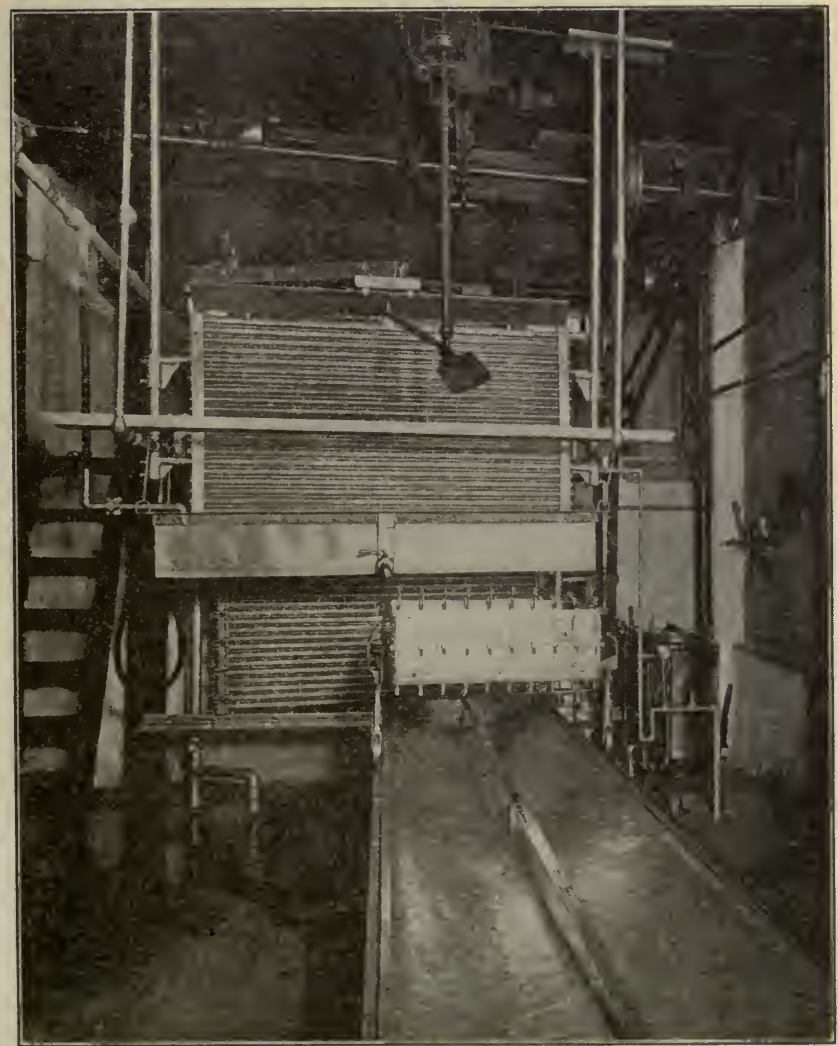

FIG. 24. - Regenerator in use in Schier's Dairy, Baltimore, Md.

milk by means of the Pasteurizer is used to partly heat the milk which shall enter the Pasteurizer, while the cold milk helps to cool that which flows from it. It is obvious that if the service of conduct is large enough a complete exchange of the two temperatures must take place. 


\section{EXERCISE VIII}

\section{Starter Making}

Sterilize a clean-flavored batch of sweet skimmed or whole milk by running it through a pasteurizer and heating to about $212^{\circ} \mathrm{F}$., preferably two days in succession. Allow the milk to run into a sterile quart bottle. ${ }^{1}$ Cover spout of pasteurizer and opening in the bottle with clean white cloth or parchment paper to prevent contamination from the surrounding atmosphere, as in the case of pasteurization. Cover bottle as soon as full and cool to $80^{\circ} \mathrm{F}$. Add contents of bottle or capsule of commercial culture and allow to remain at $80^{\circ} \mathrm{F}$., until milk becomes partially thickened, or has the consistency of thick cream. This usually requires from eight to twelve hours. At this stage it is called startoline. Pour from the top of the bottle into a can containing from five to ten gallons of pasteurized milk the entire contents of the bottle, with the exception of about one tablespoonful remaining in the old bottle. Put the spoonful of starter remaining in the old bottle into a clean sterile bottle and

${ }^{1}$ Where glass jars are used a steaming cabinet is very convenient. This should be made to hold three times as many jars as are required daily. Place one day's supply in, heat to from $200^{\circ}$ to $212^{\circ} \mathrm{F}$. for half an hour. On the following day add a like number and repeat the heating. On the third day add another day's supply and again repeat the heating. The first jars have now received three applications of heat and are practically sterile. By replacing each day as many jars as are taken out a supply of sterile mother starter is constantly on hand. 
add enough milk to continue the propagation of the original culture, being careful thereafter to keep at $70^{\circ} \mathrm{F}$. Stir every half hour as before. Mix

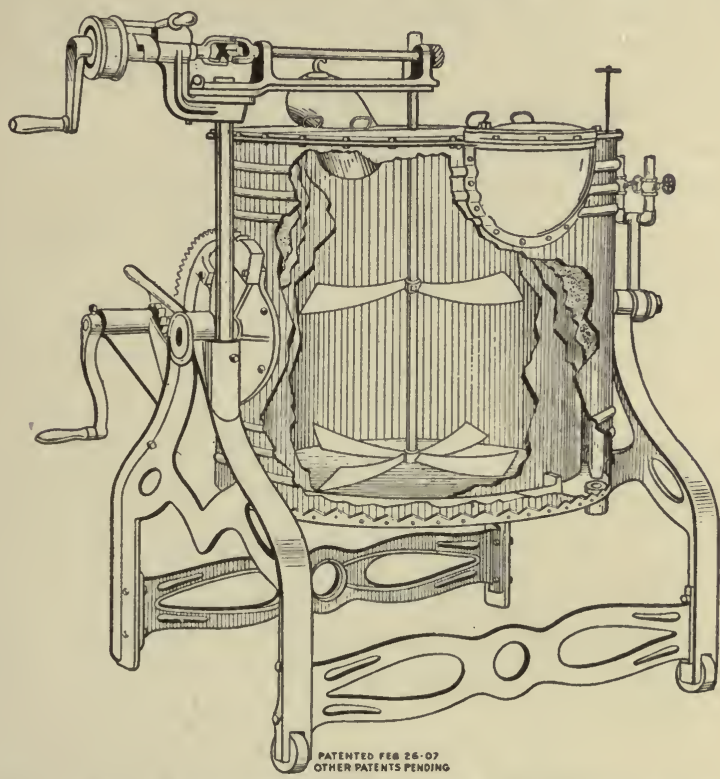

Fig. 25. - Trunnioned Starter Can. This Starter Can is trunnioned on its frame in such a manner that the starter may be drawn off from the top, leaving the lower, less contaminated portion for propagation. The agitators serve to keep the starter in a uniform condition while ripening.

The space between the jacketed sides may be used for cold water in the summer, and warm water in the winter to maintain an even temperature about $70^{\circ} \mathrm{F}$.

thoroughly the starter and skim-milk in can and allow to stand at $70^{\circ} \mathrm{F}$., until the proper consistency is reached, when it is ready for use. The following blank form may be used in this exercise: 


\section{STARTER REPORT}

Date.

Kind of starter made (Ericsson, Douglas, Hansen, Parke Davis, etc., or natural)

Number of culture used

Pounds of milk used

Acid test of milk before heating

Temperature of heating

Time held at this temperature

Temperature after cooling

Quantity of culture used

Time of setting

ACIDITY OF STARTER

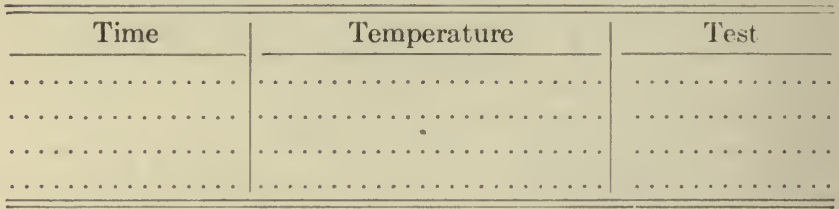

Held at what temperature when ripe

Describe flavor:

Remarks:

(Signed)

O. K.

Instructor.

In preparing starter it is advisable to keep several samples of mother cultures propagating. If an incubator cannot be obtained a small cream vat may be converted into a form of incubator which may be used for maintaining an even temperature, where such samples or small quantities of milk or cream may be kept. These vats are double-lined, having 
a dead air space of about three inches between the tin jacket and outer tank. This space surrounds the entire tin jacket or inner tank, and can be filled with warm air in the winter and cold in the summer, to impart uniform temperature to the samples contained therein. About six inches of water may be kept in
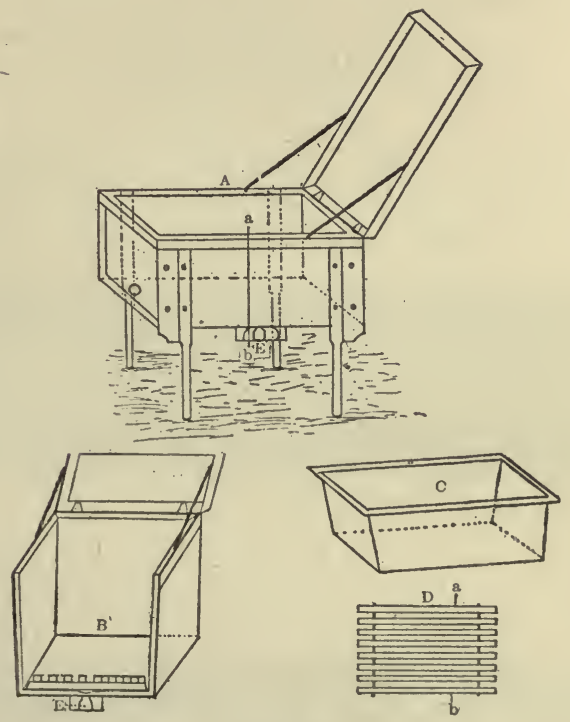

FIG. 26

the tank to aid in maintaining an even temperature. Ice may be used in summer if obtainable. Of course the opening $E$ should be closed in the summer. The accompanying cut represents the vat. $E$ represents the opening from below to the dead-air space and the place for the lamp which is kept burning continually except when room temperature is $70^{\circ} \mathrm{F}$. or 
warmer. The lamp keeps the air warm and at an even temperature regardless of the weather. In case of extreme cold weather the burner may be turned higher than in warm weather. $D$ represents the slats used in the bottom of the tank which allows the water to come in contact with bottom of the pails or bottles used.

\section{EXERCISE IX}

Curd Test

Make curd tests by placing in composite sample bottles, or other convenient glass jars, samples of

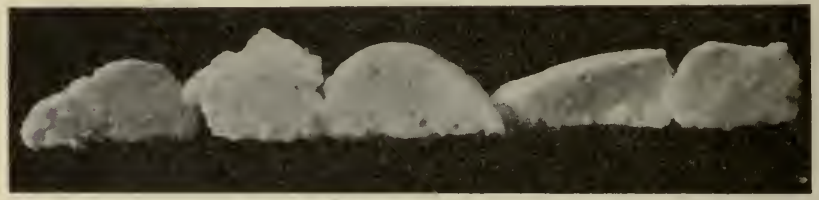

FIg. 27. - Curd of Milk from Sterilized Separator

various kinds of milk to be tested. Heat to $90^{\circ} \mathrm{F}$. and add a few drops of rennet, depending upon the

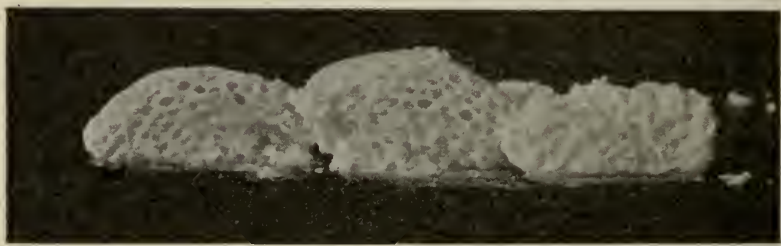

FIG. 28.-- Curd of milk from separator merely flushed with warm water. The milk in both instances was pasteurized before separating.

quantity of milk used. Place in incubator or warm room and allow to remain until curdled. Remove 
slices of curd with sterile knife and examine for flavor, odor, etc. Remove whey and allow samples to remain from eight to twelve hours and examine as before. Also note presence or absence of pin-holes and other defects caused by gas forming or putrefactive bacteria.

\section{EXERCISE $\mathrm{X}$}

\section{Cream Ripening}

After separating and pasteurizing as indicated in Exercises 3 and 7, add starter as prepared in Exercise 8 , the amount depending on the per cent acid in the cream and the length of time previous to churning. Keep the cream at $70^{\circ} \mathrm{F}$. luring cold weather and $60^{\circ} \mathrm{F}$. in warm weather, until an acidity of about .5 per cent has developed. Now cool the cream to $45^{\circ} \mathrm{F}$. and allow it to remain at that temperature for at least two hours, when it is ready to churn. Why leave at this temperature so long? Heat to $50^{\circ} \mathrm{F}$. for churning in summer and $55^{\circ} \mathrm{F}$. for churning in winter.

Formula for Adding Starter to Sweet Cream, or Cream which is to be churned immediately without ripening.

Suppose your standard of acidity for ripened cream is .5 per cent, that of the starter is .9 per cent, and the standard amount of starter is 10 per cent, the acidity of the cream on hand is .4 per cent, and that of the starter is .8 per cent; then 
$\frac{.5 \times 90+.9 \times 10-.4 \times 100}{8-.4}=35$ per cent starter to be used.

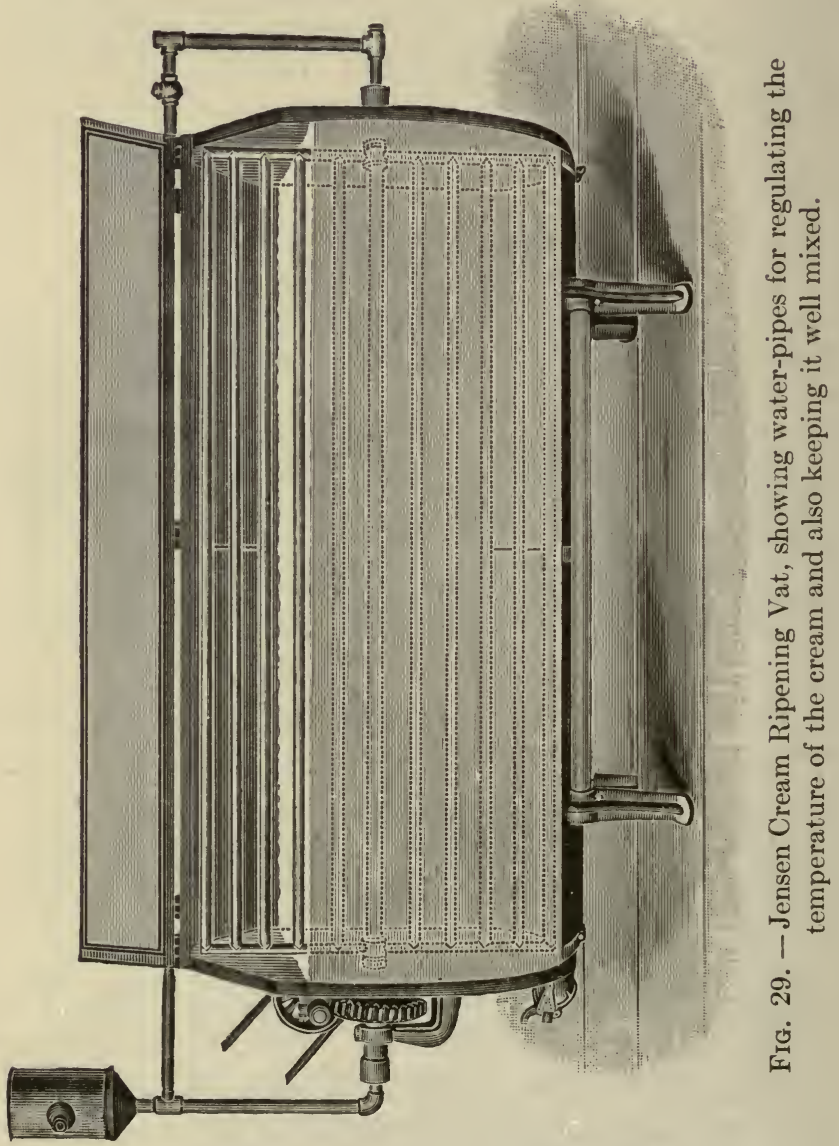

Experiment with the use of commercial lactic acid for ripening cream, using from 10 to 20 c.c. per gallon. 
The following blank form may be used in this exercise:

\section{CREAM RIPENING REPORT}

Date.

Name and capacity of vat used.

Pounds of cream in vat

Pounds of starter added

Kind of starter used

Acidity of starter when used

Number of culture

Babcock test of cream after adding starter

Required acidity

Was cream pasteurized?

\section{TESTS FOR ACIDITY}

\begin{tabular}{|c|c|c|}
\hline Time & Temperature & Test \\
\hline$\ldots \ldots \ldots \ldots \ldots$ & $\cdots \cdots$ & $\ldots \ldots \ldots \ldots$ \\
\hline$\ldots \ldots \ldots \ldots \ldots \ldots$ & $\ldots \ldots \ldots$ & $\cdots$ \\
\hline$\ldots \ldots \ldots \ldots \ldots$ & $\cdots \cdots$ & $\ldots \ldots \ldots \ldots$ \\
\hline … & $\ldots \ldots \ldots \ldots \ldots \ldots \ldots \ldots$ & $\ldots \ldots \ldots \ldots$ \\
\hline
\end{tabular}

Time required to ripen

Temperature to which cream was cooled Acid test after cooling.

Manner of cooling

Remarks:

(Signed)

O. K.

Instructor.

\section{Viscogen}

When cream has been pasteurized above $150^{\circ} \mathrm{F}$. its viscosity is reduced by a loosening of the galactase which holds the fat globules in groups. To restore 
the viscosity add viscogen. The formula for viscogen is $2 \frac{1}{2}$ parts of sugar, or all that will dissolve without caramalizing, 5 parts water, $\frac{3}{10}$ part milk of lime. Prepare one gallon. Mix thoroughly and allow to stand for at least twenty-four hours. Viscogen is an alkali and if too much be added it gives a bad odor and bitter taste. One ounce of viscogen is sufficient to restore the viscosity in five gallons of sweet cream. The higher the per cent of acidity the more it will require. Where viscogen is added to cream for market it should be labeled visco-cream.

\section{EXERCISE XI \\ Cream Grading}

Make acid test; curd test; heat a sample of milk or cream to $120^{\circ} \mathrm{F}$., and note odor. Take lactometer reading. First-grade cream should test between 30 and 50 per cent butter fat, from 0 to .2 per cent acid, and have a good clean flavor. Second-grade cream may test from 20 to 50 per cent butter fat and have not higher than .3 per cent acid, and fair flavor. Third-grade cream should not be used for buttermaking.

A test for ammonia in milk or cream may also be made by adding 10 c.c. of 10 per cent solution of bichloride of mercury and potassium iodide (Nessler's Reagent) to 10 c.c. of milk. A precipitate is at once thrown down. Filter and add 3 per cent solution of pure milk of lime until a black precipitate is formed which disappears with an excess of reagent. This 
test is seldom used and is unnecessary except where the water used in the dairy is suspected of being contaminated with sewage.

Scrupulous cleanliness should be practised in bottling milk. It should never be retailed in any other form. The caps should never be removed until delivered to the consumer.

\section{SCORE CARD FOR MILK}

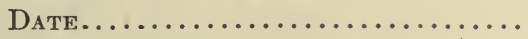

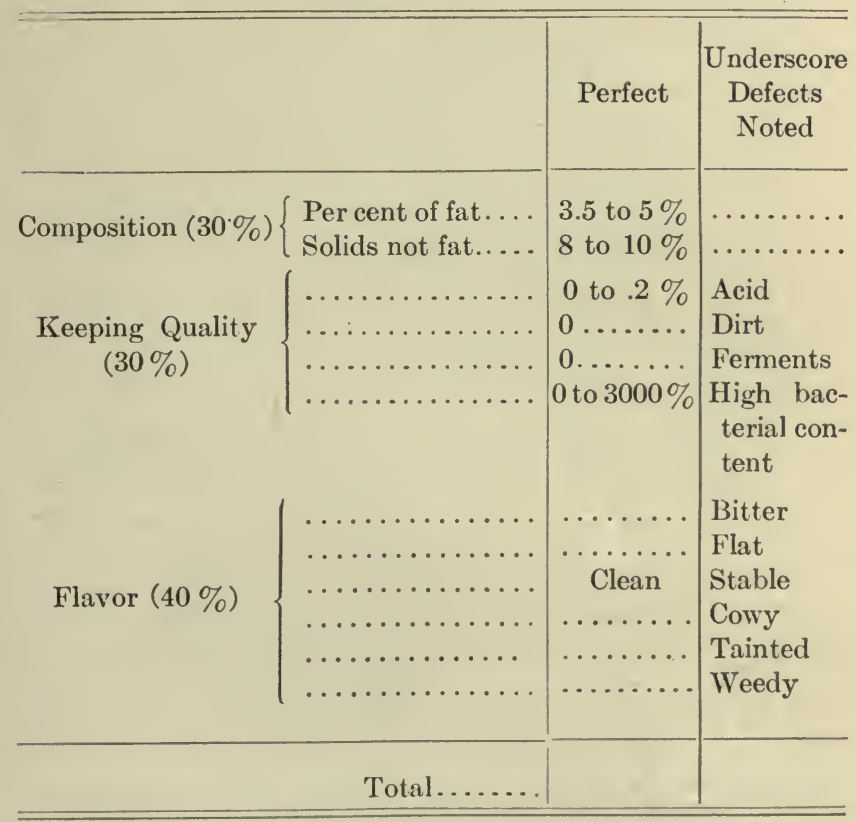


Flavor ...........................40

Composition .......................25

Bacteria ..........................20

Acidity. . ...................... 5

Appearance of package and contents ........10

The score cards used for milk and cream by the Dairy Division, Washington, D. C.:

CREAM SCORE CARD

FLAVOR

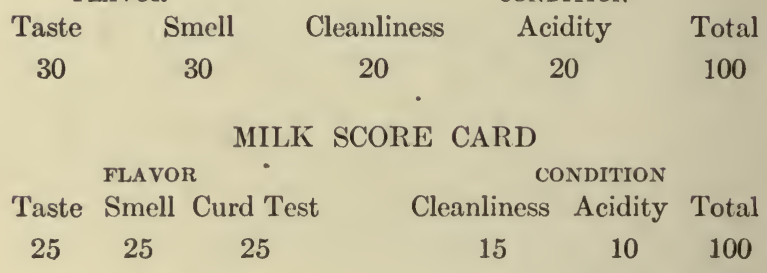

\section{EXERCISE XII}

\section{Churning}

Rinse churn with hot water from $150^{\circ}$ to $200^{\circ} \mathrm{F}$., revolving it from five to ten times, being careful to leave stopper out. Draw off water and rinse again in the same manner with pure cold water at about $40^{\circ}$ to $50^{\circ} \mathrm{F}$., leaving stopper in during the last rinsing. Draw off water and pour the ripened cream in, filling churn about one-third full so as to allow the greatest splash in churning. Add vegetable coloring, the amount depending on the time of the year and the market requirements. If cows are receiving no grass and the market demands a high color, an ounce or 30 c.c. color to each 50 pounds 
of butter fat may be used. Put cover on tight and set churn in motion, removing stopper two or three times during the first part of the churning to allow the moist air to escape.

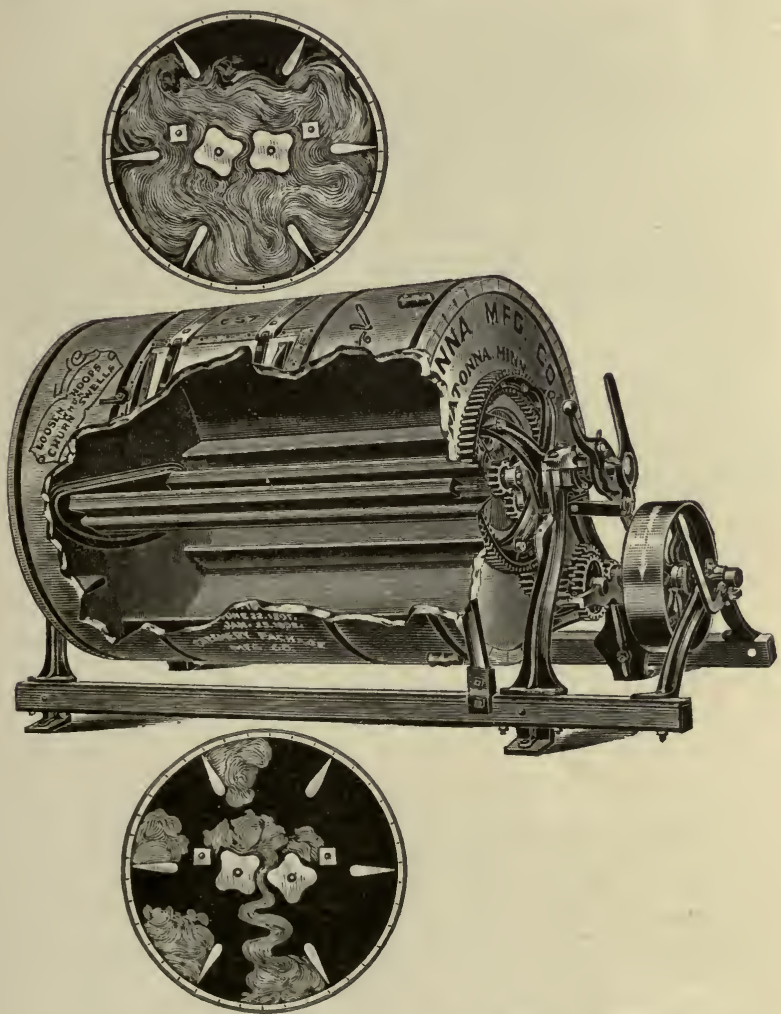

FIG. 30. - Disbrow Combined Churn and Worker with sections showing butter being worked.

When the butter has gathered in granules the size of number 4 to 00 shot stop the churn and draw 
off buttermilk. Rinse once, using one-quarter of the churnful of sterile water, or as pure as can be ob-

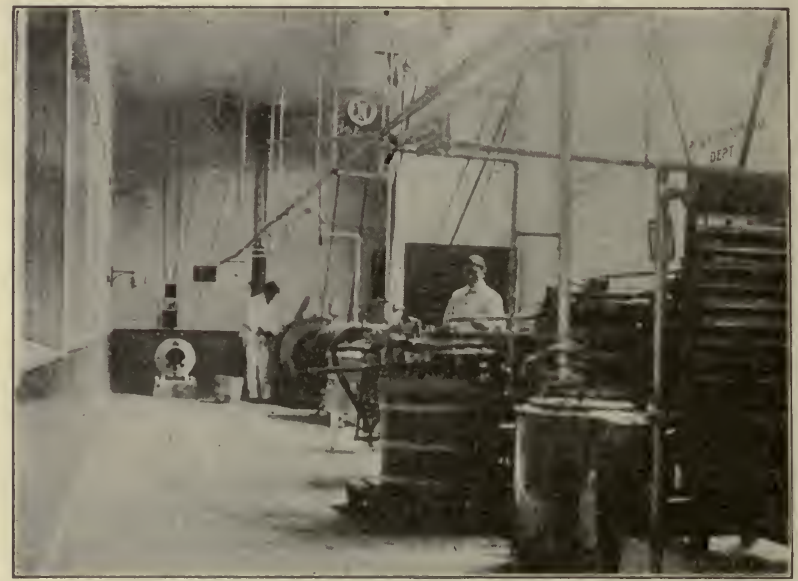

Fig. 31. - Churning and Cream Ripening Department of the Model Dairy of the Louisiana Purchase Exposition, showing machinery operated by a 5-horse-power dynamo. This is the most sanitary source of power obtainable for a creamery. One of the most important precautions for the beginner in the use of a dynamo is that of starting and stopping. In starting the current is first connected with the switch. Then the crank or starting rheostat is moved slowly over the controlling box to the magnet which holds it in place, while the current is on. If the starting rheostat is moved over quickly the field in the controlling box does not "catch up" with the current immediately and a fuse may be blown out, or the field overstrained. In stopping the dynamo, disconnect current by merely throwing off switch. Never try to move starting rheostat back while current is on. Use nothing but insulated copper-wire for connections, and see that they are kept clean and tight.

tained, revolving the churn about three times. Draw off, and if water still has milky color rinse again, otherwise not. Add salt, depending on the market 
requirements. One ounce and a half of salt per pound of butter fat is usually sufficient. See that salt is kept in a warm place, and to give best results the salt must not be colder than the butter.

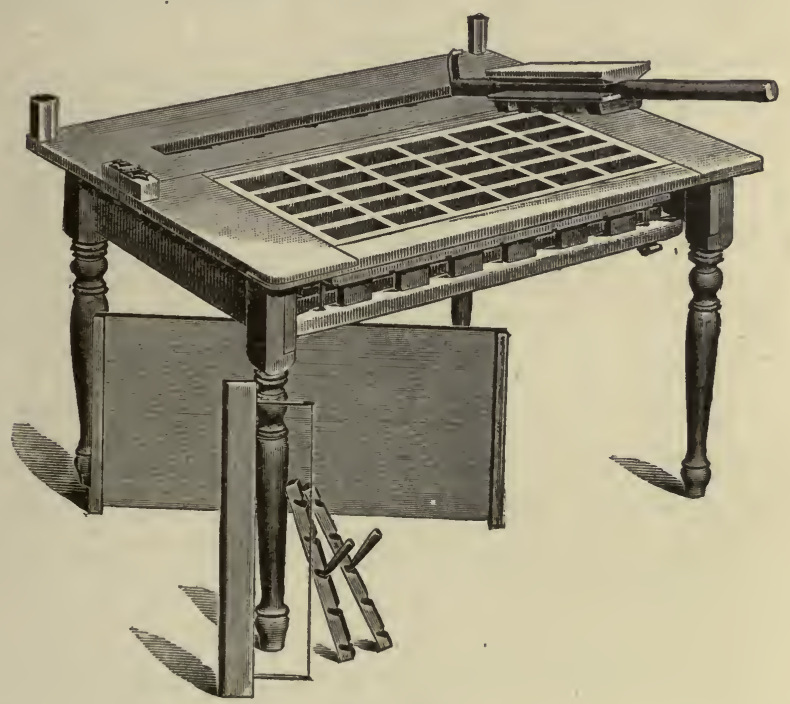

FIG. 32

The condition of the salt has a great effect upon mottles. ${ }^{1}$ Throw workers into gear, using low speed.

${ }_{1}^{1}$ The cause is the uneven distribution of salt. If butter is churned at a warm temperature the outside of the granules are chilled while the butter on the inside is still soft. The soft butter on the inside will take up the salt more easily than the outside which is harder, and thus produces mottles.

The same condition is obtained by having butter too firm to work so that it is impossible to get the salt mixed thoroughly through the butter; or by churning very cold cream and using warm wash water. Going from one extreme to another in temperature is likely to eause mottles. 
Revolve churn about ten times and allow to stand for twenty minutes to give the salt a chance to dissolve evenly. Work ten revolutions more, take out, and print or pack in cases or tubs which have been previously scalded and coated on the inside with paraffin at $250^{\circ}$ to $260^{\circ} \mathrm{F}$. Why?

In the summer give the Disbrow churn 19 to 20 revolutions. In the winter it is necessary to increase it to 25 to 28 in order to give the butter the same amount of working. Where a Victor churn is used, in place of 9 revolutions as in summer, it will require 11 to 12 in the winter.

Calculate per cent of overrun as follows:

Pounds of butter minus pounds of butter fat equals number pounds overrun. Number of pounds of overrun divided by pounds of butter fat equals per cent overrun; for example, 800 pounds of butter fat make 900 pounds of butter. $900-800=100 . \quad 100 \div$ $800=12 \frac{1}{2}$ per cent overrun.

The following blank form may be used for this exercise:

Date....................... .

Pounds butter-fat computed from exercise No. 4

Estimated pounds of butter

Pounds of butter made

Per cent overrun

Kind and size of churn used

Temperature of cream in vat

Time since cooling

Acid test . . 
Percentage of Pounds overrun on 80,000 overrun

$\begin{array}{lr}22.5 & 18,000 \\ 22 & 17,600 \\ 20 & 16,000 \\ 19 & 15,200 \\ 18.9 & 15,120 \\ 18.25 & 14,600 \\ 18 & 14,400 \\ 17.82 & 14,256 \\ 17.8 & 14,240 \\ 17.71 & 14,168 \\ 16.7 & 13,360 \\ 16 & 12,800 \\ 15 & 12,000 \\ 14.1 & 11,280 \\ 13 & 10,400 \\ 12 & 9,600 \\ 9 & 7,200 \\ 8.94 & 7,152 \\ 8.6 & 6,880 \\ 7.5 & 6,000 \\ 5.84 & 4,672\end{array}$

Value of overrun at 25c. per pound

In packing a tub of butter first boil the tub in a strong solution of brine to rid it of all undesirable bacteria and mold, apply melted paraffin on entire inner surface and then set in the refrigerator to cool off while churning. Only the best of circles and liners should be used and these should be soaked about twelve hours in a cool brine solution which has been previously boiled. After the butter has been properly worked the brine is poured from the tubs, and the small circles, still wet, are placed in the bottom of the tub; the liner should then be put in wet and neatly presserl into place, leaving about an inch 
above the top of the tub. It should then be turned down over the rim of the tub to prevent wrinkling in packing the butter. All wrinkles or kinks should be carefully smoothed out before putting the butter into the tub. If the butter is then put in in small quantities and carefully packed there will be no holes. Do not pack enough to spoil the grain. After packing the butter until the tub is rounding full, cut the top smooth by means of a fine wire trimmer, then turn the projecting inch of the liner back over the top surface of butter; place a cheese-cloth circle over this and cover the latter with the top paper circle. A single handful of salt should be sprinkled over the paper circle and the cover nailed neatly on.

RAW MATERIAL SCORE

Quality ............. 95

Cans 5.

Total 100

Organization. - Individual, Coöperative, Stock or Centralized

Name of Creamery.

Post Office. County State

Inspector. 


\section{BLANK FORM FOR CLASS IN CHURNING}

Kind of color used

Kind of salt used

C. C. or ounces color per $100 \mathrm{lbs}$. butter-fat. . . . . Total C.C.

C. C. color per 1000 lbs. milk ........... Total C. C

Ounces salt per lb. butter.............. Total lbs .

Time starting the churn

Time churning finished

Size of granules

Temperature buttermilk

Number washings given

Temperature 1st.

Temperature $2 \mathrm{~d}$.

First working, number of revolutions of churn.

No. minutes

Second working, number of revolutions of churn

No. minutes

Interval between workings, minutes.

Kind of packages put up

Babcock test of buttermilk

Pounds butter-fat lost in buttermilk

Remarks:

(Signed)

O. K. Instructor.

FIG. 33. - Butter Trier

\section{Butter SCORing}

The following score card is generally used for scoring butter: 


\section{BUTTER SCORE CARD}

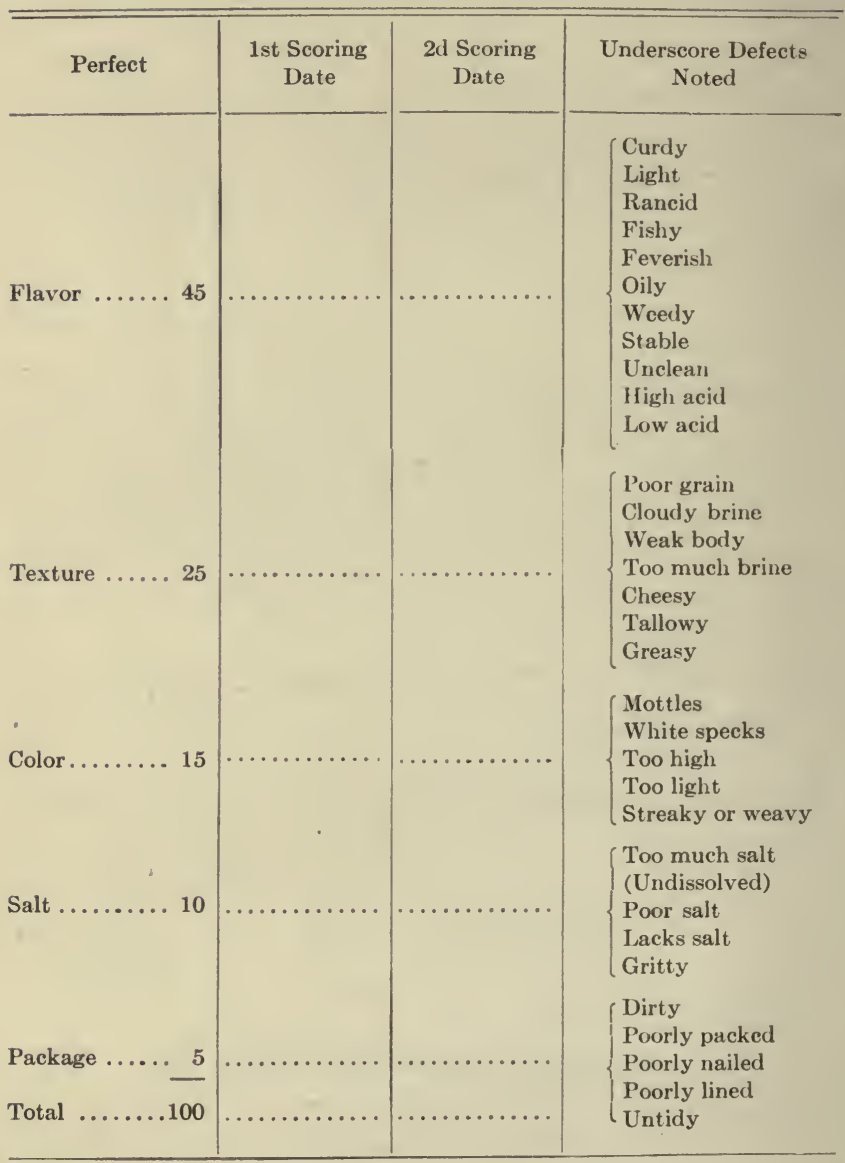

Remarks :

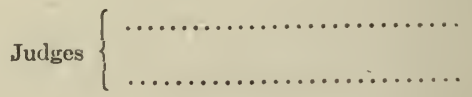

Date. 
The following score cards proposed by B. D. White of the Dairy Div. Dept. of Agri., Washington, D. C., is a most efficient means of classifying butter-makers and grading creameries. Score the College Creamery and members of the Dairy Class accordingly.

In coöperation with Dairy and Food Department in the State of ...

\section{CREAMERY SCORE CARD}

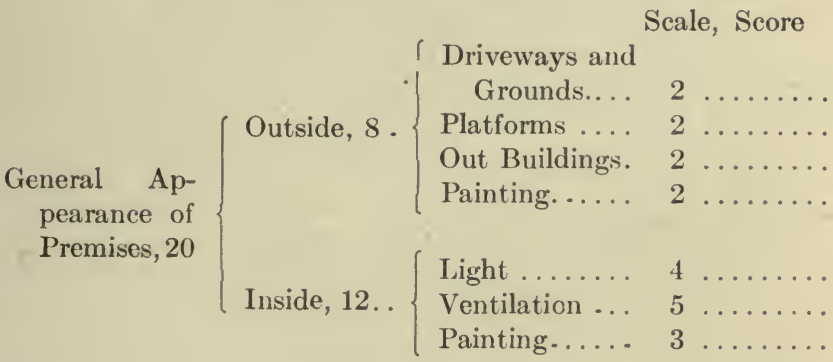

Floors, Construction and Condition ........ 10

Drainage Disposal ................ 10

Machinery, $50\left\{\begin{array}{l}\text { Arrangement } \ldots \ldots \ldots \ldots \ldots \ldots \\ \text { State of Repairs ........ } 5\end{array}\right.$

Sanitary Const ruction ...... 20

Durability ............ 10

Water, $10 \ldots\left\{\begin{array}{r}\text { Purity } \ldots \ldots \ldots \ldots \ldots \ldots \\ \text { Location and Condition of } \\ \text { Well } \ldots \ldots \ldots \ldots \ldots\end{array}\right.$

Total....... 100 


\section{BUTTER-MAKER'S SCORE CARD}

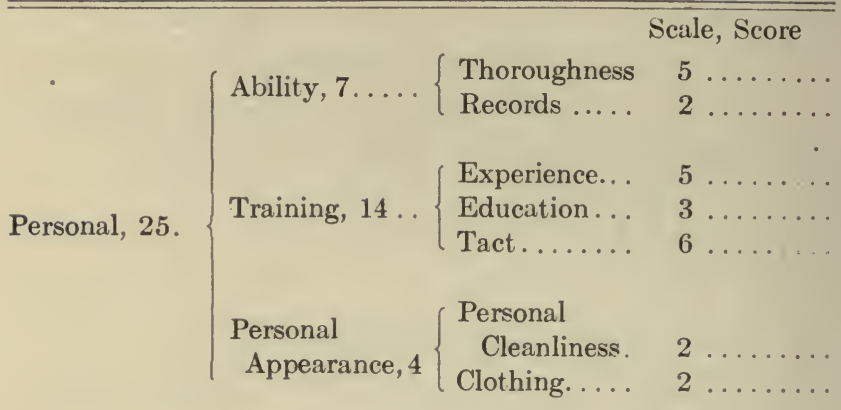

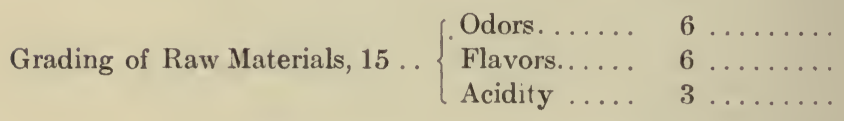

Method of Making, 50
From Weighing Can to C'ream Vat Starter, 25... $\left\{\begin{array}{c}\text { Making Starter } \\ \text { Quality of } \\ \text { Starter .... }\end{array}\right.$

Ripening Cream

Churning Working Moisture

Preparation of Package.

Sanitary Condition of Creamery

Total.

Remarks. - Write remarks on reverse side.
Name of Creamery

Post Office
County
5

10

15

6

4

4

4

2

10

100

Inspector.

Remarks. - Write remarks on reverse side. 


\section{EXERCISE XIII}

\section{Determination of the Water Content of} BUTTER

\section{Irish Moisture Test}

Read carefully the following explanations and test samples of butter according to directions.

Weigh 10 grams of butter into an aluminium cup upon a sensitive scale. Evaporate the water by holding the cup and contents over the flame of an alcohol lamp. Place a mirror over the cup to catch and condense the escaping steam. When no more steam condenses on the mirror the sample has been boiled long enough. Cool and weigh again, the percentage of loss being calculated and considered as water. $^{1}$

\section{Gray's Method}

A number of schemes have been tried, some giving results more or less satisfactory, but one only, that of Prof. C. E. Gray of the Dairy Division of the Department of Agriculture,-Washington, D. C., has been perfected to such an extent as to give results which seem wholly satisfactory. With this method (requiring apparatus costing only a few dollars) any one of average intelligence, after a few trials, may make moisture determinations with comparative

${ }^{1}$ The weights added to indicate the loss in weight by removal of moisture are so marked that, by adding the figures upon them, the percentage of water can be determined direct. 
accuracy. The test is described by Professor Gray in the following manner:

\section{Apparatus}

The apparatus required for making the test is as follows:

Balances. Sensitive to 0.025 gram. A balance suitable for weighing samples of cream for the Bab-

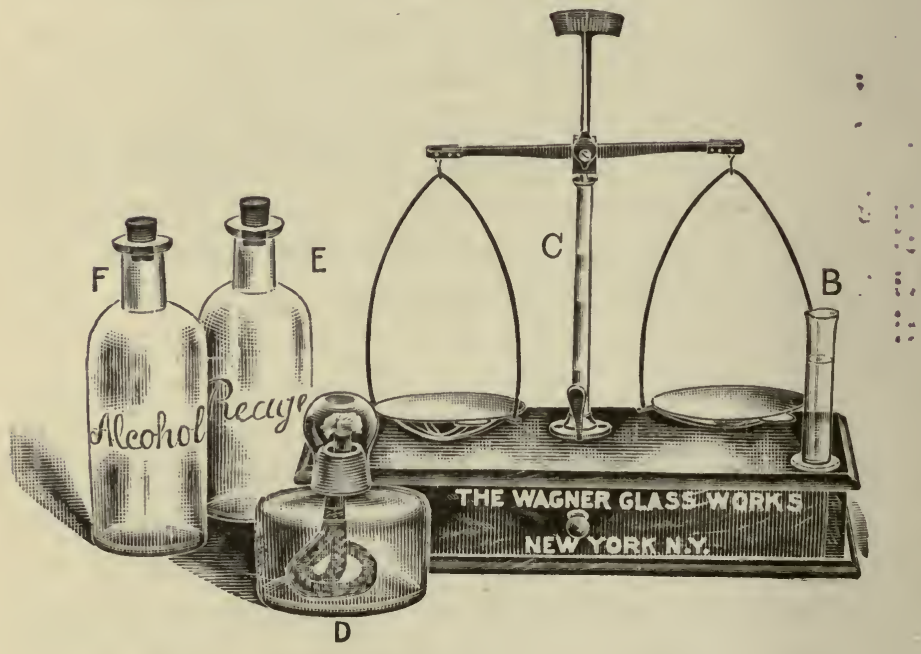

FIG. 34

cock test should be satisfactory for weighing samples of butter for this test; however, there are many cream balances in use which are not accurate enough for weighing either cream or butter samples.

Weights. One 5 gram and one 10 gram.

Graduate. For measuring 6 c.c. 
Burner. If gas is not readily available an alcohol lamp may be used.

Paper. Parchment 5 by 5 inches; must be perfectly dry.

Special Apparatus. As shown in figures. Referring to figure $35, A$ is a flask of a capacity of a little

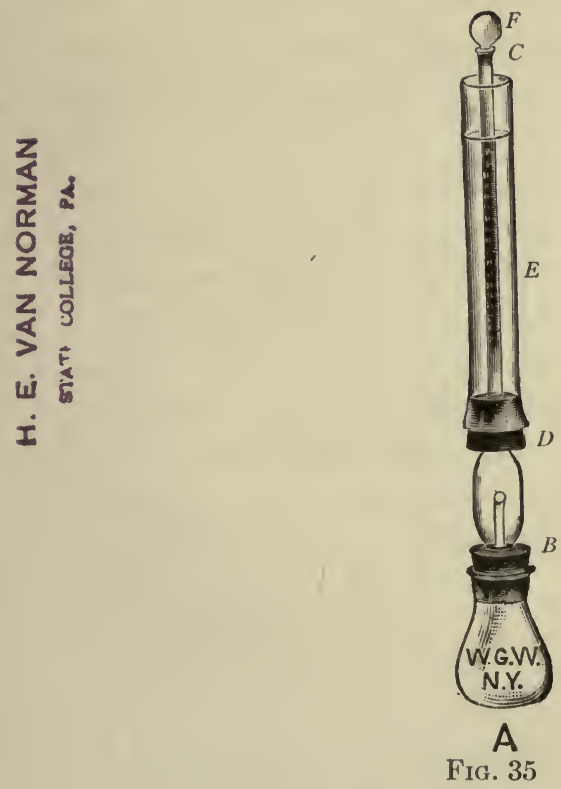

over 75 c.c. $C$ is a graduated tube, which is connected with the flask $A$ by means of a rubber stopper $B ; F$ is a glass stopper ground into the tube $C$. Each glass stopper is ground to fit a particular tube and will not properly fit other tubes. Each stopper and tube should be marked, by the 
manufacturers, to eliminate this danger of using a tube with a stopper which has not been ground to fit. The tube $C$ is graduated after the stopper $F$ is ground in, the zero mark being the end of the stopper. Each mark of the graduation represents onefiftieth c.c., or when a 10-gram sample of butter is used each mark represents two-tenths of 1 per cent of water. $E$ is a glass condensing jacket connected to the graduated tube $C$ by rubber stopper $D$, as shown in figure 35 , or ground onto the bulb of the tube $C$ at the point $D$, as shown in figure 34 . The apparatus shown in figure 1 , having the condensing jacket connected by means of a rubber stopper, is the form which seems most satisfactory for general use.

Rubber Stoppers. The rubber stopper $B$ will be slowly decomposed by the heat and reagent during the process of making the tests. As a stopper is rendered unfit for use by making about one hundred determinations, extra rubber stoppers should be obtained.

\section{Reagents}

Amyl Reagent. A mixture of amyl acetate 5 parts and anyl valerianate 1 part. Must be free from water-soluble impurities in order to give accurate results. Users not in position to test this reagent for impurities should insist on a tested article.

Alcohol (for burning) when alcohol lamp is used. 


\section{Making a Determination}

Preparing the Sample. The sample of butter is placed in a suitable container (1-pint Mason jar or metal cup will be satisfactory). This container is placed in water at about $100^{\circ} \mathrm{F}$. The butter is stirred with a spatula or spoon until it is about the consistency of thick cream and no free water can be seen. Samples of butter should not be left standing in open containers any length of time before making water determination, as some of the moisture will evaporate and the percentage of water shown when the determination is finally made will be too low.

Weighing the Sample. Place on each pan of the balances one sheet of parchment paper and balance accurately. Place the 10-gram weight on one pan and balance again by placing butter on the parchment paper on the opposite pan, placing the sample as near the center of the paper as possible.

Transferring Sample to Flask. When exactly 10 grams are weighed out remove the sample from the pan, folding it in the parchment paper in such a shape that the paper and butter may be slipped into the flask $A$. Always use care that none of the butter is lost in transferring.

Adding Amyl Reagent. Fill the graduate with amyl reagent to the mark 6 c.c., first being sure that the graduate is free from water. Place the 6 c.c. of amyl reagent in the flask with the butter.

Connecting the Apparatus. Connect the apparatus as shown in figure 1 and fill the condensing 
jacket $E$ with cool water to within one inch of the top. Remove the stopper $F$.

Distilling off the Water. Caution: Be sure that the glass stopper $F$ is removed.

Place the apparatus over the flame of the burner, applying heat to the bottom of the flask $A$. In a short time the butter will melt, running from the parchment paper into the amyl reagent. The water

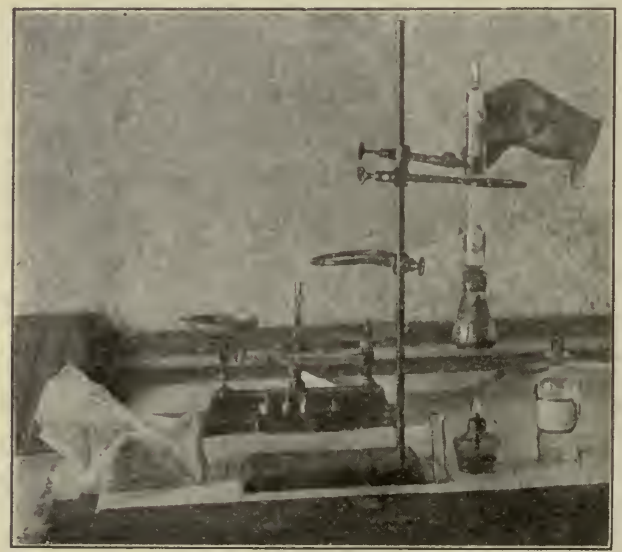

FIG. 36. - Heating the sample of butter with amyl reagent over alcohol flame.

in the sample then boils and passes as steam into the tube $C$, where it is condensed and trapped. Watch the condensation in the graduated part of the tube $C$, and do not let the steam get higher than the 15 per cent mark. If it goes higher than this, remove the flame, as there is danger of water being lost. If there is any indication of liability of the mixture in the flask $A$ foaming over, remove the flame. Foam- 
ing is usually prevented by 6 c.c. of amyl reagent, but some samples of butter, especially those of high moisture, require a trifle more than 6 c.c. In case of continued foaming, allow the mixture in the flask to cool, and add about 2 c.c. of the amyl reagent, and continue heating. After the water in the sample has boiled out, the temperature rises and the amyl reagent boils, driving the last traces of water and water-vapor from the flask and bottom of the stopper. Some of the amyl reagent is carried into the tube $C$ with the steam, and some is boiled over after the water has been driven off. This amyl reagent in the tube is of no disadvantage.

Determining when all Water has Evaporated. The time required for driving all water from the sample is not less than five minutes and with most samples need not be more than eight minutes. When the mixture in the flask becomes a brown color and all the crackling noises in boiling cease, it is safe to conclude that all water has been driven from the flask.

Disconnecting the Apparatus. Disconnect the flask $A$ from the stopper $B$, place the glass stopper $F$ in the tube $C$, giving it a slight turn to insure its being held firmly; invert the tube $C$, first being sure that the mouth of the small tube inside the bulb is held upwards; pour the water from the condensing jacket $E$, after which the jacket may be removed.

Separating the Reagent from the Water. When the tube $C$ is inverted the water and amyl reagent flow into the graduated part of the tube. To separate 
these and to get the last traces of water down into the graduated part, the tube $C$ is held with the bulb in the palm of the hand and the stoppered end away from the body, raised to a horizontal position, and swung at arm's length sharply downward to the side. This is repeated a number of times until the dividing line between the water and amyl reagent is very distinct and no amyl reagent can be seen with the water or vice versa. The tube should then be held a short time with the stoppered end downward and the amyl reagent in the bulb of the tube agitated in order to rinse down any water that may be adhering to the sides of the bulb.

Reading the Test. The reading should not be taken until the tube and its contents have cooled so that very little warmth is felt. The water is in the bottom of the tube, and when a 10-gram sample is taken the percentage may be read directly. Read to the lower part of the meniscus.

Other than Io-Gram Samples. With butter very low in moisture it may be desirable to take a 15-gram sample, and with butter extremely high 5-gram samples may be used. The reading multiplied by ten and the product divided by the weight in grams of the sample taken equals the percentage of water.

Time Required. To make a determination, including weighing sample, requires from fifteen to twenty minutes. 


\section{Cleaning the Apparatus}

Flask. The flask may be cleaned by washing with soap, washing powder, or washing soda in hot water. It is not absolutely necessary to wash the flask after each determination; the residue may be poured out and the flask wiped with a cloth or thin paper. The flask must always be dry (free from water) before making a determination.

Graduated Tube. After making the test, empty the tube $C$ by holding the stoppered end downward, removing the stopper and allowing the contents to flow out quickly. In this way the amyl reagent runs out after the water and carries with it practically all of the water, which might otherwise adhere to the tube. The tube, after emptying, should be swung in the manner described for separating water from amyl reagent, which will almost completely empty it. Following this plan it is not necessary to dry the tube after each determination. Occasionally the tubes should be washed carefully with a hot solution of sodium carbonate (sal soda) or other good washing powder and thoroughly dried before using.

\section{EXERCISE XIV}

Determination of Casein, Ash, and Salt of
Butter

Carefully weigh a dry porcelain dish or crucible and place thereon a sample of butter. Weigh and subtract weight of dish. Dissolve ether extract (fat) 
by addition of anhydrous alcohol-free ether. Decant the ether and repeat until the fat has all been dissolved. Allow the residue to dry in the air and weigh. Cover the crucible and heat gently at first, gradually raising the temperature to just below redness. The cover may then be removed and the heat continued till the contents of the crucible are white. The loss in weight of the crucible and contents represents casein, and the residue in the crucible mineral matter. In this mineral matter, dissolved in water slightly acidulated with nitric acid, chlorine may be determined gravimetrically with silver nitrate, or volumetrically after dissolving in water only, using potassium chromate as an indicator. From the amount of chlorine, $\mathrm{Cl}$, present the quantity of salt, $\mathrm{NaCl}$, may be calculated or it may be determined as follows:

\section{Determination of Salt}

Weigh in a counterpoised beaker from 5 to 10 grams of the butter. The butter is placed, in portions of about 1 gram at a time, in the beaker, these portions being taken from different parts of the sample. Hot water is arlded (about 20 c.c.) to the beaker containing the butter, and after it has melted the liquid is poured into the bulb of a separating funnel. The stopper is inserted and the contents shaken for a few moments. After standing until the fat has all collected on top of the water, the stopcock is opened and the water is allowed to run into an Erlenmeyer flask, care being exercised to let none of 
the fat globules pass. Repeat extraction from ten to fifteen times, using from 10 to 20 c.c. of hot water each time. The resulting washings contain all but a mere trace of the sodium chlorid originally present in the butter. The sodium chlorid is determined in the separated fluid by a standard solution of silver nitrate, $\mathrm{AgNO}_{3}$ using a few drops of solution of potassium chromate as an indicator.

$$
\begin{aligned}
& \mathrm{NaCl}+\mathrm{AgNO}_{3}=\mathrm{AgCl}+\mathrm{NaNO}_{3} . \\
& 23.0 \text { At. wt. of } \mathrm{Na} \\
& \frac{35.5}{58.5} \text { At. wt. of } \mathrm{Cl} \text {. } \\
& \text { Focular wt. of } \mathrm{NaCl} \text {. } \\
& \text { Fory } 35.5 \mathrm{Cl} \text { there are } 58.5 \mathrm{NaCl} \text {. }
\end{aligned}
$$

When a permanent reddish brown color is obtained, note the number of c.c.'s used. Each c.c. of standard solution $\mathrm{AgNO}_{3}$ used indicates the presence of .0585 grams of salt.

Example: 10 grams butter in sample, and solution required 4 c.c. $\mathrm{AgNO}_{3} .4 \times .0585=.234$ grams. $10 \times$ $.234=2.3$ per cent salt, or $.234 \div 10 \times 100=2.3$ per cent.

Method for the Quantitative Determination of Proteids of Milk

\section{Bogg's Method}

Phosphtungstic acid in hydrochloric acid solution precipitates instantly all the proteids in a finely divided condition. The precipitate contracts evenly in a vertical direction and reaches a constant minimum 
volume within twenty-four hours. The supernatant fluid is perfectly clear and gives no trace of proteid by any tests. The solution which seems to be the optimum is composed as follows:

Phosphotungstic acid, 25 grams; distilled water, 125 c.c.

After thorough solution is obtained there is added:

Hydrochloric acid (conc.), 25 c.c., diluted with distilled water, 100 c.c.

This yields 250 c.c. of a 10 per cent solution of phosphotungstic acid in about 3 per cent $\mathrm{HCl}$. The solution is quite stable if kept in a dark bottle, and gives satisfactory results after months of standing. It is desirable that the components be mixed as indicated, i.e., the well-diluted $\mathrm{HCl}$ added after solution of the phosphotungstic acid in order to avoid precipitation.

The diluted milk is poured into the tube to the mark $U$, being careful to read from the bottom of the meniscus. The phosphotungstic acid solution is added to the mark $R$, the tube corked and slowly inverted twelve times to secure thorough mixing; care being had to avoid shaking roughly and thus mixing air in the fluid. The tube is then placed in a rack for twenty four-hours and the percentage read off at the level of the top of the precipitate. Fractions of per cent between the graduations are readily judged by the eye. At dilutions of 1 part in 10 , percentage of proteid is read directly from the scale, while if the dilution be 1 in 20 , we multiply the reading by two; if 1 in 5 , we divide by two. 
The optimum solution for human milk is 1 in 10 . That for cow's milk 1 in 20 . If the proteid content be found extremely low we nay use 1 in 5 for human milk and 1 in 10 for cow's milk.

The minimum volume of the precipitate is reached in twenty-four hours. Readings at thirty and fortyeight hours showed no appreciable variations.

COMPOSITION OF BUTTER

\begin{tabular}{|c|c|c|c|}
\hline & Maximum & Average & Minimum \\
\hline Fat & $85 \%$ & $84 \%$ & $80 \%$ \\
\hline Water & $16 \%$ & $12.8 \%$ & $7 \%$ \\
\hline Salt .. & $3 \%$ & $2 \%$ & $1 \%$ \\
\hline Protein & $.75 \%$ & $.6 \%$ & $.6 \%$ \\
\hline $\operatorname{Sugar} \ldots \ldots \ldots \ldots \ldots \ldots$ & $.5 \%$ & $.4 \%$ & $.3 \%$ \\
\hline $\operatorname{Ash} \ldots \ldots \ldots \ldots \ldots$ & $.2 \%$ & $.2 \%$ & $.1 \%$ \\
\hline
\end{tabular}

\section{EXERCISE XV \\ Cheese Making}

Since the process of making cheese of the various kinds is based upon the same fundamental principles, namely, that of condensing the food of milk by liberating the water, we will merely outline the process of cheddar, gouda, and cottage cheese making, which are most commonly used. The process may be repeated with variations in acidity of milk for quicker or slower curing cheese; pressed hard or merely drained, for hard or soft cheeses, and cut, salted, and cured in various methods and molds for the different kinds of cheese desired. 


\section{Cheddar Cheese}

Weigh the milk to be used. Take accurate sample for fat test, acid test, and rennet test. The Marshall rennet test is perhaps the most commonly used in the Cheddar cheese process, although the Monrad test is very efficient. The rennet test is made by filling the graduated cup to the zero mark with milk at $86^{\circ} \mathrm{F}$. Add 1 c.c. pipette full of 5 per cent rennet solution. Allow the milk to pass through the narrow glass bore of the cup and note amount that passes through before coagulation begins. The riper the milk the quicker it will thicken, with a corresponding less reading on the scales. The aciclity of the milk should be about .2 per cent for Cheddar cheese. By once determining the acidity of the milk and the corresponding rennet test the latter may be substituted for the acid test in the following exercises. If milk tests less than .2 per cent acid it may be ripened with starter. After reaching the proper acidity pour the milk into vat and heat to $86^{\circ} \mathrm{F}$, the temperature at which rennet works best. Add rennet if in liquid form, two to four ounces to each 1000 pounds of milk; if in tablet form, dilute one tablet in one-half pint of cold water and pour in as indicated on directions. If pepsin be substituted for rennet, only scale pepsin (strength 1-3000) should be used. Use .5 of a gram for every 500 pounds of milk. Dissolve in cold water before adding to milk. Why? Mix thoroughly and allow to stand until curdled enough to break clean over a thermometer 
slanted at an angle of 45 degrees. Cut first with horizontal knife, then with perpendicular knife. Wire stringed knives are preferable. Cook curd by heating at from $95^{\circ} \mathrm{F}$. to $100^{\circ} \mathrm{F}$. until it is of a rubbery consistency, grits between the teeth, or strings threads one-eighth inch long when touched to a hot iron. This usually requires one and one-half hours from time rennet is added. Stir continuously while cooking to prevent matting together and assist curd in heating evenly. Draw off whey and allow curd to mat by placing on curd rack for five to ten minutes until firm enough to handle, then pile the curd about six inches deep and allow that to drain from underneath the rack. An even temperature of $95^{\circ} \mathrm{F}$. to $100^{\circ} \mathrm{F}$. must be maintained to keep up fermentation. After ten to fifteen minutes the curd will have matted and can be cut into blocks which are frequently turned. These should be about six inches wide. Turn the curd so as to facilitate expulsion of whey, and when it has a meaty consistency similar to that of a chicken's breast it is ready to mill. Mill when the curd becomes flaky and shows from one to one and a half inch acid (strings one to one and a half inches long) on the hot iron. If curd has been tainted it may be improved by washing with water at a temperature of $105^{\circ} \mathrm{F}$. before milling.

There are numerous kinds of curd mills, including the Pig, Pohl, McPhearson, Kasper, and the Knife. The Kasper rotary mill, however, is generally used. The milling should be done about an hour and a half after drawing whey, and the salt added about an 
hour and a half after milling. During this time the temperature should be kept at about $90^{\circ} \mathrm{F}$. Why?

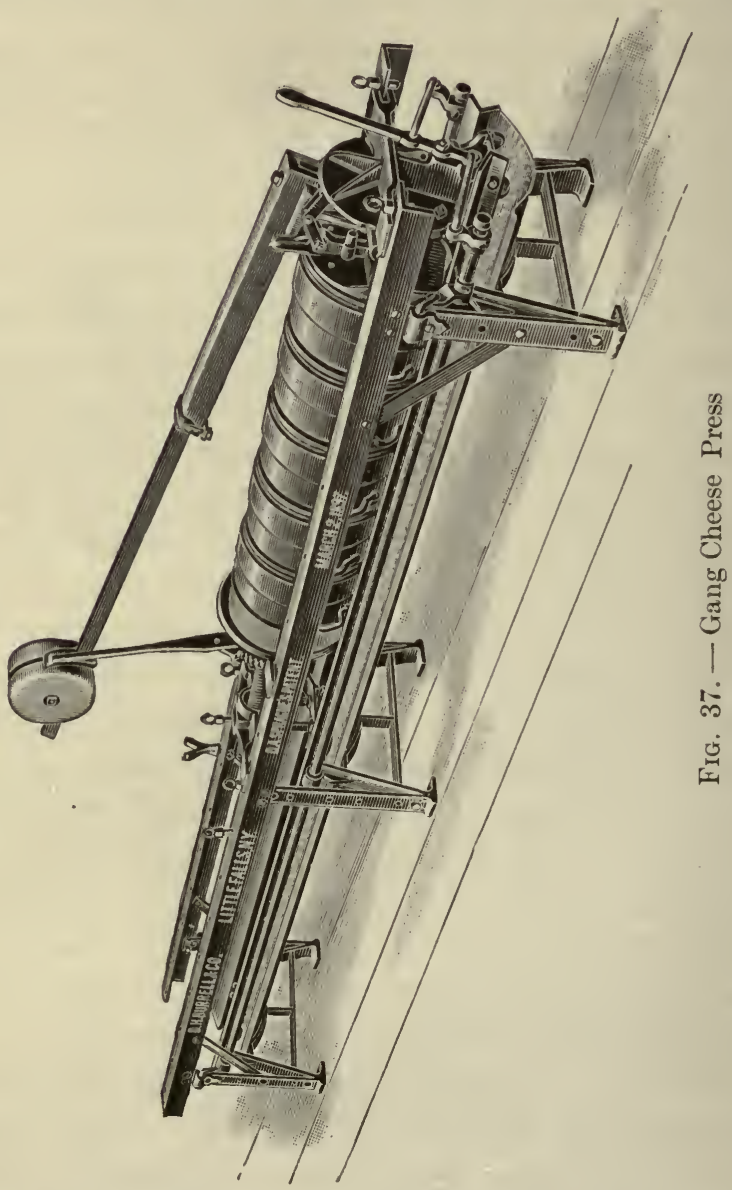

The curd should take all the acid it will before salting, which is indicated by the length of strings 
which will draw out on a hot iron. These should be about two inches long. Now the curd is ready for salting. It should be soft and silky. In hot weather reduce the temperature as much as possible before salting and putting the curd into the press. Use at the rate of $2 \frac{1}{4}$ to $2 \frac{1}{2}$ pounds of salt per 1,000 pounds of milk, varying the weight of salt according to the amount of moisture in the curd, and according to market demands. Most any of the common brands of salt are very good. Worcester, Anchor, Ashton, Diamond, Crystal, Kansas, Genesee, Colonial, and others are used. To determine their purity dissolve a small amount of salt in clear water, and if it remains clear there is no dirt present. If sediment settles, or if cloudiness is produced, impurities are present. Distribute the salt evenly by mixing with the hands or forked ladle. Stir every ten minutes to keep salt from settling to the bottom of the pile. Keep at $90^{\circ} \mathrm{F}$. When a velvety feeling is regained, which usually requires fifteen to twenty minutes, the curd is ready for pressing. Cool curd to between $80^{\circ}$ and $85^{\circ} \mathrm{F}$. Why? Place in hoops so that the bandlages are even with edges, turning down over the circles. Press for an hour by tightening press every few minutes. The curd will now be pressed together and it should be taken from the press and the bandages smoothed and neatly trimmed. Soak into position with warm water if necessary. Place followers in carefully so as to make uniform shape. Press from twelve to twenty-four hours, depending on the size of the cheese and the pressure. Take 
from press and place in cooling room for about five to ten days. Dip in melted paraffin at $200^{\circ} \mathrm{F}$. to $250^{\circ} \mathrm{F}$. and place in cooling room at from $40^{\circ}$ to $60^{\circ} \mathrm{F}$., having a humidity of from 65 to 80 per cent (which is the amount of saturation), depending on

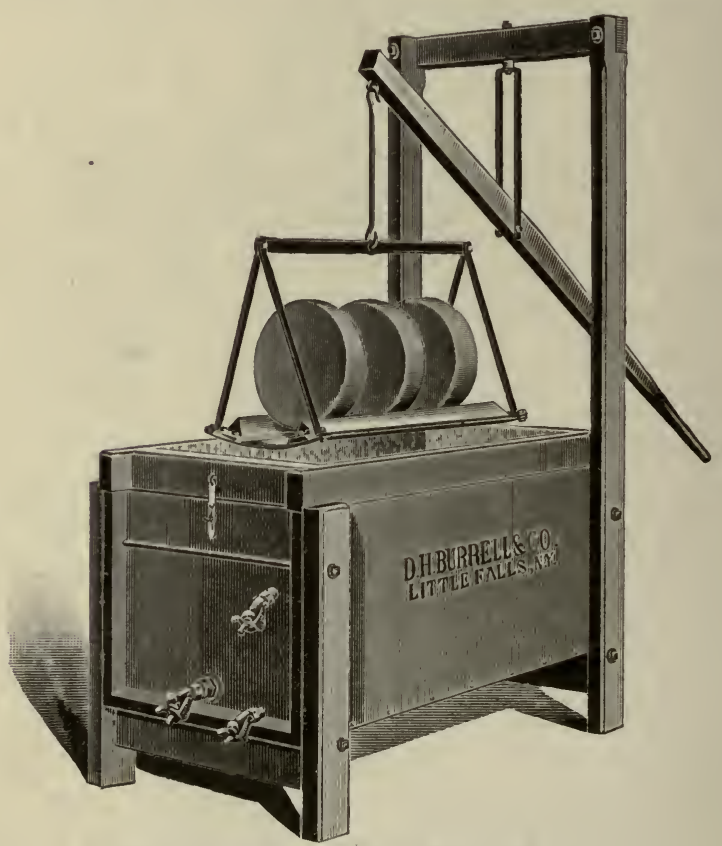

Fig. 38. - Vat for Paraffining Cheese

the temperature and length of time desired to cure. The per cent of moisture should be as high as possible without causing a growth of mold. The humidity of the curing room is determined by a psychrometer. The psychrometer is more reliable than the hy- 
grometer (or hygroscope) and consists of two ordinary thermometers fastened side by side with a cup and wick, or tube of water between, the latter being turned at the bottom in the form of a small cup and

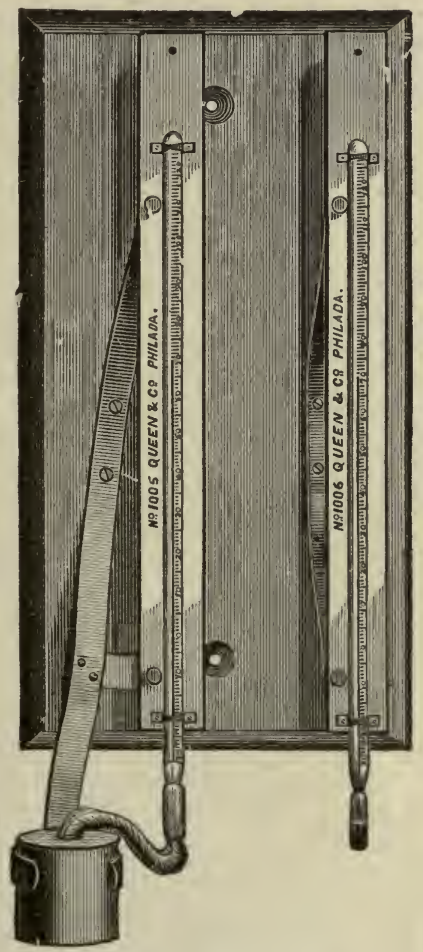

FIG. 39. - Psychrometęr

closed at the top to prevent the water from running away. In the stationary psychrometer the cup end contains a wick which also covers the bulb of one of the thermometers. The temperature shown by this 
thermometer is, of course, lowered more or less according to the rate of evaporation from the wick, and this rate is affected by the relative humidity of the air. In a saturated air there could be no evaporation and the thermometers would register alike; in a very dry air the evaporation would be rapid and the difference of temperature indicated would be considerable.

Table Showing the Relative Humidity in the Air of Curing Rooms. (King.)

Directions: Notice that the table is in three-column sections. Find air temperature in first column, then find wet bulb temperature in second column, same division. In third column opposite this is relative humidity.

Example: Air temperature is $50^{\circ}$ in first column; wet bulb is $44^{\circ}$ in second column, same division. Opposite $44^{\circ}$ is 61 , which is the per cent of saturation, or relative humidity of the air.

\section{FAHRENHEIT SCALE}

\begin{tabular}{|c|c|c|c|c|c|c|c|c|c|c|c|}
\hline $\begin{array}{l}\text { Dry } \\
\text { bulb }\end{array}$ & $\begin{array}{l}\text { Wet } \\
\text { bulb }\end{array}$ & $\begin{array}{l}\text { Rel. } \\
\text { hum. }\end{array}$ & $\begin{array}{l}\text { Dry } \\
\text { bulb }\end{array}$ & $\begin{array}{l}\text { Wet } \\
\text { bulb }\end{array}$ & $\begin{array}{l}\text { Rel. } \\
\text { hum. }\end{array}$ & $\begin{array}{l}\text { Dry } \\
\text { bulb }\end{array}$ & $\begin{array}{l}\text { Wet } \\
\text { bulb }\end{array}$ & $\begin{array}{l}\text { Rel. } \\
\text { hum. }\end{array}$ & $\begin{array}{l}\text { Dry } \\
\text { bulb }\end{array}$ & $\begin{array}{l}\text { Wet } \\
\text { bulb }\end{array}$ & $\begin{array}{l}\text { Rel. } \\
\text { hum. }\end{array}$ \\
\hline 41 & $\begin{array}{l}32 \\
33 \\
34 \\
35 \\
36 \\
37 \\
38 \\
39 \\
40\end{array}$ & $\begin{array}{l}31 \\
38 \\
46 \\
53 \\
60 \\
68 \\
76 \\
84 \\
92\end{array}$ & 44 & $\begin{array}{l}34 \\
35 \\
36 \\
37 \\
38 \\
39 \\
40 \\
41 \\
42 \\
43\end{array}$ & $\begin{array}{l}29 \\
36 \\
43 \\
49 \\
56 \\
63 \\
70 \\
78 \\
85 \\
92\end{array}$ & 47 & $\begin{array}{l}36 \\
37 \\
38 \\
39 \\
40 \\
41 \\
42 \\
43 \\
44 \\
45 \\
46\end{array}$ & $\begin{array}{l}28 \\
34 \\
40 \\
46 \\
52 \\
59 \\
66 \\
72 \\
79 \\
86 \\
93\end{array}$ & 50 & $\begin{array}{l}39 \\
40 \\
41 \\
42 \\
43 \\
44 \\
45 \\
46 \\
47 \\
48 \\
49\end{array}$ & $\begin{array}{l}32 \\
37 \\
43 \\
49 \\
55 \\
61 \\
67 \\
74 \\
80 \\
87 \\
93\end{array}$ \\
\hline
\end{tabular}




\section{To Prepare Table for Psychrometer Reading.}

See W. B. Bulletin No. 235, Department of Agriculture, Washington, D. C., or Smithsonian Physiological tables, p. 155.

Observe, 1, psychrometer reading; 2, dew point.

From table referred to determine relative humidity as follows: (from dew point reading): Example: If dew point $=10^{\circ} \mathrm{C}$. $\left(50^{\circ} \mathrm{F}\right.$. $)$ and temperature of air $=30^{\circ} \mathrm{C} .\left(86^{\circ} \mathrm{F}\right.$.) the weight of saturated vapor in air at $10^{\circ} \mathrm{C}=9.33 \mathrm{grm}$. per e. $\mathrm{m}$.; the weight of saturated vapor in air at $30^{\circ} \mathrm{C}=30.04$ grm. per c.m.

(This table was made for the sling psychrometer and does not exactly correspond to the one on the opposite page.)

$$
\text { Relative Humidity }=\frac{9.33}{30.04}=31.1 \%
$$

Then prepare table:

$\begin{array}{ccc}\text { Dry Bulb } & \text { Wet Bulb } & \text { Rel. Hum. } \\ 30^{\circ} \mathrm{C} & 18^{\circ} \mathrm{C} & 31.1^{\circ} \mathrm{C}\end{array}$

Moisture can be supplied by sprinkling the floor, or better still, by hanging up wet sheets that are constantly supplied with water.

To supply a curing room of 5000 eubic feet capacity at least 3 cloths 30 inches wide by 12 feet long are needed. To keep them saturated with water hang them on pipes with fine holes drilled on the upper side, and a gutter below to carry off the surplus drippings. When the cloth gets stiff from sediment, boil it in water to which a little hydrochloric acid has been added. 
In cold weather, when the curing room is artificially heated, there is rarely any danger of the air in it being overladen with moisture; and there is little danger of this in summer if the room is cooled artificially by air circulation through an ice chamber, because the air in passing over the ice is cooled to a point at which it can contain little moisture in comparison to its capacity when at the higher temperature of the room. But when the curing room is not artificially cooled by refrigeration it may often in summer be overladen with moisture.

Air at $20^{\circ} \mathrm{F}$. may contain 1.30 grains of water to the cubic foot, while at $30^{\circ}$ it may contain 1.97 grains, at $40^{\circ} 2.86$ grains, at $50^{\circ} 4.09$ grains, at $60^{\circ} 5.76$ grains, at $70^{\circ} 7.99$ grains, at $80^{\circ} 10.95$ grains, at $90^{\circ} 14.81$ grains, and at $100^{\circ} 19.79$ grains.

Cheese should be cured for from six weeks to a year, depending on the kind of cheese, market requirements, temperature of curing room, and condition of cheese when made. The lower the uniform temperature at which cheese can be ripened economically the better will be the texture and quality of the cheese and the less will be the loss in weight during the ripening process. The cheese score card is as follows: 
Yield of Cheese from Milk Varying in Richness

Lbs. milk

100

100

100

100

100

100
Per cent fat

.1

1.

2.

3.

4.

5.
Yield of cheese

5.5

6.7

8.

9.2

10.9

12.4

Flavor ...................... 50

Texture .................... 25

Salt......................... 10

Color

10

Package

$\frac{5}{100}$ Total

A good flavor should not be sharp so that it will bite the tongue, but of a mild lasting taste and aroma. Texture comes next in importance. A good texture can be determined as follows: The plug should be smooth, not fuzzy. If the cheese is not fully cured the plug should bend a little before breaking. When held between the eye and the light it should be slightly translucent. If the light does not come through it, it is a sign of too much acid. If the plug has round holes in it too little acid has been given the curd. When pressed between the fingers it should not stick to them but mold like wax. Cheese should not be mealy as is the case with highly acid or too highly salted cheese. Color comes next. It should be straight and translucent. Then comes make-up. A cheese should have square edges evenly bandaged and clean. Make-up adds considerable to selling value of cheese as well as appearance. 


\section{EXERCISE XVI}

\section{Gouda Cheese}

Repeat Exercise XV, using milk containing less than 2 per cent acid. Do not use curd mill, but press without milling or salting. After pressing sufficiently place cheese in a saturated salt solution. Brine should be strong enough to float cheese. Keep entirely immersed, or turn every six hours until rind forms. This usually requires about twenty-four hours.

\section{EXERCISE XVII}

\section{Cottage Chense}

Ripen 100 pounds skim or whole milk to .8 or .9 per cent acid. Place in vat and heat to $95^{\circ} \mathrm{F}$. When whey is sufficiently liberated draw off. Drain curd in cheese-cloth until most of the whey is removed and cheese can be molded. A small amount of cream mixed into the curd adds materially to its palatability. Salt to taste and mold in desired form. With similar variations the following cheeses may be made, but there is seldom time during the short course to make more than three or four different kinds. Nor is it practical, for the main difference between some of them is the name of the county, province, or town in which they are made, with only a slight difference in method of manufacture or curing. Various cultures of molds and bacteria are frequently employed in the latter. 
The following is a list of some of the different kinds of cheese:

\section{SOFT CHEESE}

Brick cheese ..................... United States

Cottage cheese .................. United States.

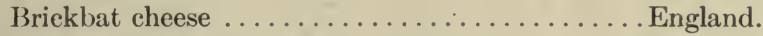

Slipcoat cheese .................. England.

Fromage blane (white eheese) ............. France.

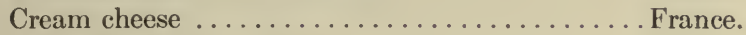

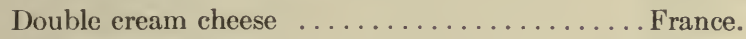

Coulommier eheese ................... France.

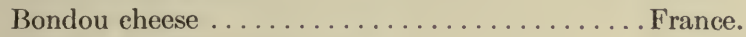

Fromage de Marseilles cheese ............ France.

Pont-L'Eveque cheese................. France.

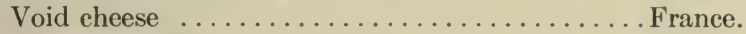

Cantal eheese ....................... France.

Livarot cheese ................... France.

Menster cheese ................... France.

Gerome cheese .................... France.

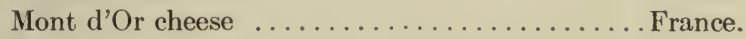

Brie cheese . . . . . . . . . . . . . . France.

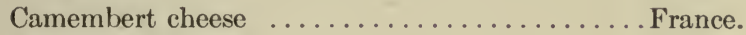

Roquefort cheese .................... France.

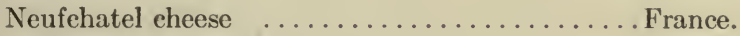

D'Arles cheeselets . . . . . . . . . . . . . . France.

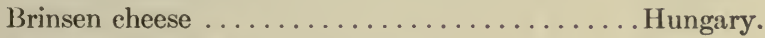

Masearporie eheese ................ Italy.

Fromaggio fresco di Pecora cheese ........... Italy.

Robbiola ........................... Italy.

Parmesan eheese . . . . . . . . . . . . . Italy.

Reggrom cheese ................. Italy.

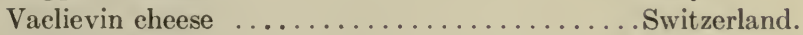

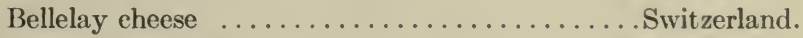

Caerphilly cheese .................. Wales.

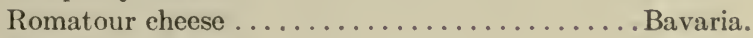

Limburger eheese ................... Belgium.

Kaiserkace............................. Germany. 


\section{HARD CHEESE}

Pineapple cheese ................... United States.

Cheddar cheese..$\ldots \ldots \ldots \ldots \ldots \ldots \ldots$. England.

Stilton eheese ...................... England.

Blue Dorset cheese ................... England.

Cheshire eheese ...................... England.

Rex eheese ....................... France.

Gruyere cheese $\ldots \ldots \ldots \ldots \ldots \ldots \ldots \ldots$. . . France.

Port du Solut ......................... France.

Edam cheese ........................ Holland.

Gorgonzola cheese ................... Italy.

Cacio eavolla cheese ................... Italy.

Gouda eheese ........................ Holland.

Whey cheese ....................... Norway.

Blundeer cheese ...................... Norway.

Old (Norwegian) cheese ................. Norway.

Mysort cheese ...................... Sweden.

Emmenthaler cheese .................. Switzerland.

Schweitzer eheese.................... Switzerland.

Danish export cheese .................. Switzerland.

Schabzieger (SapSago) cheese .............. Switzerland.

Zieger (albumin) cheese ................. Switzerland.

Sera Do Estrella ...................... Portugal.

THE FOLLOWING BLANK FORM MAY BE USED IN CHEESE-MAKING

Date

Weather

Vat No

Condition of milk

flavor

temperature

acidity .

per cent of fat

Pounds milk in vat .

Starter, amount used

kind

condition

Color, amount

kind 
Rennet test

Setting, hour.

temperature

acidity.

amount rennet or pepsin

Curd cut, hour

Steam turned on, hour

Time taken to raise temperature to ... degrees

Whey drawn, hour.

\section{temperature}

acidity

condition of eurd.

pounds of whey

per cent of fat in whey

Milling, hour.

acidity

Salted, hour.

amount

kind

Put to press, hour

temperature

condition of curd

Time in press

Number cheese made.

Pounds cheese made

Temperature of curing room

Humidity of curing room

Remarks

\section{EXERCISE XVIII}

\section{ICE Cream}

The principle of ice-cream making is the incorporation of air while freezing the cream. This is readily accomplished by the use of the ordinary freezer, which is so constructed that it retains the cold within the outer wooden tub and imparts it to the cream through the inner tin cylinder. 


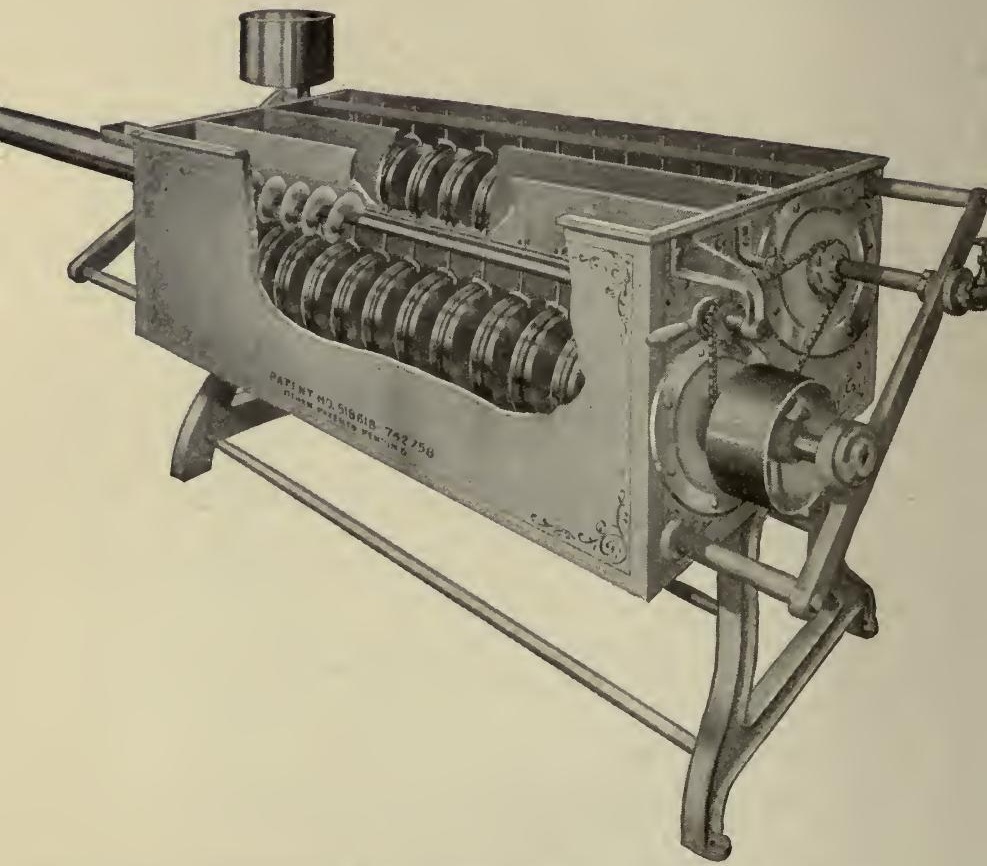

Fig. 40. - Continuous Ice Cream Freezer. The cream flows into the first compartment from the supply tank and coming in contact with the cold disks, in which brine solution is circulating, at once commences to freeze. As the disks revolve the cream is kept agitated. The metal fingers suspended between the disks prevent the cream from freezing on. From the first compartment the partially frozen mixture overflows into the second. The latter compartment is deeper than the first, and contains in addition to the freezing disks a revolving screw which carries away the cream as fast as the freezing is completed. This conveyor extends about 18 inches from the freezer and discharges into the packing can. 
For 5 gallons of ice cream use $2 \frac{1}{2}$ gallons of 20 per cent cream, $2 \frac{1}{2}$ ounces of flavoring, and $2 \frac{1}{2}$ pounds of sugar. Slight variations are frequently advantageous. Place in freezer and put two parts of finely pulverized ice to one of salt around the cream can. Salt has a great affinity for water and causes the ice to melt rapidly. The ice changing from solid to liquid absorbs heat rapidly. The heat is taken from the cream and the latter thus reduced to freezing point. Revolve slowly about 80 revolutions per minute until cream begins to freeze so as to avoid churning. Then turn rapidly 120 to 140 revolutions per minute so as to pulverize it and make a fine grain, and at the same time incorporate air enough to give the desired overrun. In freezing the flavoring is sometimes weakened and it is therefore desirable to add flavoring as soon as the cream begins to freeze. Keep the entire top of can continually covered with ice while freezing. The freezer should never be stopped until the freezing process is finished, as lumps of ice may form, causing a granular body. When the freezer is stopped before the process is completed, a portion of the air incorporated is likely to escape, much the same as when half-beaten cream is allowed to stand. The air escapes and the cream settles.

Various kinds of flavoring and crushed fruits are often used in making ice cream and sherbets. Fruit may be crushed and added to the cream just before freezing, the same as flavoring is added. The use of geletina and corn-starch in making ice cream is not 
to be recommended, for cream made with their use frequently tastes more like custard than ice cream.

\section{Harlequin or Neapolitan Ice Cream}

Freeze several freezers of ice cream of various colors, say one of chocolate, one of strawberry, one of plain vanilla, and one of carmine color. Freeze until the cream flows with difficulty, but not so stiff as to crumble. Spread first one layer the desired thickness, usually about one-half inch, then another of different color on top of the first, and so on until the cake is complete. Place in packer and allow to harden, cut in desired form and serve.

In packing ice cream take the latter from the freezer with a ladle and deposit with a swinging motion against the periphery of the packing can which has been thoroughly cooled by placing fine ice and salt around the outer space. Thus by retaining the incorporated air the over-run may be maintained.

\section{Molding Ice Cream}

If molds are used the cream should be packed closely into them, filling every crack and corner. The cover should fit over and not into the mold. Smear the edges with paraffin to keep out salt and water. Bury molds in crushed ice and salt. A slightly smaller proportion of salt should be used than in freezing. Cover ice with wet burlap. Draw off the brine as fast as the ice melts. Allow to stand for an hour or more before serving. 


\section{EXERCISE XIX}

\section{Dairy BaCteriology}

Examine microscope carefully under the direction of the instructor and ascertain difference between high and low power objectives with different eye pieces. Manipulate reflector, condenser, and diaphragm to ascertain various combinations.

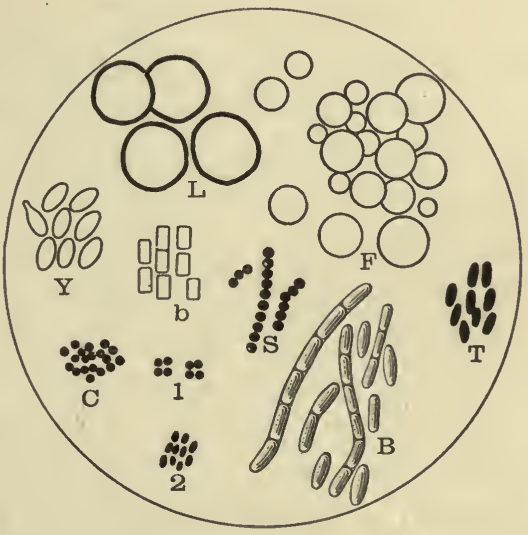

FIG. 41

The above cut represents a portion of a drop of milk containing $\mathrm{F}$, fat globules, L, leucocytes, $\mathrm{Y}$, yeast, and B, b, c, s, T, 1 and 2, seven species of bacteria frequently found in milk. B represents the hay bacillus group which are among the largest known species of bacteria, and frequently form chains; b represents one species of bacillus viscosus 
which forms slimy milk; e represents a common coccus form; s represents a streptococcus (forming chains); T represents bacillus typhosus; 1 represents tetragenococci, and 2, one of the lactic acid group.

Place a drop of water on a clean cover glass by means of platinum wire, then touch the end of the wire in a sample of milk, mix with water on a cover glass, place on clean slide and examine under microscope. The water dilutes the milk enough to make a clear field. Examine for fat globules, bacteria, and leucocytes, if present. The latter are from two to ten times larger than fat globules and an irregular outline. Examine samples of skim-milk for fat globules. Make hang-drop slides and examine in the same manner.

To find the correct measurements for microscopic work place a micrometer in the eye piece, or ocular, and a stage micrometer (which equals 1-100 mm.) on the stage of the microscope. Determine the relation of the divisions of the former to those of the latter by making the initial lines coincide and counting the number of divisions of the stage micrometer that is required to make one of the ocular micrometer.

Example: where a $\frac{1}{6}$ power ocular is used. When 13 divisions of ocular equals 5 divisions of the stage micrometer, let $\mathrm{A}$ equal stage division, and $\mathrm{O}$, ocular division.

$$
\begin{aligned}
& 13^{\circ} \text { equals } 5 \mathrm{~s} . \\
& 1^{\circ} \text { equals } \frac{5}{13} \mathrm{~s} . \\
& 1^{\mathrm{s}} \text { equals } .01 \mathrm{~mm} \text {. } \\
& \frac{5}{13} \mathrm{~s} \text { equals } \frac{.01^{\mathrm{c}} \text { equals } .003846 \mathrm{~m} . \mathrm{m} \text {. }}{1}
\end{aligned}
$$


A plain slide may then be substituted for the stage micrometer and all measurements taken by means of the ocular micrometer.

A table may then be constructed in the following manner which will save time in calculating the measurement of objects:

.5 division

.75 division

1.00 division

1.25 division

1.3 division

1.5 division

1.75 division

2.00 division

2.25 division

2.5 division

2.75 division

3.00 division
.001923 m.m.

.002888 m.m.

.003846 m.m.

.004825 m.m.

.005012 m.m.

.005785 m.m.

.006748 m.m.

.007712 m.m.

.008676 m.m.

.009640 m.m.

.010604 m.m.

.011569 m.m.

Prepare a clean cover glass and place thereon a drop of water. Transfer a minute portion of decayed material, starter, or clabber milk, and spread uniformly over the surface of the glass and allow film to dry. When dry, pass cover glass, smeared surface upward, three times through a Bunsen flame at about the rate of a pendulum of a clock. The heat coagulates the albumen around the bacteria and fixes them firmly to the glass. Place a drop of staining solution prepared from anilin dyes (gentian-violet, basic fuchsin, and methylene blue, are most commonly used) on the glass and allow stain to remain for from two to ten minutes, depending on the strength of the staining solution and the kind of bacteria. Rinse in water. Dry the unsmeared side on filter paper, 
mount film side down in a drop of water on clean slide and examine. If bacteria are properly stained, dry both sides with filter paper and mount film side down in a drop of balsam. Label and preserve.

Prepare cultures for bacterial growth as follows (after Gorham):

\section{PREPARATION OF CULTURE MEDIA}

\section{Bouillon}

1. Infuse finely chopped lean beef for twenty hours with twice its weight of distilled water in the refrigerator, say 1000 grams of meat, 2000 grams of water.

2. Make up weight of meatinfusion (and meat) to original weight by adding water - i.e., to 3000 grams

3. Filter infusion through cloth to remove meat.

4. Weigh infusion, say 1800 grams.

5. Set infusion on water-bath, keeping temperature below $60^{\circ} \mathrm{C}$.

6. Add peptone, 1 per cent, 18 grams; salt, 0.5 per cent, 9 grams.

7. After ingredients are dissolved, titrate; 2 reaction probably +2.3 to +2.5 per cent.

8. Neutralize.
II. Gelatine

Ditto.

Ditto.

Ditto.

Ditto.

Ditto.

Ditto, and sheet gelatine, 10 per cent 180 grams.

Ditto, probably +4.0 to +5.0 per cent.

Ditto.

\section{Agar}

Boil 30 grams of thread agar in 1 liter of water for half an hour. Make up loss by evaporation to a weight of 1000 grams.

1. Infuse finely chopped lean beef for twenty hours with its own weight of distilled water in the refrigerator, say 1000 grams of meat, 1000 grams of water.

2. Make up weight of meatinfusion (and meat) to original weight by adding water -i.e., to 2000 grams.

3. Ditto. (Sce 3.)

4. Ditto, say 900 grams. (See 4.)

5. Ditto. (See 5.)

6. Add peptone, 2 per cent, 18 grams; salt, 1 per cent, 9 grams.

7. Ditto, probably +4.5 to 4.7 per cent. (See 7.)

8. Ditto.

To the 900 grams of meatinfusion (containing new peptone and salt) add 900 grams of the 3 per cent agar jelly described at the head of this column. 
Heat over boiling water or steam thirty minutes. Restore weight lost by evaporation to original weight for bouillon and gelatine and twice that weight for agar. Titrate and adjust reaction to the final point desired. Sterilize for three consecutive days so as to kill all germs present, and fill test tubes one-third full. Cork with sterile cotton and sterilize again.

Certain species of bacteria grow sufficiently well on media made from beef extract instead of lean beef. The former requires less work and may be used in the following proportions:

\section{BOUILLON}

Beef extraet ............. 3 grams

Peptone ................. 10 grams

Salt ................. 5 grams

Water ....................

\section{Gelatine}

Beef extract ............. 5 grams

Peptone ................. 10 grams

Salt $\ldots \ldots \ldots \ldots \ldots \ldots \ldots \ldots \ldots .5$ grams

Gelatine ................ 100 grams

Water ...................... 1000 e.c.

Agar

Beef extraet ............. 5 grams

Peptone .................. 10 grams

Salt $\ldots \ldots \ldots \ldots \ldots \ldots \ldots \ldots \ldots .5$ grams

Agar .................. 20 grams

Water ......................

Make potato media by washing sound potatoes and cutting the ends, and with sterile cork-borer cut out cylinders of the potato a little smaller than the tubes to be used. Handle potato under water as much as 
possible to prevent darkening of surface. Cut cylinders into two equal parts by a diagonal cut. Place in cool running water for twelve to eighteen hours. This usually renders the potato neutral. Sterilize in steam sterilizer for thirty minutes on three consecutive days. Place in sterile test tubes, slanting surface upward, and plug with sterile cotton. Sterilize once after plugging.

\section{Milk Media}

Heat fresh milk for fifteen minutes in steam sterilizer at $200^{\circ}$ to $212^{\circ} \mathrm{F}$. Place in ice-box over night. Titrate, and if less than .2 per cent acid place in tubes and sterilize for twenty minutes on four consecutive days in a steam sterilizer. If more than .2 per cent acid reduce to .15 per cent by the addition of one-tenth normal solution of sodium hydroxide. Place in sterile test tubes with sterile cotton plugs. Make cultures of the above media from milk, cheese, ice cream, and butter from various sources. Note behavior and color of culture on the various kinds of media. Make plate cultures of agar and gelatine by warming them to melting point and adding a drop of milk. Shake thoroughly and pour into sterile petra dish and allow to cool. Place in incubator for twelve to twenty-four hours at $100^{\circ} \mathrm{F}$. in case of the agar plates and $80^{\circ} \mathrm{F}$. in the case of gelatine plates. Examine every few hours or as often as convenient. Make medium more condensed for quantitative analysis of liquids.

After washing with cleaning mixture prepared in 
Exercise I, sterilize all empty glassware for at least thirty minutes at a temperature of $212^{\circ} \mathrm{F}$. in a dry air sterilizer. After turning off the gas allow utensils to remain in sterilizer for ten minutes before opening the door. Otherwise the cool air coming suddenly in contact with the hot glass may cause some of the parts to crack.

Before sterilizing pipettes wash each one thoroughly, and while the ends are moist roll a piece of clean cotton to a point and insert in the end of pipette. Turn the remaining part of the cotton back over the pipette, and if the latter is moist it will wrap tightly around the same between the thumb and fore-finger while revolving the pipette with the thumb and forefinger of the other hand. Repeat the operation with the other end of the pipette.

When using sterile pipette hold in vertical position and pull lower plug first. This prevents contamination to a great extent.

The media must all be sterilized in a steam sterilizer in order to prevent evaporation. Sterilize at $212^{\circ}$ F. thirty minutes for three consecutive days to kill all bacteria which are likely to germinate from the spores which resist boiling temperature.

Make a quantitative analysis of bacteria in a sample of whole-milk by drawing into a delicately graduated pipette .1 c.c. of the milk to be analyzed. Transfer this into a sterile water blank test tube containing .9 c.c. of sterile water. After shaking well, transfer .1 c.c. of this in the same way to a test tube containing sterile melted agar media. Mix 
well and pour into a petra dish. The solution will then contain .01 c.c. of milk, and the number of colonies that develop in the petra dish is therefore multiplied by 100 to obtain the average number of bacteria per cubic centimeter.

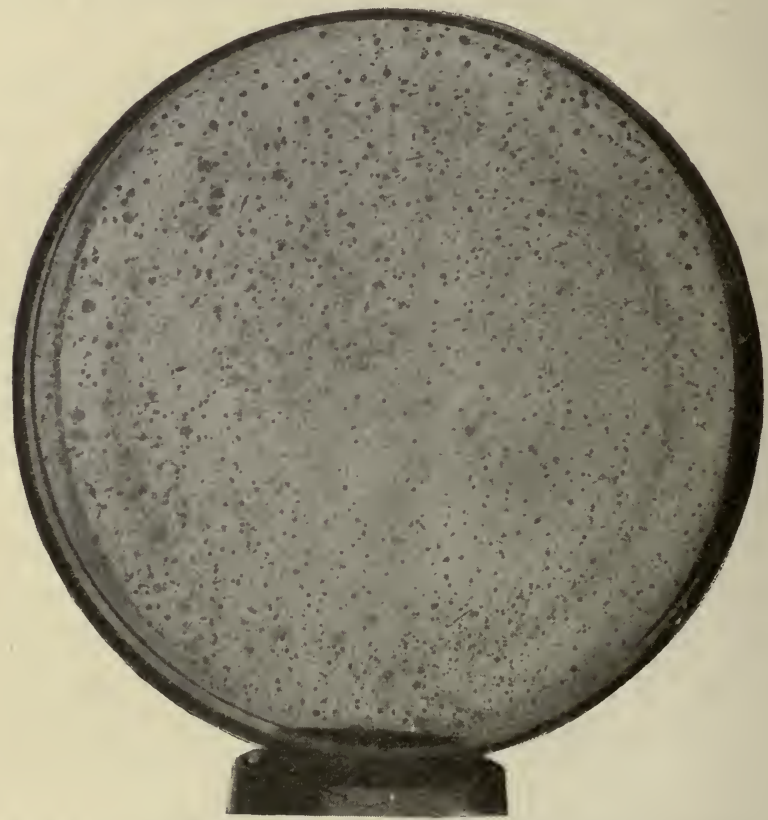

FIG. 42. - Culture of 1-100 c.c. mill from separator which had been flushed with warm water only.

Measure from .1 to 1 c.c. of milk into test tubes containing 5 c.c.'s sterile water (water blanks). To a given number of these add 5 c.c. of washing powder in solution. Pour contents of each tube into test tubes containing melted agar. Shake thoroughly 
and pour into petra dishes. The number of colonies that develop in each indicates the efficiency of the disinfectant. The smaller the number of colonies the more efficient the washing powder.

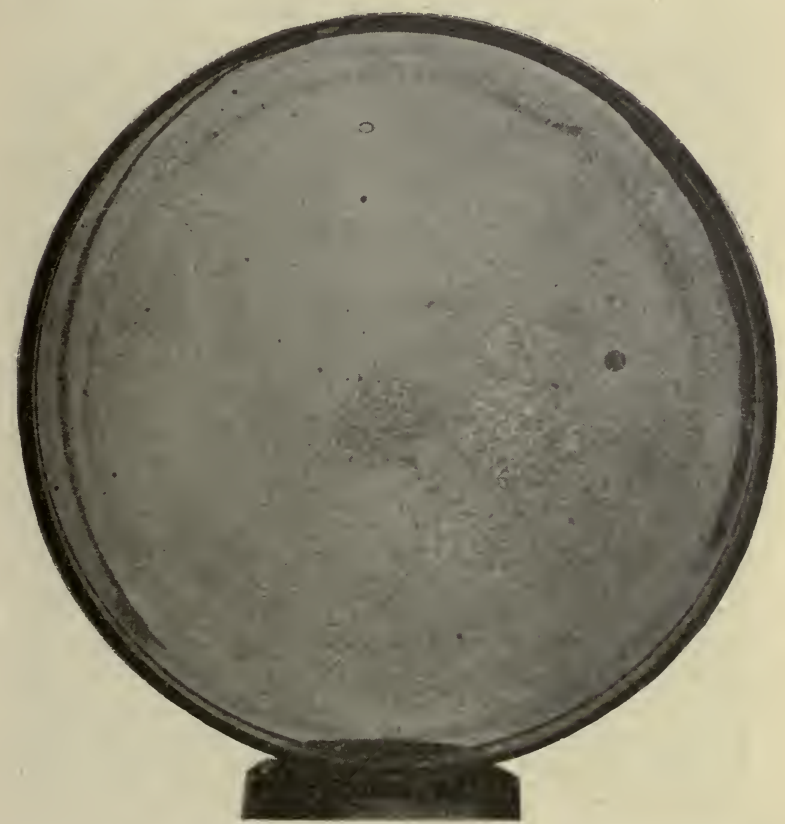

FIG. 43. - Culture of 1-100 c.c. milk from average sterilized separator.

Repeat, using a small speck of manure or dirt from your finger nail. Also make plate cultures from a drop of milk taken from a cow at beginning and last part of milking. Make plate exposures by filling petra dishes with melted agar and allowing to solidify. Expose one, two, and three minutes in open air, 
barn, dairy, and various places of interest. Place in incubator as before and note results. Determine gas fermentation by use of curd test and also by placing sterile bouillon in fermentation tubes. A small test

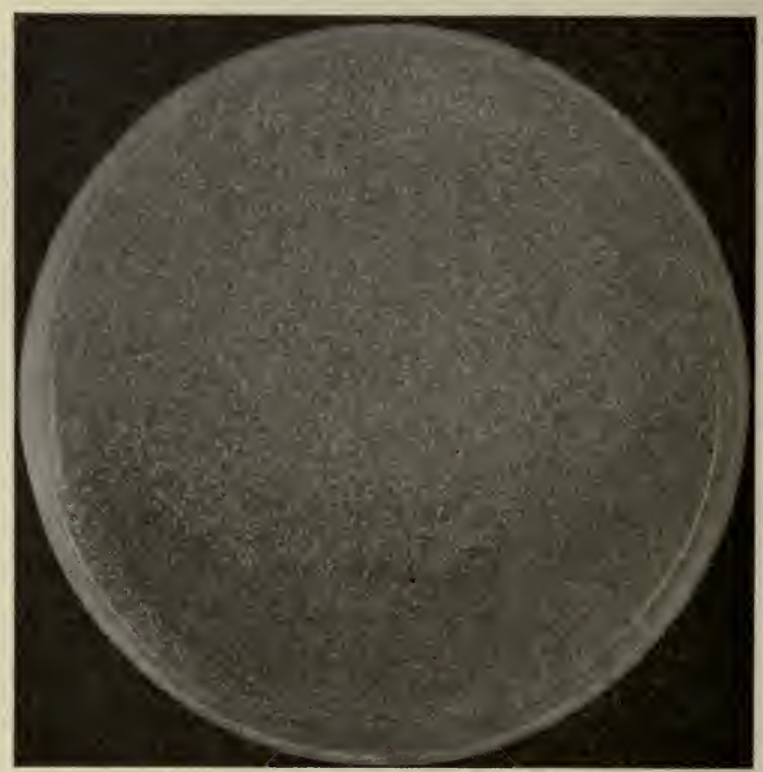

FIG. 44. - Shows a plate exposed one-half minute during the process of milking, under cow's udder treated by merely brushing with the hand. Each of the little spots represents a colony of some kind of bacteria.

tube inverted inside of a large one will answer for a fermentation tube. Add a few drops of milk or cream to be tested and allow to remain at $100^{\circ} \mathrm{F}$. for twelve to twenty-four hours, and note amount of gas collected. 


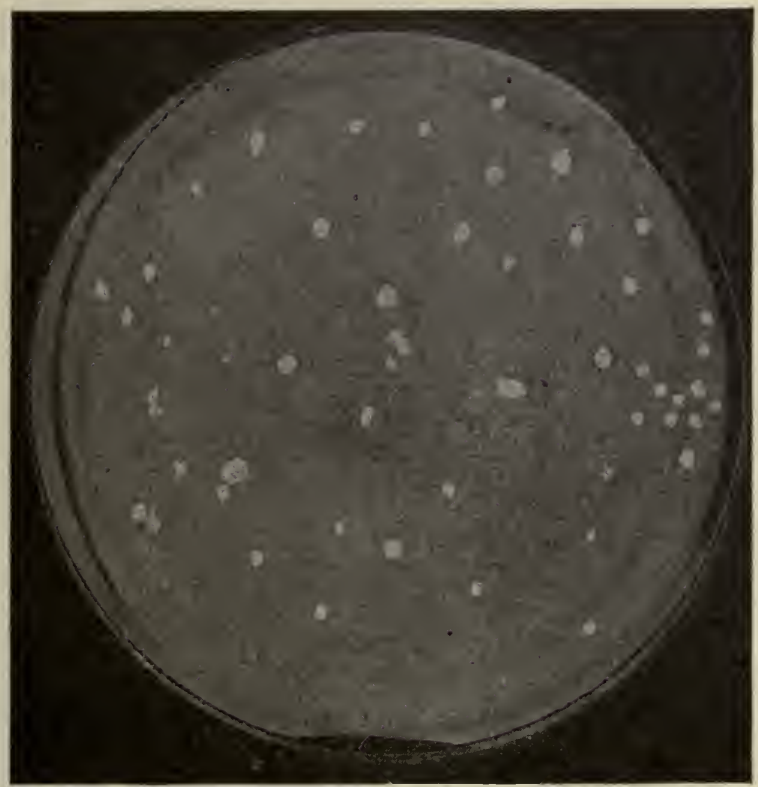

FIG. 45. - Shows a plate exposed one-half minute during process of milking, under a cow's udder treated with a 5 per cent solution of carbolic acid. The animal was on a cement floor and bedding was present. It will be noted this plate is quite an improvement over plate shown in Fig. 44.

\section{EXERCISE XX}

\section{Mit.K Paint}

Stir into one gallon of skim-milk 3 pounds of Portland cement and add sufficient paint powder to impart desired color, and apply to board or fence post while thoroughly mixed. Note the effect of this paint upon standing in vessel and the necessity of constant stirring while being used. Repeat the experiment, using a small amount of carbolic acid or 
other disinfectant and apply to a board or fence post in the same vicinity. On the following day secure cultures from the posts and determine by means of plate cultures the difference in the number of the bacteria obtained from the two sources.

\section{EXERCISE XXI}

Tests for Preservatives

\section{$\mathrm{HCHO}+\mathrm{H}_{2} \mathrm{O}$}

Add one drop of formaldehyde to $\frac{1}{2}$ pint of milk and shake thoroughly. Obtain, by means of a pipette, 17.6 c.c. or any convenient amount of the milk, and place in Babcock test bottle. Add a similar amount of sulphuric acid and allow to stand quietly for five minutes. Note color line at junction of acid and milk, which should be a distinct purple or violet, indicating the presence of formaldehyde. Repeat the experiment using concentrated hydrochloric acid. Also add a few drops of ferric chloride to aid the color reaction. Formaldehyde is a colorless, volatile liquid chemically intermediate between methyl alcohol and formic acid. When consumed with milk it produces various intestinal disturbances, and if present in excessive amounts produces poisoning.

\section{Test for Boracic Acid. $\mathrm{H}_{3} \mathrm{BO}_{3}$}

Place $\frac{1}{2}$ gram or any convenient amount of borax in a pint of milk and shake thoroughly. Obtain sample of milk by means of pipette and place in small porcelain dish. Evaporate about one-half to 
concentrate amount of borax present. Add as much alcohol as there is milk present, and ignite. A green flame indicates the presence of borax.

\section{Test for Salicylic Acid. $\quad \mathrm{C}_{6} \mathrm{H}_{4} \mathrm{O} \cdot \mathrm{HCOOH}$}

1. Place a few crystals of salicylic acid in $\frac{1}{2}$ pint of milk and agitate thoroughly as in the previous tests. Pour a small quantity of same in test bottle and add about the same quantity of sulphuric acid, with about 30 c.c. of chloroform or ether. These dissolve the fat present and greatly facilitate the test. Add a few drops of ferric chloride. The presence of salicylic acid is indicated by a purple or violet color similar to that of formaldehyde. The distinction between these tests being that the color reaction does not appear in the presence of salicylic acid unless ferric chloride $\left(\mathrm{Fe}_{2} \mathrm{Cl}_{6}\right)$ be used, but appears in the presence of formaldehyde in either case.

2. Place 5 c.c. suspected solution in porcelain dish and evaporate to dryness. Warm residue with one drop of concentrated nitric acid. Add two or three drops of ammonia until alkaline. The presence of salicylic acid is indicated by the formation of a yellow color or ammonium picrate which will dye a thread of fat free wool.

\section{EXERCISE XXII}

\section{Test For Oleomargarine}

Place 5 grams or any convenient amount of oleomargarine in a small dish and apply flame. Place in 
another dish a similar quantity of butter. Note the difference in the manner in which they melt. The oleomargarine sputters like grease in a frying-pan on account of the excessive amount of water present. It does not foam, however, as much as the butter. The butter meits quietly and foams a great deal. Also note odor of lard in oleomargarine. Score a sample of each for flavor, texture, grain, and body.

\section{Test for Renovated Butter}

Repeat test for oleomargarine and note the similarity with which renovated butter melts. The distinction between the two, however, lies in the fact that when added to a small amount of milk renovated or any other kind of butter may be incorporated into the milk by heating and stirring. The fat from oleomargarine, on the other hand, cannot be incorporated into the milk. If stirred while cold into cold milk the butter will form in small flakes or grains in the milk, while oleomargarine will collect in a ball. The fat from good butter will crystallize out more perfectly than that of renovated butter. The latter has a very poor grain and body, the grain having been destroyed in processes of renovation.

\section{EXERCISE XXIII}

Repairing Creamery Machinery

Repair broken belts by cutting broken ends of belt square so that the parts come evenly together. 
Punch holes in a line one inch from cut edges, the number depending on width of the belt. They should be about one and one-half inches apart. Punch the back holes one and one-half inches from first row and directly between. Begin lacing at middle of belt. Be careful to have smooth side of lacing next pulley. The ends are fastened by running them through small holes punched in line with the lace holes. Repair broken belt with steel wire lacing by using only one row of holes on each end of belt. Also repair with steel belt lacing.

Repair broken belts with glue by cutting each end off squarely and then cut widthwise, a slant beginning back two inches from edge of belt, and slant to a narrow edge. Glue slanting surface of both ends. Place together and press until dried. Determine the efficiency of the four methods by daily use.

Determine speed of main shaft and pulleys on machinery by the following formula:

\section{To Determine Diameter of Pulley on Main Shaft}

When the speed of engine pulley is 1000 revolutions per minute, the diameter of the engine pulley is 5 inches and the speed of the main shaft is 180 revolutions per minute.

$$
1000 \times 5 \div 180=27.7 \text { inches. }
$$

To determine the speed of the main shaft when the diameter of pulley on main shaft and diameter and speed of engine pulley is given as in above example.

$$
1000 \times 5 \div 27.7=180
$$


Line up shaft by fastening chalked string along ceiling parallel to direction of shafting. Snap string and put hangers up loosely in line with chalk mark. Place shaft, arranging its position in hangers in a plane parallel to the floor, and fasten hangers and shaft securely. Line up machinery to shafting by holding one end of string so that it touches both sides of pulley on shaft and tight pulley on machine.

Repair worn valves by repacking and grinding when worn.

Repair cement floor by thoroughly mixing, while dry, one part of cement to two of sand. Moisten with water until thoroughly wet but without excess of water. Apply, press thoroughly, and smooth with trowel. If corners of dairy floor are not rounded, fill in with cement and smooth neatly as shown in Fig. 5.

Adjust a small electric battery with bell and

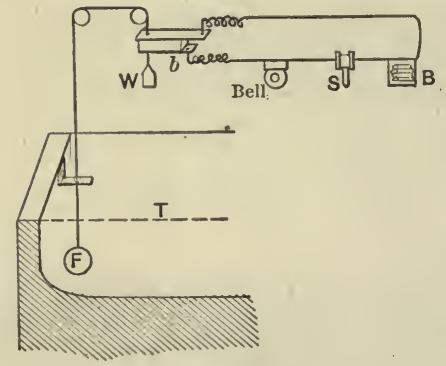

FIG. 46 switch connections above the milk vat and attach a string with float on one end and a weight on the other, as shown in accompanying cut. When the milk is being pumped or drawn from the vat to the separator or pasteurizer, the float will lower until the weight on the opposite end of the string touches the break and 
rings the bell, thus notifying the operator that the tank is almost empty.

$F$ represents float.

$b$, brake.

$T$, tank or vat.

$w$, weight.

$s$, switch.

$B$, battery.

See that everything is arranged for convenience, neatness, and sanitation, and that there is no unnecessary waste. All corners, joints, seams, and crevices, in any apparatus in which milk or cream is to come in contact should be smoothly soldered. See "Creamery Conveniences" Exercise 35.

\section{EXERCISE XXIV}

The Modification of Milk for Infants and INVALIDS

The following is the average composition of various kinds of milk:

\begin{tabular}{|c|c|c|c|c|c|}
\hline & Water & Sugar & Protein & Fat & Ash \\
\hline Cows . & $87 \%$ & $5 \%$ & $3.3 \%$ & $4 \%$ & $.7 \%$ \\
\hline Sheep . & 83.5 & 3.96 & 5.74 & 6.14 & .66 \\
\hline Goats & 86.91 & 4.45 & 3.69 & 4.09 & .86 \\
\hline Mares.. & 90.06 & 6.65 & 1.89 & 1.09 & .31 \\
\hline Human ............. & 88.2 & 6.8 & 1.50 & 3.3 & .20 \\
\hline Commercial Swcetened & & & & & \\
\hline Condensed Milk . . . . . & 27.25 & 12.50 & 8.63 & 9.13 & 1.75 \\
\hline Commercial Condensed & & & & & \\
\hline Milk, Unsweetened . . & 70.44 & 10.96 & 8.35 & 8.71 & 1.54 \\
\hline
\end{tabular}

Very few invalids or infants are constituted exactly 
alike, and therefore, although the upper third of milk in combination with barley water, etc., is frequently advocated for such use, it must be modified to suit the individual. In many cases peptone in the form of peptogenic milk powder must be added to partially digest the casein.

The average diet for infants, with variations to meet individual demands, should be as follows:

Four per cent milk and 20 per cent cream is intended for each formula in the following table:

$1 \mathrm{oz}$. equals 2 standard tablespoonfuls.

$1 \mathrm{drm}$. equals one tablespoonful.

$30 \mathrm{gr}$. equals $\frac{1}{2}$ teaspoonful.

$20 \mathrm{gr}$. equals $\frac{1}{3}$ teaspoonful.

\section{TABLE FOR PREPARING FOOD FOR INFANTS}

\begin{tabular}{|c|c|c|c|c|c|}
\hline Age of Infant & Cream & Whey & Water & Milk & $\begin{array}{l}\text { Milk } \\
\text { sugar }\end{array}$ \\
\hline $\begin{array}{l}\text { First week........ } \\
2 \text { d to } 6 \text { th week .... } \\
6 \text { th wk. to } 2 \mathrm{~d} \mathrm{mo...} \\
3 \mathrm{~d} \text { to } 6 \text { th mo....... } \\
6 \text { th to } 7 \text { th mo...... } \\
\text { 8th to } 9 \text { th mo...... } \\
\text { 10th to } 14 \text { th mo.... }\end{array}$ & $\begin{array}{l}2 \mathrm{drm} . \\
2 \mathrm{drm} . \\
\frac{1}{2} \mathrm{oz} . \\
\frac{1}{2} \mathrm{oz} . \\
\frac{1}{2} \mathrm{oz} . \\
\frac{1}{2} \mathrm{oz} . \\
\frac{1}{2} \mathrm{oz} .\end{array}$ & $\begin{array}{l}3 \mathrm{drm} . \\
\ldots \ldots \cdots \\
\ldots \ldots \\
\ldots \ldots \\
\ldots \ldots \\
\cdots \cdots\end{array}$ & $\begin{array}{l}3 \mathrm{drm} . \\
1 \mathrm{oz} . \\
\frac{3}{4} \mathrm{oz} . \\
1 \mathrm{oz} . \\
2 \mathrm{oz} . \\
1 \frac{1}{2} \mathrm{oz} \\
1 \frac{1}{2} \mathrm{oz} .\end{array}$ & $\begin{array}{c}\frac{1}{2} \mathrm{oz} \\
\frac{3}{4} \mathrm{oz} \\
2 \frac{1}{2} \mathrm{oz} \\
3 \frac{1}{2} \mathrm{oz} \\
6 \mathrm{oz} \\
7 \frac{1}{2} \mathrm{oz}\end{array}$ & $\begin{array}{l}20 \mathrm{gr} . \\
20 \mathrm{gr} . \\
30 \mathrm{gr} . \\
1 \mathrm{drm} . \\
1 \mathrm{drm} . \\
1 \mathrm{drm} . \\
1 \mathrm{drm} .\end{array}$ \\
\hline
\end{tabular}

Both lime and barley water are frequently substituted for a part or all of the water, depending on the patient. They aid in separating the curd of milk but are somewhat constipating. The greater the per cent of cream in milk the less constipating, and vice versa. 
Prepare mixtures of the above feeds by each of the formulas.

Example 1: Prepare a feed for infant four months old that is constipated, otherwise normal: $2 \frac{1}{2} \mathrm{oz}$. 4 per cent milk, $1 \mathrm{oz}$. plain or oatmeal water, $1 \mathrm{oz}$. 20 per cent cream, 1 dram milk sugar.

Example 2: Prepare a feed for infant four months old that has diarrhœa, otherwise normal: $2 \frac{1}{2}$ oz. 4 per cent milk, $1 \mathrm{oz}$. barley or lime water, 0 to $\frac{1}{2} \mathrm{oz} .20$ per cent cream, 1 dram milk sugar.

Similarly prepare feeds for infants of various ages.

The cream for infants should be gravity raised rather than separator cream, as the latter has a tendency to destroy the natural emulsion of milk and cream, rendering it less digestible for delicate infants or invalids.

\section{EXERCISE XXV}

The Standardization of Milk

The standardization of milk consists of bringing the butter fat content to a certain standard or per cent regardless of the quality of milk produced.

Example 1: Take 10 pounds of milk testing 4.5 per cent fat, and standardize to 4 per cent. 10 pounds milk testing 4.5 per cent $=.45$ pound butter fat.

$$
\begin{aligned}
& .45 \div .04=11.25=\begin{array}{c}
\text { number of pounds of } 4 \text { per } \\
\text { cent milk required }
\end{array} \\
& 11.25-10=1.25=\begin{array}{c}
\text { number of pounds of skim- } \\
\text { milk to be added. }
\end{array}
\end{aligned}
$$


Example 2: 10 pounds of milk containing 3 per cent fat is to be standardized to 4 per cent. How much skim-milk must be taken from the whole milk?

$10 \times .03=: 30$ number of pounds of fat in original milk.

$.30 \div .04=7.5$ number of pounds of standardized milk.

$10-7.5=2.5$ number of pounds skim-milk to be separated from the original milk.

The table on the opposite page by Professor Erf indicates the quantity of skim-milk to be added to or subtracted from 100 pounds of milk to make a desired per cent.

To find the pounds of skim-milk to be added or removed, trace the vertical column of the per cent of fat desired down to where the horizontal column representing the per cent of fat in the milk on hand intersects, and the result will be the number of pounds of skim-milk to be added or removed, as indicated by a plus or minus sign before the result.

To illustrate: If milk containing 4.5 per cent is desired and milk containing 3.8 per cent is on hand, then 15.5 pounds for every hundred pounds or 15.5 per cent of the quantity must be separated out as skim-milk. 


\begin{tabular}{|c|c|}
\hline & 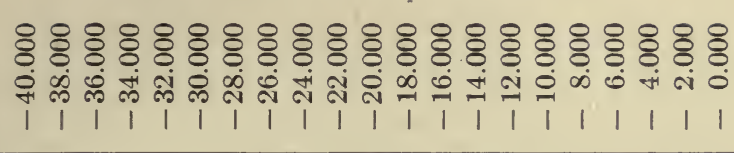 \\
\hline & 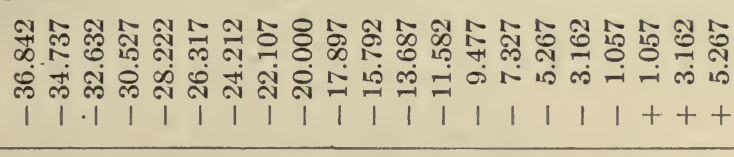 \\
\hline مُ & 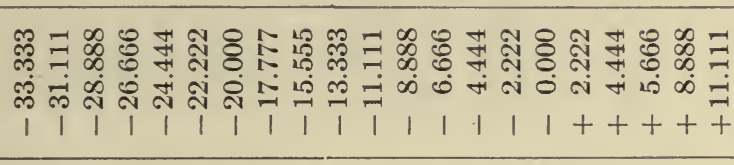 \\
\hline ঙ্ণ & 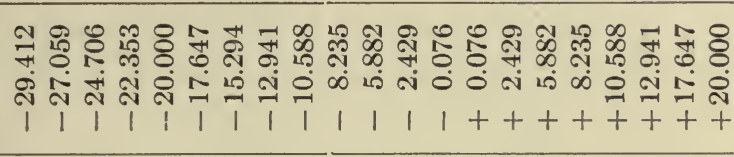 \\
\hline & 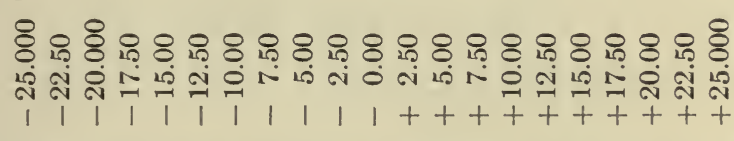 \\
\hline
\end{tabular}

है 동 를 뎌 동 . 항. 드 $\frac{5}{0}$ . $+0$ 㝴 कु ๘ 륭

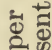
В ๓ ○. का एक

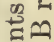
कี ¿ 는 $\frac{2}{8}$ 40 (ี) . 융ำ

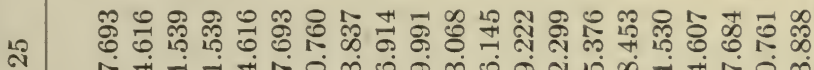
ஸे N

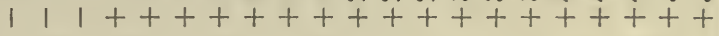
$++\infty$

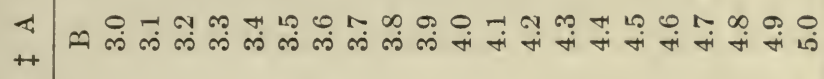




\section{Standardizing with Whole Milk}

Example 1: 20 pounds of milk containing 3 per cent fat is to be standardized to 4 per cent fat with 5.2 per cent milk.

$$
\begin{aligned}
& .04-.03=.01 \\
& .052-.04=.012 \\
& .01 \div .012=.833
\end{aligned}
$$

$20 \times .833=16.66$, number of pounds of 5.2 per cent milk to be used.

Example 2: 20 pounds of milk containing 5.2 per cent butter fat is to be standardized to 4 per cent with milk containing 3 per cent butter fat.

$$
\begin{aligned}
& .052-.04=.012 \\
& .04-.03=.01 \\
& .012 \div .01=1.2
\end{aligned}
$$

$20 \times 1.2=24$, number of pounds of 3 per cent milk to be added to the 20 pounds of milk to decrease per cent fat to 4 per cent.

The same principle will apply in standardizing of cream.

\section{EXERCISE XXVI}

Condensing Milk

1. Attach rubber tubing to Bunsen pump and connect to a strong rounded, quart flask containing about a pint of perfectly sweet milk which is free from all taints. Also connect to a graduated glass tube inserted in mercury to designate the amount of vacuum produced, which should be about $756 \mathrm{~mm}$. 
or 30 inches. Tie rubber and glass connections securely. Heat milk over flame at $130^{\circ} \mathrm{F}$. and allow to boil for from six to eight hours until the milk has a consistency of very thick cream. Examine and taste.

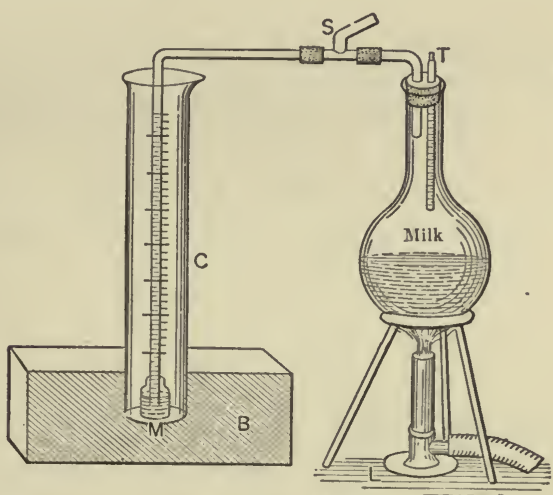

FIG. 47. - Condensing Milk. (b) block of wood; $(m)$ mercury in bottle; $(c)$ graduated cylinder; $(s)$ suction from Bunsen pump; $(t)$ thermometer; $(l)$ lamp or Bunsen burner.

2. Condense milk as above, but allow to remain at $90^{\circ} \mathrm{F}$. instead of boiling-point during several laboratory periods until it.has entirely dried. Pulverize with mortar and pestle and examine.

3. Take 10 pounds of curd from the cheese vat. After removing fat evaporate to dryness in incubator or oven. Pulverize and feed a small portion to chickens. Take one ounce of the remaining portion and boil together with 5 c.c. water. When an emulsion is formed boil to a pasty consistency and test the sticking qualities for glue. 


\section{Milk Paste}

Thoroughly mix three parts of casein with one part of sodium borate (borax), moisten with water and test for paste. This is frequently used for library paste. Mix one part of casein with one part of quick lime, moisten and test for glue.

\section{Dried Milk}

Heat 15 pounds of skim-milk in vacuum at $165^{\circ} \mathrm{F}$. until it dries to a paste. Frequently turn until it forms a crisp and then pulverize.

\section{Milk Sugar}

Rapidly coagulate skim-milk by means of rennet or acetic acid. Filter whey and render slightly alkaline by the addition of lime water. Evaporate to about one-half bulk and precipitate albumen by boiling or with small amount of alum. Remove by again filtering and evaporate the second time to about one-sixth of its bulk. Add equal volume of methyl alcohol, and allow to stand for three to six hours. A pure white, finely crystalline precipitate of lactose is thrown down which is removed by filter. Cool and taste.

\section{EXERCISE XXVII}

\section{JUNKET}

To 1 small junket tablet add 1 dram ( 1 teaspoonful) of cold water. Crush tablet and dissolve thor- 
oughly. Heat 1 quart of pure milk to about $90^{\circ}$ to $98^{\circ} \mathrm{F}$. and add sugar and flavor to suit taste. Add the dissolved tablet to the milk, mix thoroughly, pour into desired dishes and allow to stand at $90^{\circ}$ to $95^{\circ} \mathrm{F}$. until solidified. Then place in refrigerator until ready to serve.

If no junket tablets are readily obtainable substitute a mixture of ten drops of rennet and a few grains of salt.

\section{Papanized Cheese Paste}

This process is patented

Moisten any of the breakfast food cereals and put in a digester. Heat under pressure, not exceeding three atmospheres, to a temperature not exceeding $134^{\circ} \mathrm{C}$., but preferably at a pressure of two atmospheres and a temperature of $121^{\circ} \mathrm{C}$. for an hour or more, depending on the amount of dextrinization desired. Under the influence of the moisture and high temperature the starch in the eereals becomes converted into dextrine. Cut cheese into small bits and crush into a paste with equal quantity of whole or skim-milk. One to one-half per cent of soda may be used and the entire mixture cooked to the desired taste over Bunsen flame until the cheese is completely dissolved. An egg may also be added if obtainable. 


\section{EXERCISE XXVIII}

\section{Atimidcaseose}

Process patented

Render skim-milk slightly alkaline with lime-water or sodium carbonate $\left(\mathrm{Na}_{2} \mathrm{CO}_{3}\right)$ and heat to $4^{\circ} \mathrm{C}$. Add just sufficient rennet to coagulate and filter out whey. Wash curd. Place in autoclave if obtainable and subject to superheated steam at a pressure of 100 pounds per square inch, for three hours. Curd thus prepared is very nutritious and readily assimilated by invalids. Repeat, using 5 pounds of whole milk and coagulate as rapidly as possible by means of rennet. Neutralize by baking soda and filter. Taste filtrate, which is said to be very digestible and which is often used for invalids.

\section{Milk Shake}

To $\frac{1}{2}$ pint of whole or skim-milk add about one tablespoonful of sugar, about twice that amount of powdered ice, a pinch of baking soda, and a few drops of flavoring. Shake well in lemonade shaker and serve.

\section{Buttermilk Highball}

Mix $\frac{1}{2}$ pint of buttermilk, $\frac{3}{4}$ pint of ice cream, and a pinch of baking soda, or an infusion of carbonic acid gas $\left(\mathrm{CO}_{2}\right)$. Shake thoroughly in lemonade shaker and drink. 


\section{Buttermilk Pop}

To $\frac{1}{2}$ gallon of fresh buttermilk add $\frac{1}{4}$ pint of 20 per cent cream and $\frac{1}{4}$ pound of sugar, also a few granules of salt. Heat to boiling, stirring constantly to keep curd well mixed. Add 8 grams of cornstarch previously mixed with cold water.

Repeat experiment, using $\frac{1}{4}$ pound of corn meal in place of corn-starch. Add a pinch of baking soda; shake well and drink.

\section{Koumiss}

To 7 pints of pasteurized milk, either skimmed or 3 per cent, add 4 ounces of cane sugar and $\frac{1}{3}$ cake of bakers' yeast after pulverizing and dissolving in about 3 ounces of lukewarm water. Mix thoroughly at $95^{\circ} \mathrm{F}$. and pour into a long-necked quart bottle. A champagne bottle answers the purpose very well. Fasten a light wire over cork to prevent the escape of air. Allow to cool gradually and remain at $60^{\circ} \mathrm{F}$. to $70^{\circ} \mathrm{F}$. for twenty-four to thirtysix hours. Then it is ready for use. If desired to keep longer put on ice. A koumiss faucet inserted in the cork before allowing to ferment greatly facilitates opening the bottle for use. The acid developed in koumiss, like that of buttermilk, has a high dietetic value, is readily digested, and very nutritious.

\section{Buttermilk}

Make buttermilk by ripening skim-milk with starter at $70^{\circ} \mathrm{F}$. until it is slightly coagulated but has 
liberated no whey. Add about 30 per cent of good flavored buttermilk and churn at $50^{\circ}$ to $55^{\circ} \mathrm{F}$. until the curd is entirely emulsified, when it is ready for use. Repeat, using whole milk instead of skim-milk and omit the addition of buttermilk.

Drink two glasses of buttermilk daily for a week and note effect on digestion.

Buttermilk contains about the proper amount of lactic acid necessary to produce perfect digestion. It is anti-scorbutic and forms carbonic acid in the stomach, which unites with the calcium, magnesium, or potassium salts that are always present in the food, and forms carbonates which purify the blood by preserving its alkalinity; while alkaline in reaction the blood throws off uric and other waste acids which would otherwise be absorbed. It has, therefore, a great diuretic and dietetic value. The casein is in a coagulated, finely divided flocculent state, and is readily converted into peptones for body use. It contains enough water to quench the thirst, takes the place of fresh fruit to a great extent, keeps the body in a laxative condition, and at the same time furnishes considerable valuable readily digestible food.

\section{Moose}

Make what is known as Moose by adding to 15 per cent cream about 20 per cent of sugar and flavoring to suit the taste. Put in a small baking powder can or small ice cream packer and set in pulverized ice to which a small amount of salt has been added. Allow to freeze without stirring. 


\section{Dried Milk Cocktail}

Take a given quantity of skim-milk and add one per cent of grain alcohol until precipitation of casein has ceased. Filter the precipitated casein from the liquid. Dry at from $145^{\circ}$ to $149^{\circ} \mathrm{F}$. Above this temperature the albumen may become insoluble. Pulverize and mix with water, milk, beef-tea, cocoa, or hot water in proportion about half and half, or to suit the taste. Where casein has thus been precipitated with alcohol and then dried and redissolved in water it can no longer be curdled by pepsin in the stomach. It is converted from insoluble to a soluble form without losing any of its food value.

\section{EXERCISE XXIX}

(This exercise may be taken or omitted at the option of the instructor.)

\section{Preparations made from Milk}

Make plasmon or caseon by precipitating casein with $\mathrm{HCl}$, neutralize with carbonate of soda.

Make casein of lime by precipitating casein and dissolve by phosphoric acid equal to quantity of lime used.

Make nutrose by boiling together in any alkali solution dried casein and caustic acid.

Make Santogene by mixing 95 per cent glycerophosphate of sodium and 5 per cent casein. Precipitate casein with acetic acid, wash with methyl alcohol and dry slowly.

Make eucasine or ammoniacal casein by passing ammonia through the emulsion of alkaline casein. 
Make eulactol by dissolving proteic vegetable substance and adding hydrates of carbon, salts, such as phosphate of calcium, cooking salt, or carbonate of sodium, and allow to vaporize.

Obtain albumine "nikol" from sterilized whey and dissolve precipitate in soda and render soluble by treating successively with $\mathrm{HCl}$ and alkali.

Mix albumine "nikol" with oxblood 10 to 2 . This mixture is a hygiene albumen frequently used by people suffering from chlorosis.

\section{EXERCISE XXX}

\section{Solid Milk}

Prepare solid milk by adding to any desirable quantity of whole or skim milk 1 per cent of liquid gelatine. Put up in any desired form, and allow to solidify at 30 to $50^{\circ} \mathrm{F}$.

\section{Soap}

Boil 1 pound of milk with any alkali and note difference in per cent of fat before and after adding. 12.5 per cent of glycerine unites with 87.5 per cent of fatty acid to form fats. When fat is boiled with alkali the latter takes the place of glycerine and forms soap. When boiled again with an acid the fat returns to its original condition. 


\section{Preparation for Ivy Poison}

Mix 1 pound of buttermilk with 2 ounces of salt or all that will dissolve. Apply to parts of skin affected by poison ivy or similar skin diseases.

\section{A Method for Modifying Milk for Invalids}

Heat a given quantity of milk to $86^{\circ} \mathrm{F}$. Add sufficient rennet to coagulate in twenty minutes and mix thoroughly. After precipitating the casein, filter out whey and modify with proper per cent of casein thus obtained to give the percentage of protein (1.5 per cent) of human milk.

\section{Preserving Casein}

Precipitate casein of milk by use of sulphuric or hydrochloric acid with which a small percentage of borax or other preservative has been added in proportion of $\frac{1}{2}$ to 1 per cent of the preservative. Dry and pulverize. Thus preserved the casein is unfit for food, but may be used in the manufacture of glue and paint.

\section{EXERCISE XXXI}

\section{Disinfectants}

Prepare the following disinfectants: Solution of corrosive sublimate $\left(\mathrm{HgCl}_{2}\right) 1$ to 1000 ; carbolic acid, $\mathrm{C}_{6} \mathrm{H}_{5} \mathrm{OH}, 1$ to 20 ; formaldehyde ( $\left.\mathrm{HCHO}+\mathrm{H}_{2} \mathrm{O}\right) 1$ to 20. Apply to infected places and note results. Potassium permanganate $\left(\mathrm{KMnO}_{4}\right) 1$ to 20 , cold water; 
Wyandotte Dairyman's Cleaner and Cleanser 1 to 20; Banner Purifying Compound 1 to 20; borax 1 to 20 ; sal. soda 1 to 20 ; Fairbanks' washing powder 1 to 20 ; Tessico washing powder 1 to 20 ; gold dust 1 to 20 ; powdered unslaked lime 1 to 20 ; powdered gypsum 1 to 20. Use and note results. Gypsum is preferable to lime in barns or on any material which may afterwards be used for fertilizer, for the latter forms soluble salts with the nitrogen of manure and liberates a large per cent of the ammonia present. $\left(\mathrm{NH}_{4}\right)_{2} \mathrm{CO}_{3}+\mathrm{CaO}=2 \mathrm{NH}_{3}+\mathrm{CaCO}_{3}+\mathrm{H}_{2} \mathrm{O}$. $\left(\mathrm{NH}_{4}\right)_{2} \mathrm{SO}_{4}+\mathrm{CaO}=2 \mathrm{NH}_{3}+\mathrm{CaSO}_{4}+\mathrm{H}_{2} \mathrm{O}$. This causes a loss of valuable fertilizer and produces an offensive odor which milk readily absorbs. Gypsum, on the other hand $\left(\mathrm{CaSO}_{4}\right)$, is insoluble with the nitrogen of manure and is retained until deposited in the fields.

\section{EXERCISE XXXII}

\section{Mechanical Refrigeration}

If refrigerating machinery is in use at the college, note the kind of machine, whether vacuum, absorption, compression, or combined absorption and compression. Note principle of refrigeration which is the production of cold air by the evaporation of liquids which absorb the heat in vaporizing. Anhydrous ammonia is generally used on account of its low boiling point. It liquifies at $30^{\circ} \mathrm{F}$. under one atmospheric pressure. It liquifies at higher temperatures by subjecting it to pressure. It is alternately evap- 


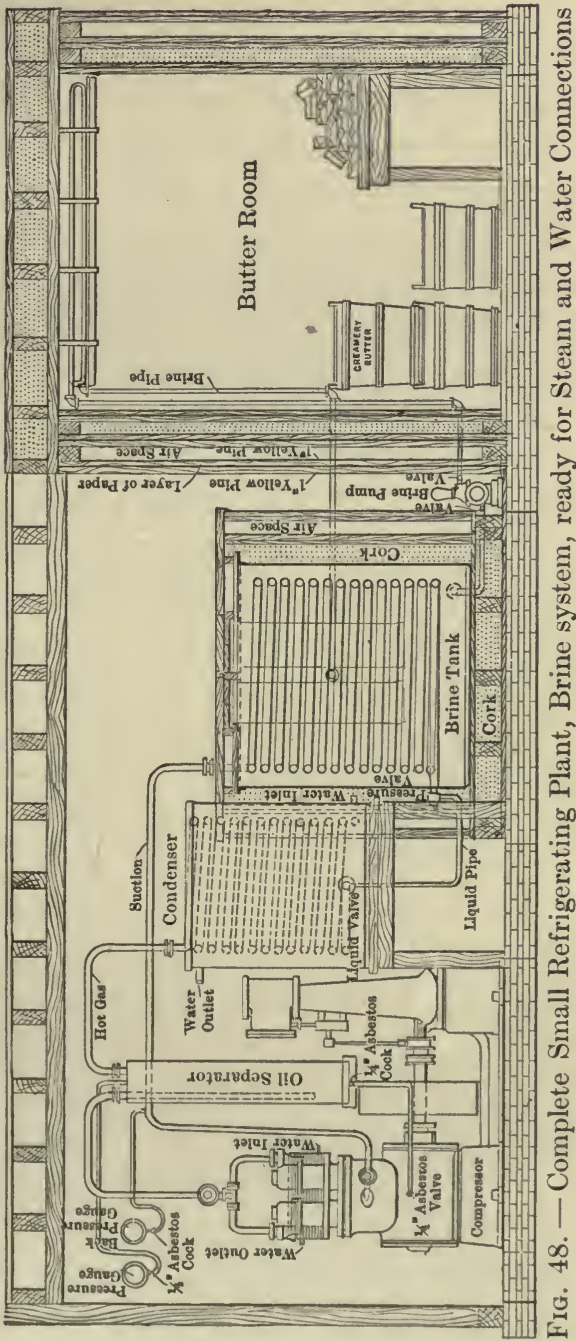


orated and liquified so that its use is continuous. The cycle of its operation starts from the liquid receiver and enters the refrigerating coils in which it evaporates, absorbing a large amount of heat. By means of a compression pump operated by an engine the ammonia vapors are forced in the condenser coils where the ammonia under pressure is again liquified by running cold water over the coils. Here it again enters the liquid receiver and repeats the cycle. The amount of refrigeration is regulated by an expansion valve placed between the liquid receiver and the refrigerating coils. This valve may be adjusted so as to admit the condensed quantity of liquid ammonia to the coils. Note difference between brine system and direct refrigeration. Take temperatures of brine. At different regulations of the expansion valve, take temperature of the room surrounding the brine tank. If the direct refrigeration system is used entirely, take temperatures similarly as above directed. Note size of compressor refrigerating pipes, power required, expense of operating, etc. After careful examination of the machine, charge it and operate under direction of the operating engineer as deseribed by $\mathrm{H}$. $\mathrm{H}$. Kelley:

"Discharge air with special valves by starting the compressor and pumping it out by reversing the operation of the gas cylinder to that of its working order. Charge with proper amount of anhydrous ammonia through the charging valve by connecting the ammonia cylinder with suitable pipe, and open the valve. Run compressor slowly with the suction 


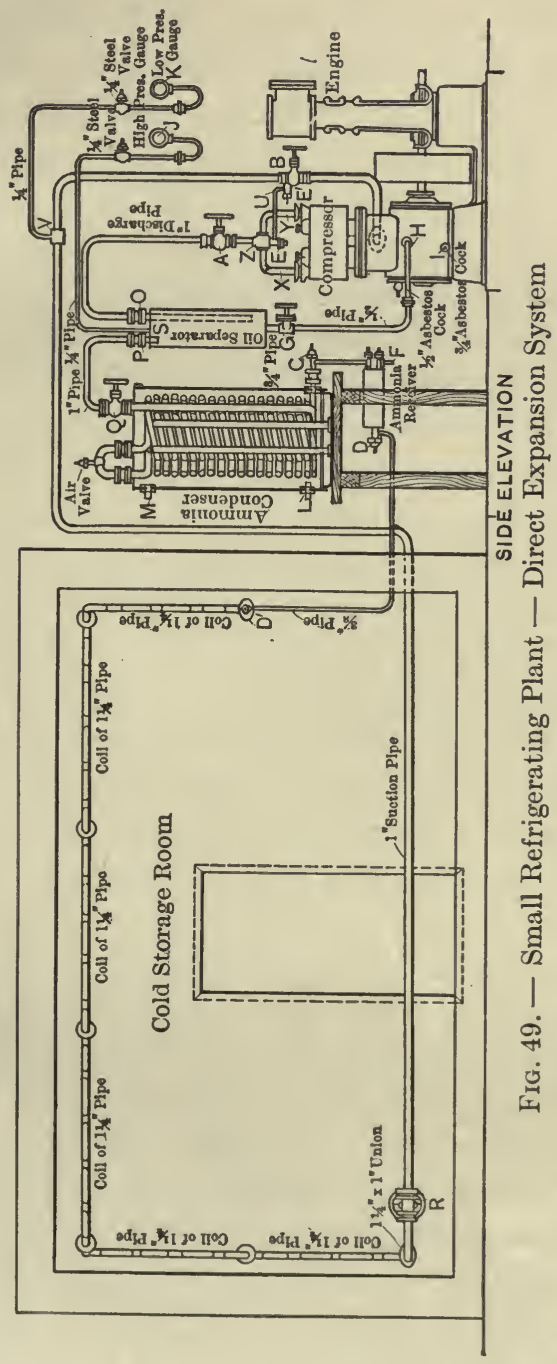


and discharge. valves wide open and expansion valve closed. As soon as one cylinder is empty replace with another, being careful to close the charging valve before attempting to remove the empty cylinder; opening it when the fresh cylinder is connected. From 60 to 75 per cent of the full charge is sufficient to start with, so that any air not having been removed may escape with as little loss of ammonia as possible. Add a small amount of ammonia each day until full charge has been introduced. The glass gage on the ammonia receiver will indicate the amount of ammonia present. The appearance of frost on the pipe leading to the coils and the cooling of the brine or air in refrigerator in the tank will indicate that enough ammonia has been introduced to start with. It sometimes requires applications of heat to entirely empty the ammonia cylinder. One part of water will absorb 800 parts of ammonia gas, therefore for use in case of accident keep a vessel of water handy. After starting compressor at the proper speed and adjusting regulating valve, note temperature of delivery pipe, and if there is a tendency to heat open it wide, and vice versa. With too light charge of ammonia the delivery pipe will become heated. The refrigerating room should be about 15 degrees lower than the brine being used, and the temperature of the water discharged from the ammonia condenser should be about 15 degrees lower than that of the condenser. By placing the ear close to the expansion valve the ammonia can be heard passing through it. If the sound is uniform and continuous the machine is 
working properly. If too much air is present the sound will be irregular. Remove air in the same manner as when charging the system. The presence of oil or water is detected by shocks occurring in the compressor cylinder. Oil is removed by an oil separator placed in main pipe between compressor and condenser."

The compressor sucks the gaseous ammonia into its cylinder, compresses it and sends it into the condenser. The latter thus describes a continuous circuit. The same ammonia is used continually. A five-ton refrigerating machine requires about an 18 horse-power boiler.

The compressor; the most essential part, is a pumping engine, used to pump the ammonia gas from the cooling apparatus and compress it and force it through the condenser at a pressure of from 150 to 185 pounds per square inch. See illustration.

The machinery for pasteurizing and clarifying 2500 quarts of milk and for a refrigerating machine of five tons, will cost about $\$ 2500$.

An ice plant which will make two and one-half tons of ice will have a refrigerating capacity of five tons; that is, it will cool as much as will five tons of ice melting in twenty-four hours.

For ice-making, pasteurizing, ice cream making and running a separator, not less than a 30 horsepower boiler should be used.

The water used in the condenser is warm and can be stored up for various purposes.

About a half ton of coal is required daily to make 
two and one-half tons of ice or five tons of refrigerating capacity. It requires from twelve to eighteen hours to cool off a room containing 1000 cubic feet and to make one ton of ice, depending on the perfection of the insulation, on the outside temperature, and on the contents of the cold storage room.

Ice ordinarily does not reduce the temperature below $40^{\circ} \mathrm{F}$., but by running the engine continually the temperature can be reduced as low as desired, even to zero.

A two-story plant: The brine tank can be placed right above the cold-storage room, and thus keep it cool after the machinery stops. A building 24 by 30 feet is ample for a dairy of 2500 quarts capacity.

Direct-expansion system is much cheaper than the brine system, providing ice is not manufactured for sale; the brine tank, brine pump, and secondary system of pipes for brine circulation being dispensed with, and also a greater efficiency is obtained. Only about two-thirds of the pipe surface is required to produce the same effect. See illustration.

\section{A Non-frosting Gage Glass}

A device to prevent frost from gathering on the glass gage is described by R. L. Shipman. The method is simply to jacket the ordinary form of gage glass with another glass of larger diameter, so that there will be an annular space of an eighth of an inch or so between the glasses. Then place a soft rubber ring between the glasses at each end, making air-tight joints. The air thus enclosed between the 
glasses will contain such a small quantity of moisture that no frost will appear on the inner glass, and this air space being such a poor conductor the outer glass will not be cooled to a temperature sufficiently low to produce frost. Although a considerable amount of moisture may be condensed on its outer surface, this will not interfere in any way with a clear view of the liquid contained in the inner glass. This combination has been used with temperatures as low as $30^{\circ}$ below zero $\mathrm{F}$., and no frost has appeared on the outer glass to obstruct the view.

\section{EXERCISE XXXIII}

\section{Creamery Bookkeeping}

Either single or double entry systems may be used, but the single entry system is more practical for creamery accounts; for it eliminates the transfer of entries and the keeping of more books. The singleentry system consists of a day book, in which careful record of all money spent for repairs, supplies, etc., and all money taken in from sales of milk, cream, butter, ice-cream, etc., credits and debits are kept; an order book, sales book, eash book, and ledger to which the above are transferred every evening. The milk sheet, test-book, butter slips, patrons' statements, etc., are figured at the end of each month, or according to the custom of the management. The following blank has been used for several years by the writer and proved to be very satisfactory: 
STATE AGRICULTURAL COLLEGE

Dairy Husbandry Dept.

Creanery Patron's Monthly. Statement

190 .

$\mathrm{Mr}$

No

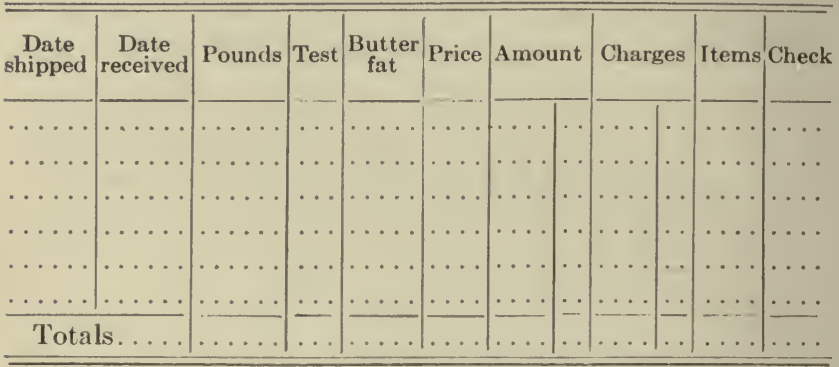

Check herewith

A creamery record should be kept by every buttermaker in order to trace causes of difficulty in ripening cream, or in churning, and also to aid him in maintaining regularity of work and uniformity of product. The following blanks by Professor Erf may be used for keeping daily records: 


\section{DAILY REPORT IN BUTTER MAKING}

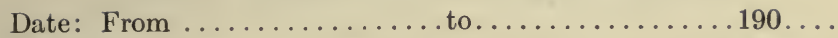

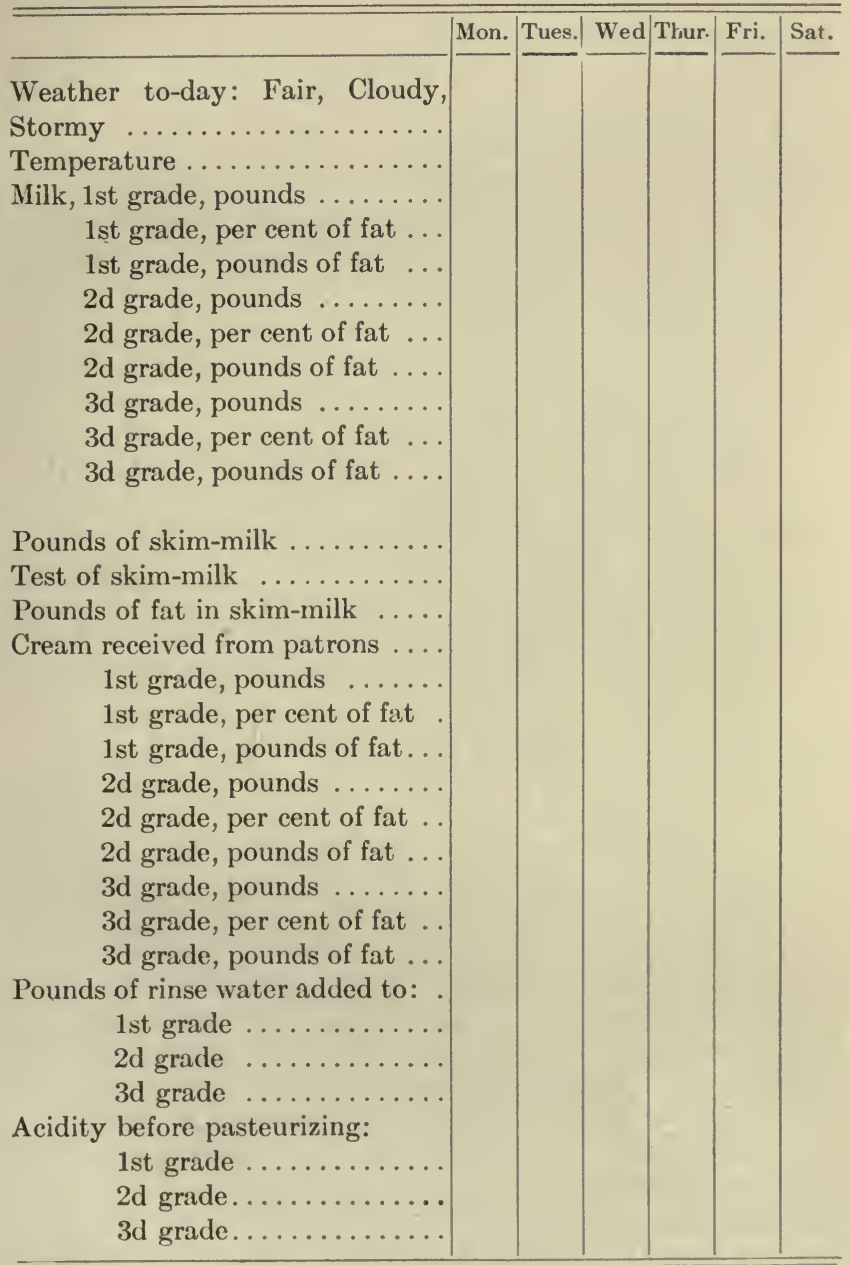


GRADE OF CREAM NO. ( )

Temperature pasteurized

Temperature cooled to

Acidity after pasteurizing

Starter-pounds or per cent added

Acidity of starter when used.....

Cream-temperature cream ripened Pounds cream to be churned.... .

Test of cream to be churned ..... Pounds butter fat.............

Per cent of acidity in cream .....

Temperature of cream

How long held at this temperature Time between pasteurizing and churning..............

Color - Ounces or c.c. color used Churning - How full was churn Time required to churn ....... Temperature of butter.......... Temperature of buttermilk .... Size of granules (very fine, wheat, peas, lumps) ............. Shape of granules (round, ragged) Temperature of wash water ..... Number of times washed ....... Salt - Amount salt used ....... Working - Working time or revolutions ................

Per cent fat in buttermilk.......

Pounds fat lost in manufacturing Pounds butter made ........... Per cent overrun .............. Account - No. packages put in refrigerator Mon. Tues. $\mid$ Wed. $\mid$ Thur. $\mid$ Fri. $\mid \underline{\text { Sat. }}$

No. packages sold

Refrigerator temperature .......

Butter-maker's score ..........

Expert's score ................

Report from commission man ...

Remarks: 


\section{EXERCISE XXXIV \\ Writing to Patrons}

Prepare a letter for creamery patrons similar to the following, with variations to suit the circumstances.

We aim to put out the highest standard of dairy products from this creamery. In order to do this it is necessary that there should be perfect cleanliness in all of our operations. We wish to ask all who have anything to do with milk brought here to cooperate with us in bringing about the best results. We desire to make the following suggestions:

1. The milk haulers must keep their wagons free from dirt and filth.

2. The cow stables should be kept cleaned and ventilated.

3. The feeding and bedding of cows must be done after milking, as the dust contains bacteria that will spoil the milk.

4. The milkers must not get anything in the pail from the cow's udder but milk. To aid in this matter a damp cloth may be used to advantage in wiping the cow's udder before milking, and the first stream from each teat discarded.

5. In straining the milk use a double strainer covered pail. The common strainer is not sufficient to take out the fine particles of dirt. Milk should be cooled to as low temperature as possible immediately after milking.

6. After thoroughly washing all pails, pans, strainers, cans, etc., with good washing powder, they 
must be scalded with boiling water to destroy the harmful germs.

7. The skim-milk should never be left standing in the cans. It is best to empty the cans, wash them, and scald with hot water or steam.

8. Fresh milk should be cooled before mixing with other milk.

\section{EXERCISE XXXV \\ Creamery Conveniences}

A fan in the creamery keeps the air cool, fresh, and the flies outside.

A low-water whistle alarm on the boiler as required by the state law of Michigan.

A cord connected to the safety valve on the boiler and stapled around the periphery of the creamery, with a weight attached sufficient to pull the valve open if the cord is ever burned in two. In case of fire the steam and hot water will aid materially in extinguishing it.

An automatic scale to show the weight of the milk as soon as emptied into the weigh can, similar to a butcher's scale, with agate bearings.

The butter printing table to be fastened on the wall, with hinges and drop legs.

Pipe brushes with sectional handles to clean milk pipes.

A heater regulator to control the temperature of the milk when separating; also cream when pasteurizing. 
Steam and water connected with hose to wash vats, walls, and floor. Cases for separator and pasteurizer parts hung neatly on the wall near the machines as shown in Fig. 6.

A case similar to the above for a complete set of creameryman's tools.

An oilcloth to cover the engine and separators when not in use, to keep off the dust.

A clamp to hold small butter tubs and 5-pound boxes firm when packing them.

A home-made water pump regulator is a most helpful and economical device. It is made by attaching a.float on the water tank to one end of a lever, the other end of which is attached to the throttle of the pump in such a way that as the water in the tank rises or falls it shuts or opens the throttle. This not only keeps the tank full but the pump adjusts itself to the varying boiler pressure and to the quantity of water used. The water is pumped into and drawn out of the tank through a siphon, so that as soon as the pump starts the water comes direct from the spring or well.

An adjustable overflow on the water jacket of the cream vat, made by screwing in a short piece of pipe and elbow on the inside near the bottom, with a corresponding rod on the outside to indicate its position, and a vertical pipe in the elbow which can be turned up or down to keep the water the same height as cream. This enables one to keep a continual stream of water running around it and saves ice and time. 
Elevator for carrying boxes, etc., to attic. The milk can elevator invented by O. B. Schier, of Baltimore, consists of two endless chains running

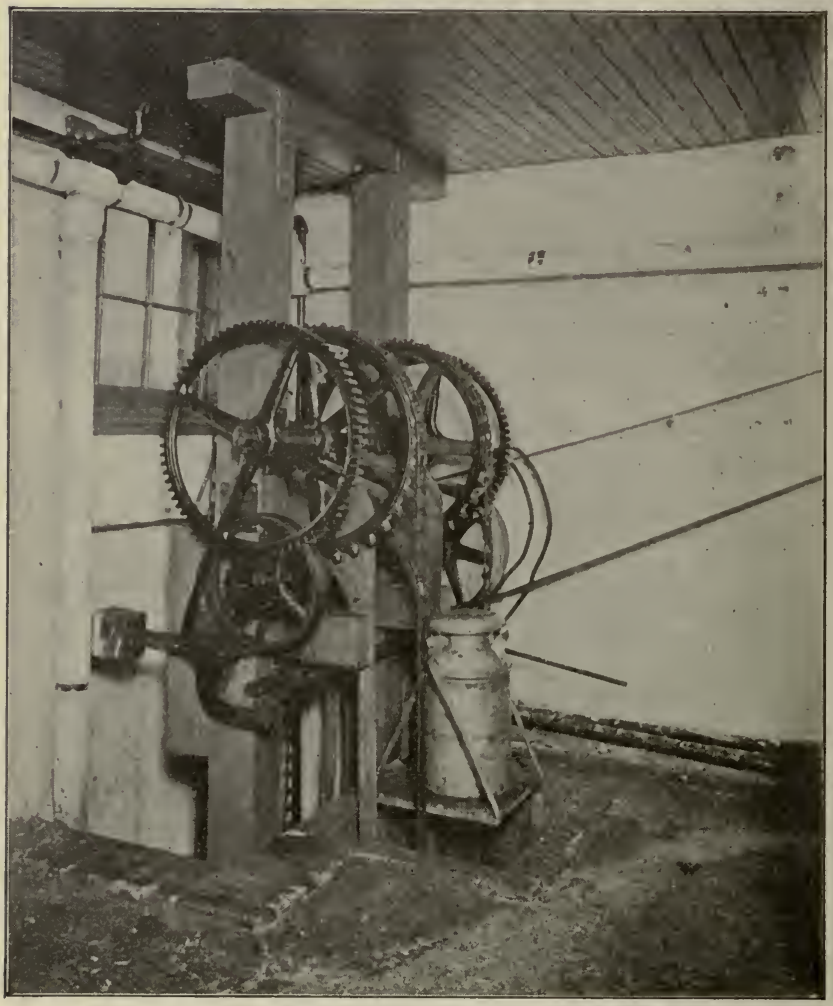

FIg. 50. - Milk Can Elevator. Upper Floor

over sprocket wheels, connected by a single shaft at the lower end in such a way that both chains must travel at the same speed. Between the chains are suspended on swivel links a number of swinging 
platforms to carry the cans from one elevation to another. They are just far enough apart to allow a man to conveniently put on the milk cans as fast

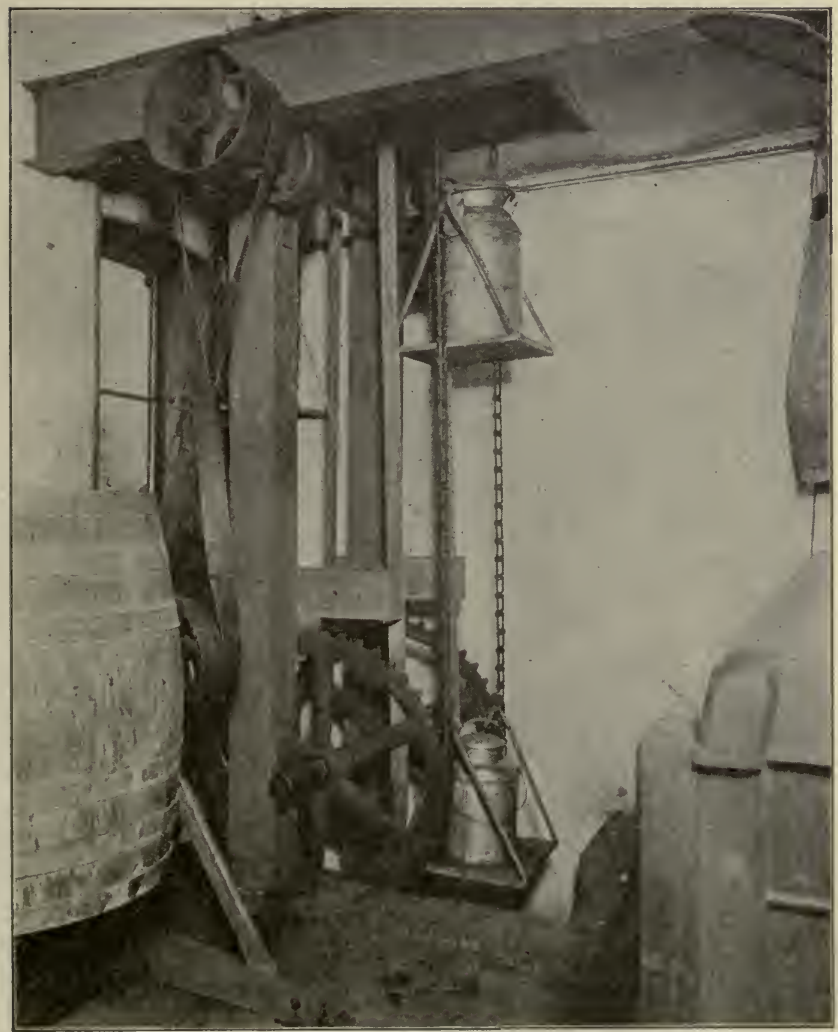

Fig. 51. - Milk Can Elevator. Lower Floor

as he takes them from the wagon. The elevator delivers the cans to a higher elevation or higher floor continuously as fast as would be possible to 
unload them; while in the regular platform elevators it is necessary to wait until the elevator is loaded. Thus, it will be seen that the endless chain elevator saves a great deal of help.

Test bottle rack with perforated top, for shaking or emptying twenty-four to forty bottles at the same time.

Automatic governor brake to stop engine in case of governor belt breaking or coming off.

Heater for warming water going into boiler; the exhaust from engine may be utilized for this purpose.

Weigh can gate opener, saves stooping.

Castors on movable vats and creamery appliances.

Steam gage in working room to show boiler pressure.

Slatted draining shelves for all creamery apparatus.

Place ice-box above the refrigerator with a sloping floor. Connect a drain at the lower side so as to run the water into a small pipe leading into a vat, which is arranged with slat shelves that hold one-half pint, pint, and quart bottles, the water reaching just to the neck of each. Insert an overflow pipe and drain the water from this into another vat beneath, where milk and cream cans may be placed. The water in the latter vat is allowed to rise to within an inch of the top of the can before it reaches the overflow. Thus, after the ice has been used for cooling the refrigerator, the ice-water may be utilized twice for cooling purposes. 
An electric alarm bell attached by means of a cord to a float in the milk vat. As the milk is pumped or drawn from the vat the float lowers and pulls a metallic weight against a brake which causes the bell to ring, thus notifying the operator that the vat is almost empty.

COMPOSITION OF NORMAL CREAM

\begin{tabular}{c|c|c}
\hline \hline Total Solids & Solids Not Fat & Fat \\
\hline $32.50 \%$ & $6.83 \%$ & $25.67 \%$ \\
$37.59 \%$ & $6.14 \%$ & $31.45 \%$ \\
$50.92 \%$ & $5.02 \%$ & $45.90 \%$ \\
$55.05 \%$ & $4.65 \%$ & $50.40 \%$ \\
$57.99 \%$ & $4.17 \%$ & $53.82 \%$ \\
$68.18 \%$ & $3.30 \%$ & $64.88 \%$ \\
\hline
\end{tabular}

Water........................68.0\%

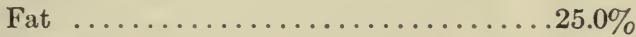

Sugar ........................ $4.0 \%$

Proteids ..................... 2.6\%

Ash

$$
\frac{.4 \%}{100.0 \%}
$$

COMPOSITION OF WHOLE MILK

Water........................ $87 \%$

Fat ..................... $4 \%$

Milk Sugar $\ldots \ldots \ldots \ldots \ldots \ldots \ldots \ldots$. $5 \%$

Proteids . . . . . . . . . . . . . . . $3.3 \%$

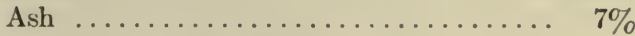

COMPOSITION OF NORMAL BUTTERMILK

Water........................ $90.39 \%$

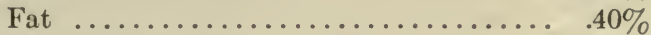

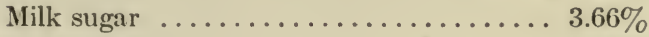

Lactic Acid $\ldots \ldots \ldots \ldots \ldots \ldots \ldots \ldots . . .60 \%$

Proteids ...................... $4.0 \%$

Ash $\ldots \ldots \ldots \ldots \ldots \ldots \ldots \ldots \ldots \ldots \ldots \ldots . .75 \%$ 


\section{COMPOSITION OF NORMAL SKIM-MILK}

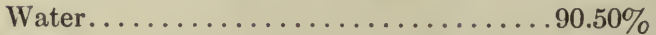

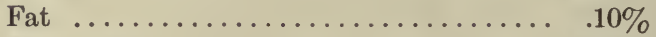

Milk Sugar ................ 4.95\%

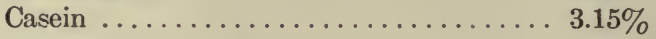

Albumen .................... $.42 \%$

Ash $\ldots \ldots \ldots \ldots \ldots \ldots \ldots \ldots \ldots . . .78 \%$ 


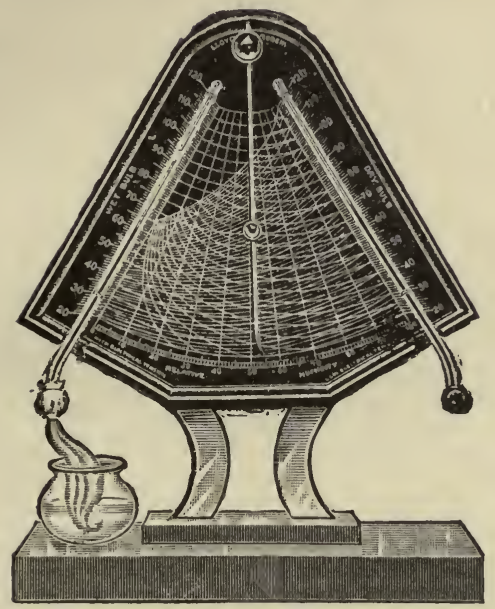

The Hygrodeik

With this instrument the Relative Humidity of the air may be determined without the use of tables. See Exereise XV.

To find the Relative Humidity swing the index hand to the left of the ehart, and adjust the sliding pointer to that degree of the Wet Bulb Thermometer Seale at which the mereury stands. Then swing the index hand to the right, until the sliding pointer intersects the curved line which extends downward to the left from the degree of the Dry Bulb Thermometer Seale at which the mercury stands. At this interseetion the index hand will point to the Relative Humidity on the seale at the bottom of the ehart.

Example: The temperature indieated by the Wet Bulb Thermometer is $60^{\circ}$, and that of the Dry Bulb $70^{\circ}$. The index hand will indieate the Relative Humidity $55^{\circ}$ when the pointer rests on the interseeting lines of 60 and 70 degrees. 


THIS BOOK IS DUE ON THE LAST DATE STAMPED BELOW

\section{AN INITIAL FINE OF 25 CENTS} WILL BE ASSESSED FOR FAILURE TO RETURN THIS BOOK ON THE DATE DUE. THE PENALTY WILL INCREASE TO 50 CENTS ON THE FOURTH DAY AND TO \$1.00 ON THE SEVENTH DAY OVERDUE.

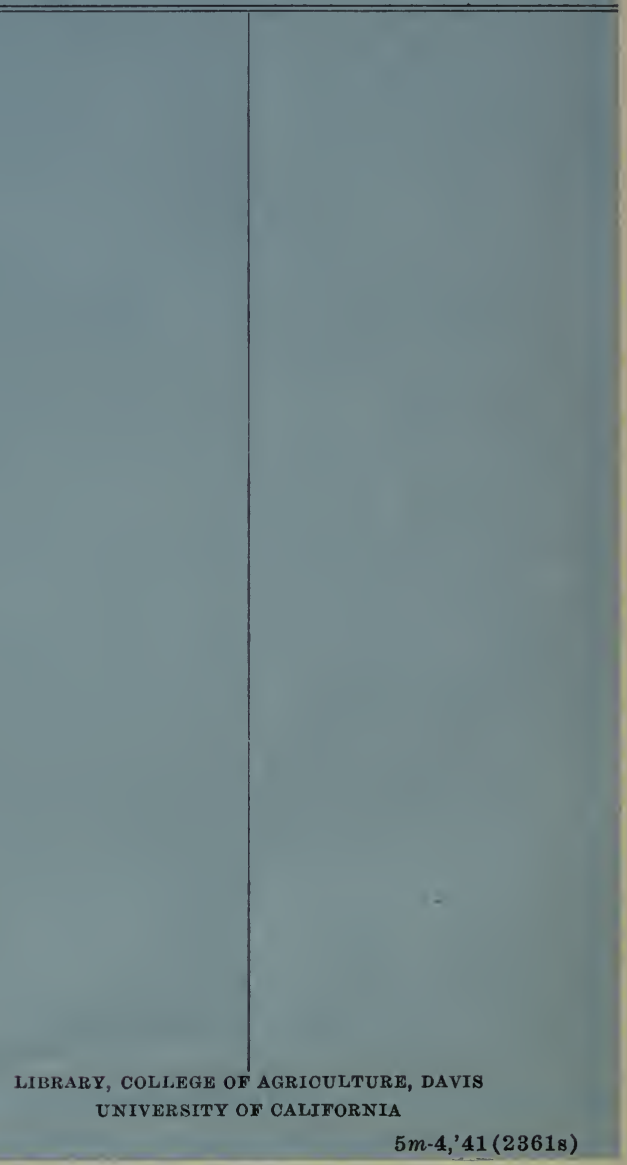


